\title{
IMPEDANCE-BASED DETECTION OF TISSUE USING A MULTI-ELECTRODE DEVICE
}

\author{
A Thesis \\ presented to \\ the Faculty of California Polytechnic State University, \\ San Luis Obispo
}

\author{
In Partial Fulfillment \\ of the Requirements for the Degree \\ Master of Science in Biomedical Engineering
}

by

Shane Killian Fleshman

December 2011 
(C) 2011

Shane Killian Fleshman

ALL RIGHTS RESERVED 


\section{Committee Membership}

TITLE:

Impedance-Based Detection of Tissue Using a MultiElectrode Device

AUTHOR:

Shane Killian Fleshman

DATE SUBMITTED:

December 2011

COMMITTE CHAIR: Dr. Lily Laiho, Associate Professor

COMMITTEE MEMBER: $\quad$ Dr. Kristen Cardinal, Assistant Professor

COMMITTEE MEMBER: Dr. Robert Szlavik, Associate Professor 


\title{
Abstract \\ IMPEDANCE-BASED DETECTION OF TISSUE USING A MULTI-
}

\author{
ELECTRODE DEVICE
}

By

Shane Killian Fleshman

Melanoma skin cancer is the abnormal growth of the melanocytes - the pigmented cells located in the epidermis. The current gold standard diagnostic technique for determining whether a lesion is cancerous involves subjectively examining suspicious lesions and performing an invasive biopsy to confirm melanoma. This method may neglect some lesions or cause scarring from biopsies that turn out to be benign. Thus, impedance-based detection using a multi-electrode device was investigated as a noninvasive technique to diagnose melanoma skin cancer. The multi-electrode device was designed with 8 equally spaced $\mathrm{Ag} / \mathrm{AgCl}$ electrodes surrounding one central electrode at a $5 \mathrm{~mm}$ radius. The electrodes were held in place by a vice-like mechanism using three circular Delrin sections. The electrodes were interfaced to an 8:1 multiplexer and National Instruments Educational Laboratory Virtual Instrumentation Suite (ELVIS) for measurement control and impedance analysis. The ELVIS system, multiplexer, and electrode device were validated for accuracy with various values of resistors and capacitors. Raw and cooked chicken thigh meat and skin were tested to evaluate the capabilities of the electrode device to discern different tissue types and tissue moisture contents by impedance measurements. Epiderm ${ }^{\mathrm{TM}}$ and Melanoma tissue-engineered skin analogues, provided by MatTek Corporation, were tested to mimic the in situ disease state. The electrode device was found to produce reliable measurements for known electrical components with resistances between $10 \mathrm{ohms}$ and $100 \mathrm{k}$-ohms and capacitances between $10 \mathrm{nF}$ and $10 \mathrm{uF}$. The measurements from the chicken tissues and tissue-engineered skin constructs - excluding cooked chicken skin data - fell within the reliable range of the electrode device and were thus considered reliable as well. All analyses concluded that a statistical difference between the impedances of raw meat and raw skin, cooked meat and raw meat, and Epiderm ${ }^{\mathrm{TM}}$ and Melanoma existed. Therefore, the hypothesis that a multi-electrode device could differentiate between melanoma and healthy skin tissues based on impedance measurements was satisfied. 


\section{Acknowledgements}

I am extremely thankful to the faculty of the Biomedical Engineering department at Cal Poly for their continued support and knowledge provided to me over the last 5 years of college. In particular, I am grateful to Dr. Lily Laiho for her time, patience, and encouragement throughout this thesis project. Without her expertise and assistance, this project was likely to continue several more quarters. I would also like to thank Mr. Dave Laiho for his help in manufacturing the electrode device and establishing an experimental setup.

Thank you to Dr. Kristen O'Halloran Cardinal and Dr. Robert Szlavik for their continued support and encouragement. Dr. Cardinal and Dr. Szlavik provided vital information concerning the thesis submission and electrical aspects of the project, respectively. Furthermore, I am grateful to the Hannah and Forbes families for their funding, without which none of this would be possible. Also, thank you to Glenn Stante for beginning this thesis project and establishing a sturdy base of information.

Above all, I would like to thank my parents, Steve and Kathy Fleshman, for their never ending love and support. Without their encouragement and confidence, I would have never been able to complete my thesis and graduate from Cal Poly. Finally, thank you to the many colleagues and friends that I have met during my five years at Cal Poly. The memories made will forever remain with me. Thank you! 


\section{Table of Contents}

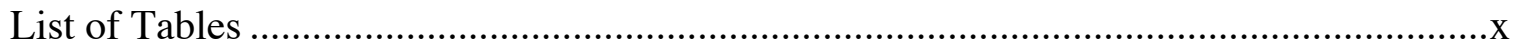

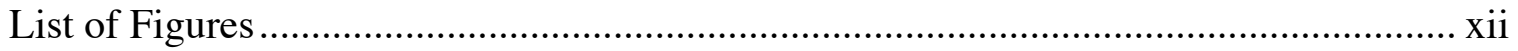

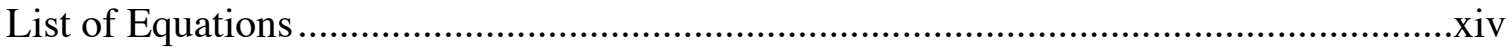

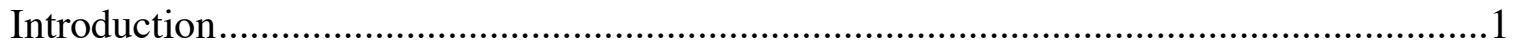

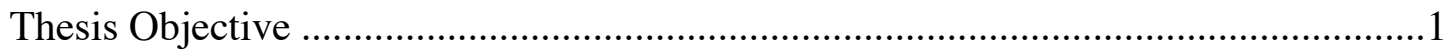

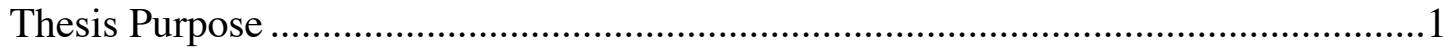

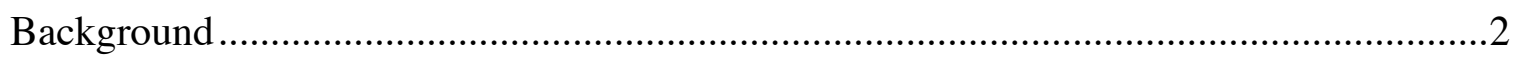

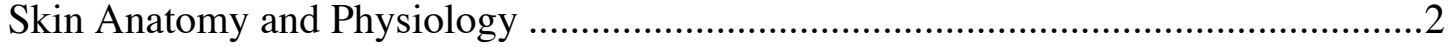

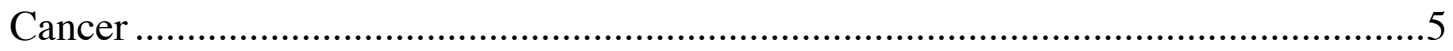

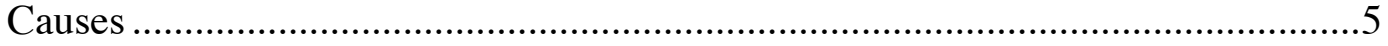

Effects and Symptoms ...........................................................................

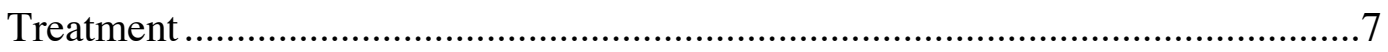

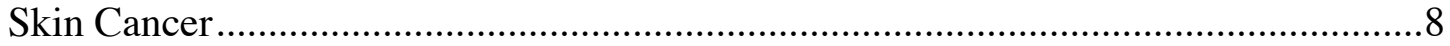

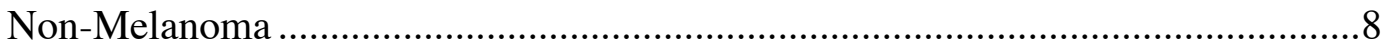

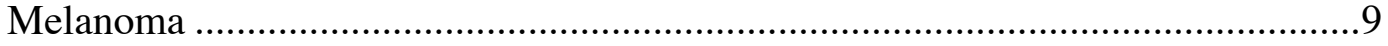

Risk Factors ...................................................................................

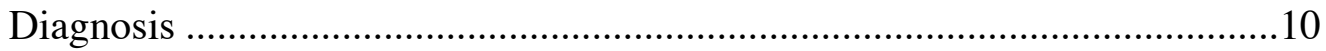

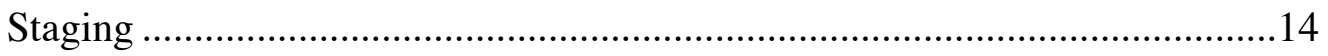

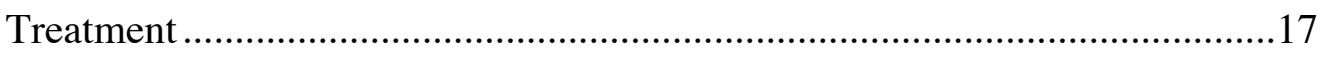

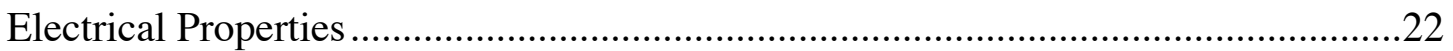

Introduction to Electrical Theory .................................................................22

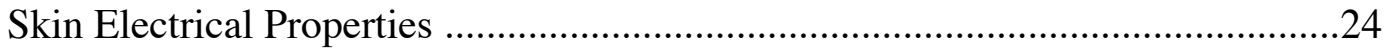


Cancerous Electrical Properties ...................................................................2

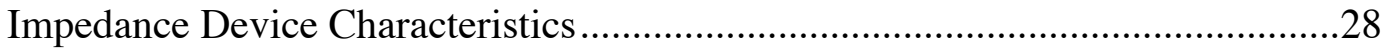

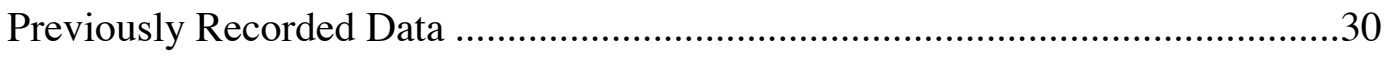

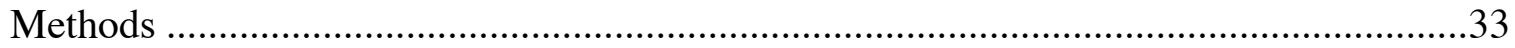

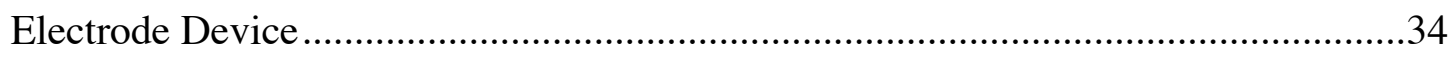

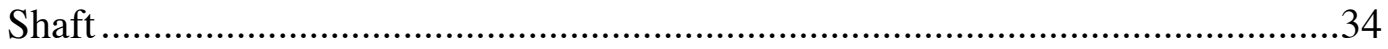

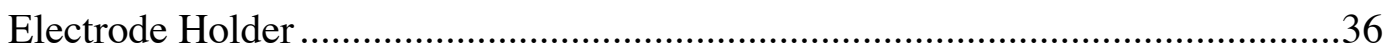

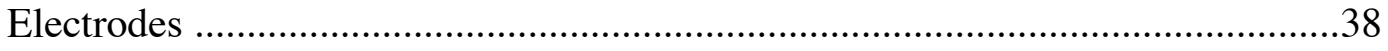

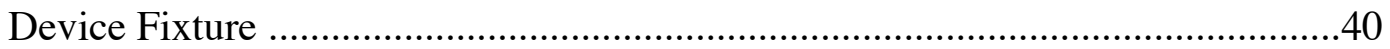

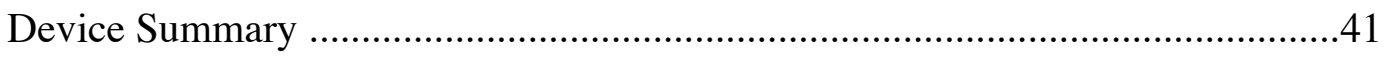

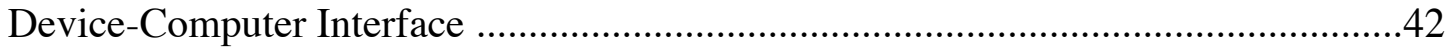

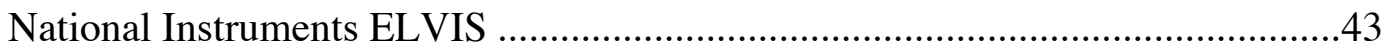

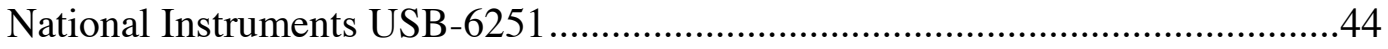

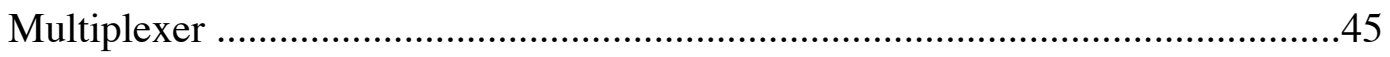

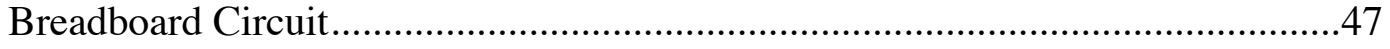

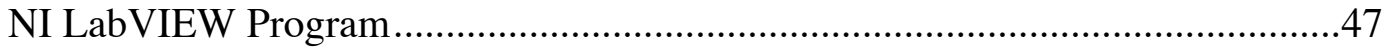

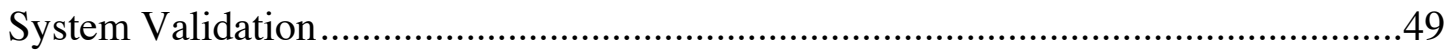

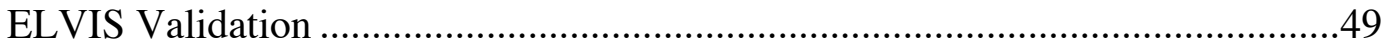

Multiplexer Validation..........................................................................50

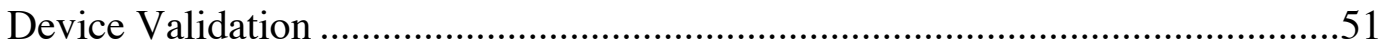

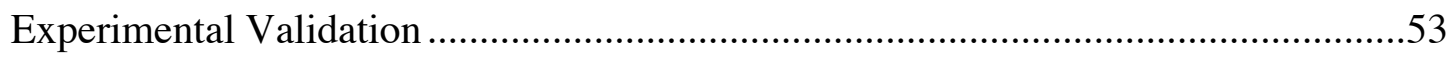

Raw Chicken Skin and Meat .......................................................................54

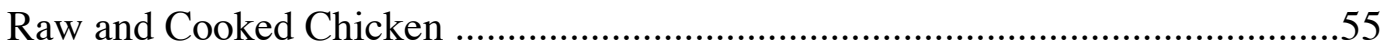


Tissue Engineered Skin Analogues ..............................................................56

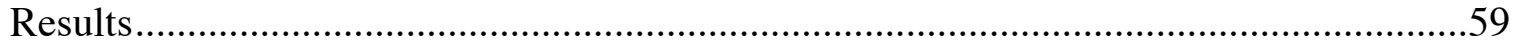

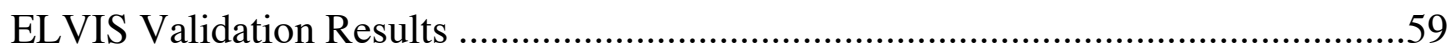

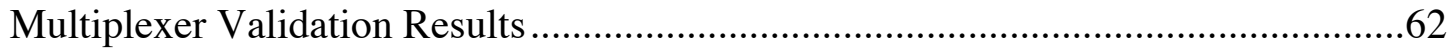

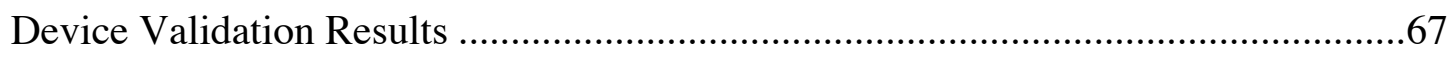

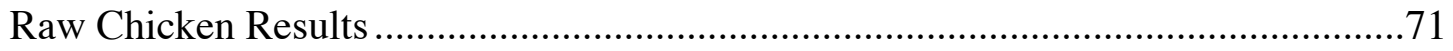

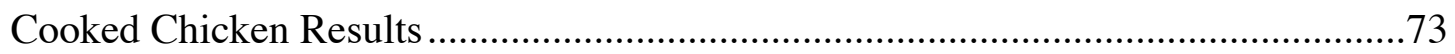

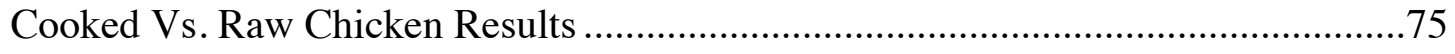

Tissue Engineered Skin Analogue Results ........................................................

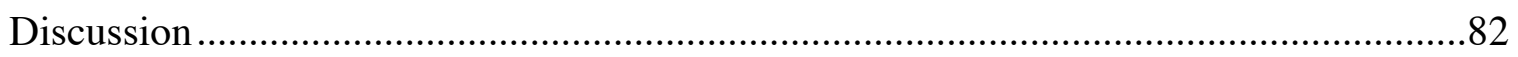

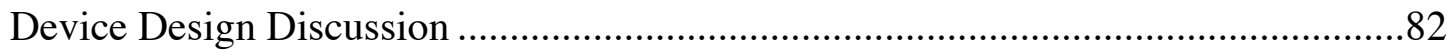

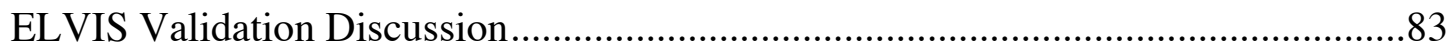

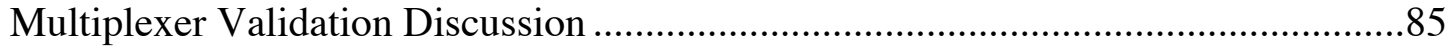

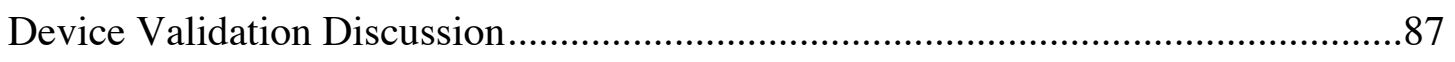

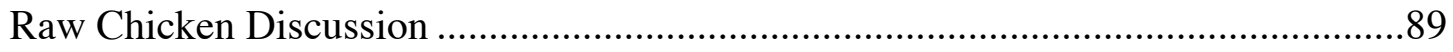

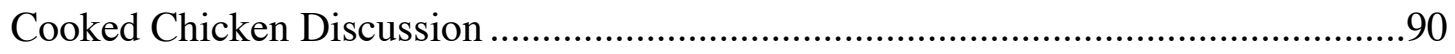

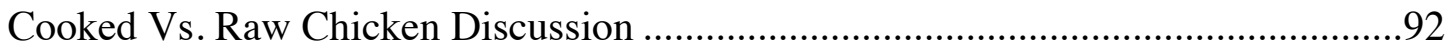

Tissue Engineered Skin Analogue Discussion ...................................................94

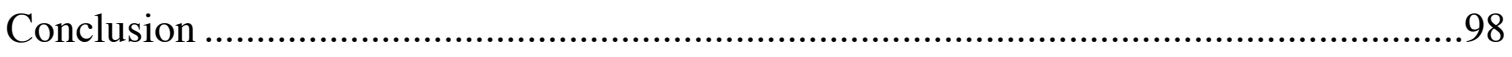

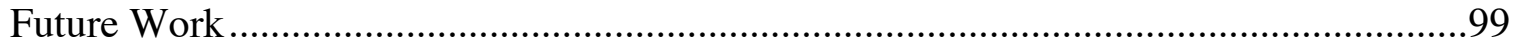

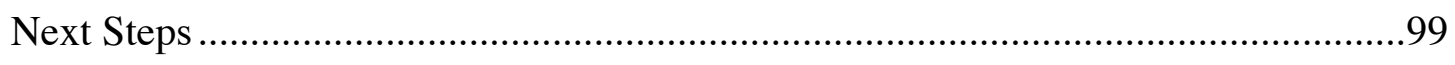

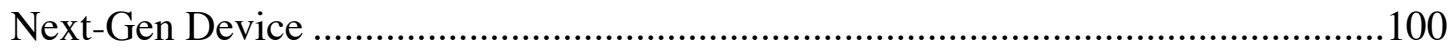

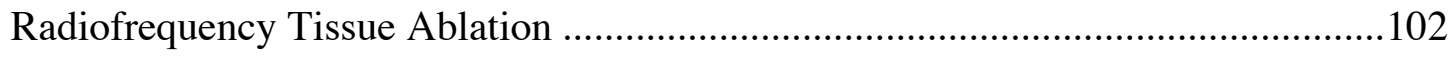


Bibliography .104

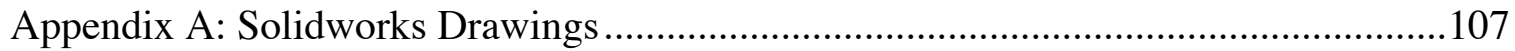

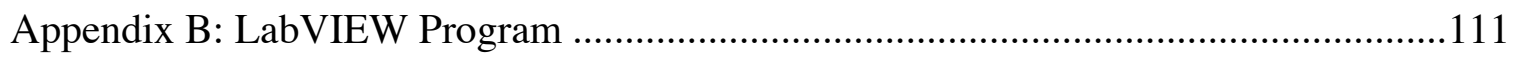

Appendix C: Validation Data ………………………...............................................113

Appendix D: Minitab Outputs .........................................................................117 


\section{List of Tables}

Table 1 - Melanoma Skin Cancer Staging ………………............................................16

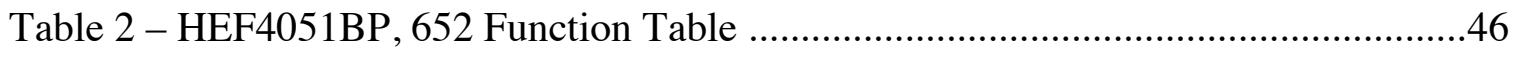

Table 3 - ELVIS Validation Resistor Values at $2 \mathrm{kHz}$..................................................60

Table 4 - ELVIS Validation Resistor Values at $10 \mathrm{kHz}$..............................................60

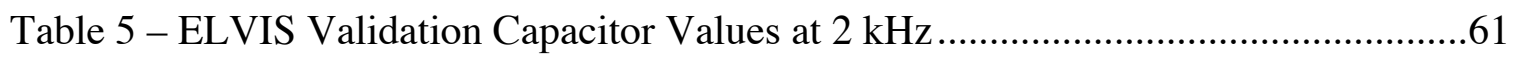

Table 6 - ELVIS Validation Capacitor Values at $10 \mathrm{kHz}$..............................................62

Table 7 - Multiplexer Validation Resistor Values at $2 \mathrm{kHz} . . . \ldots \ldots \ldots \ldots \ldots \ldots \ldots \ldots \ldots \ldots \ldots \ldots \ldots \ldots \ldots \ldots . . . . .63$

Table 8 - Averaged Intrinsic Multiplexer Impedance Values ..........................................63

Table 9 - Adjusted Multiplexer Validation Resistor Values at $2 \mathrm{kHz}$.............................64

Table 10 - Adjusted Multiplexer Validation Resistor Values at $10 \mathrm{kHz}$.........................65

Table 11 - Adjusted Multiplexer Validation Capacitor Values at $2 \mathrm{kHz} . . . \ldots \ldots \ldots \ldots \ldots \ldots . . . . . . . . . .66$

Table 12 - Adjusted Multiplexer Validation Capacitor Values at $10 \mathrm{kHz} . . . \ldots \ldots \ldots \ldots \ldots \ldots \ldots . . . . . .66$

Table 13 - Averaged Intrinsic Device Impedance Data ...................................................67

Table 14 - Adjusted Device Validation Resistor Values at $2 \mathrm{kHz}$...................................68

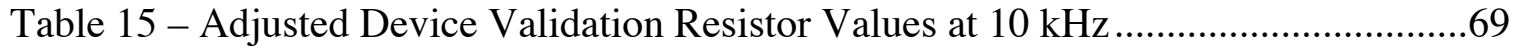

Table 16 - Adjusted Device Validation Capacitor Values at $2 \mathrm{kHz}$...............................70

Table 17 - Adjusted Device Validation Capacitor Values at $10 \mathrm{kHz}$..............................70

Table 18 - Comparing Measured Impedances to Previous Work ………………….........94

Table 19 - Unadjusted Multiplexer Validation Resistor Values at $10 \mathrm{kHz}$...................113

Table 20 - Unadjusted Multiplexer Validation Capacitor Values at $2 \mathrm{kHz}$...................113

Table 21 - Unadjusted Multiplexer Validation Capacitor Values at $10 \mathrm{kHz}$..................114

Table 22 - Unadjusted Device Validation Resistor Values at $2 \mathrm{kHz}$..............................114 
Table 23 - Unadjusted Device Validation Resistor Values at $10 \mathrm{kHz}$.........................115

Table 24 - Unadjusted Device Validation Capacitor Values at $2 \mathrm{kHz} . . . \ldots \ldots \ldots \ldots \ldots \ldots \ldots . . . . . . . . .115$

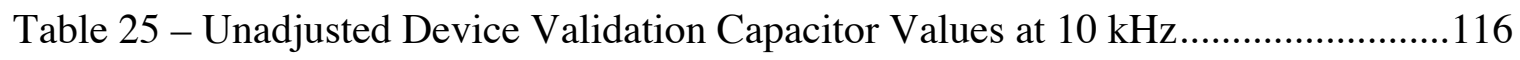




\section{List of Figures}

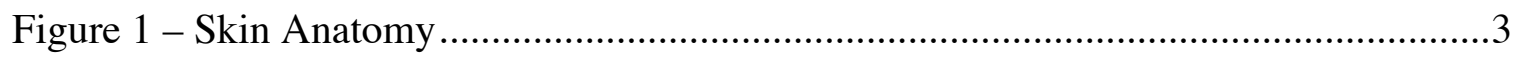

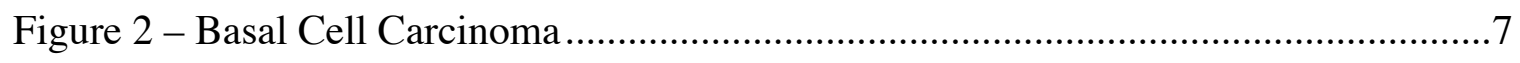

Figure 3 - Squamous Cell Carcinoma ...............................................................

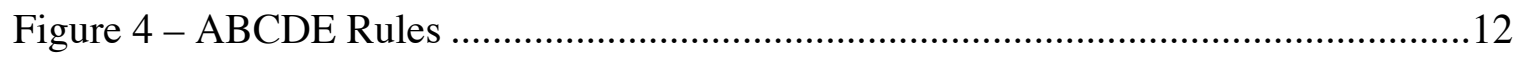

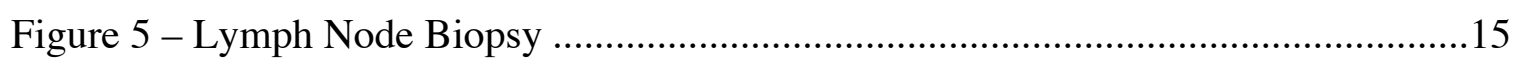

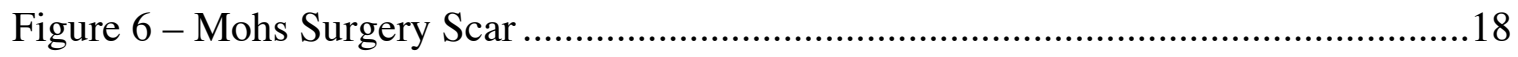

Figure 7 - Skin Tissue Equivalent Circuit Model ..................................................24

Figure 8 - Dinh et al. Electrode Pattern .................................................................29

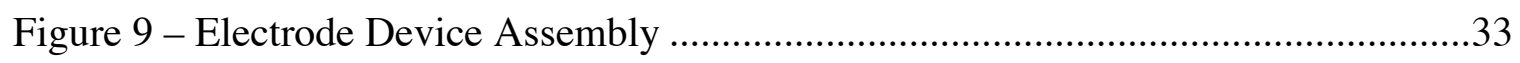

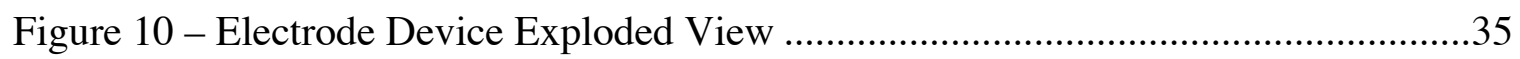

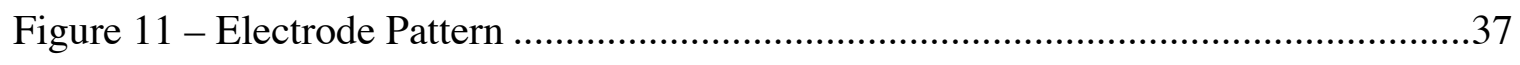

Figure 12 - Electrode Device Fixture ................................................................ 41

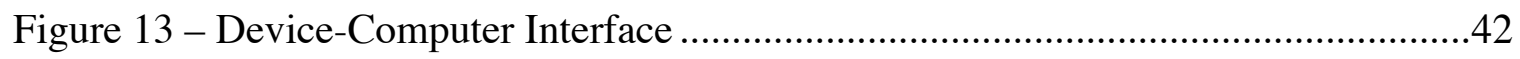

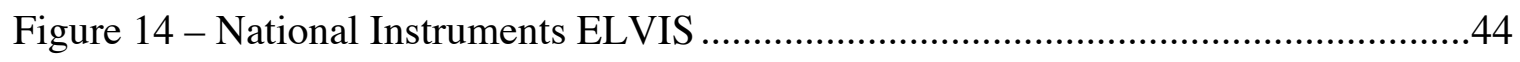

Figure 15 - HEF4051BP Pinout Diagram ............................................................46

Figure 16 - Multiplexer Validation Setup ............................................................51

Figure 17 - Electrical Testing Hook Clip ...............................................................52

Figure 18 - Electrode Device Validation Setup ......................................................53

Figure 19 - Chicken Tissue Validation Setup ............................................................55

Figure 20 - Epiderm ${ }^{\mathrm{TM}}$ Histological Cross-Section.................................................57

Figure 21 - Melanoma Tissue Analogue Histological Cross-Sections ............................58

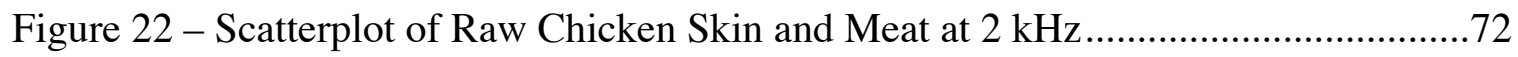




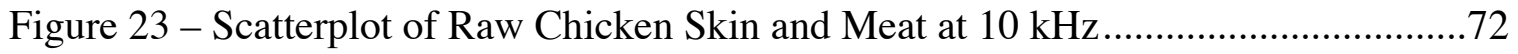

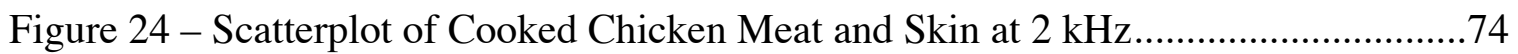

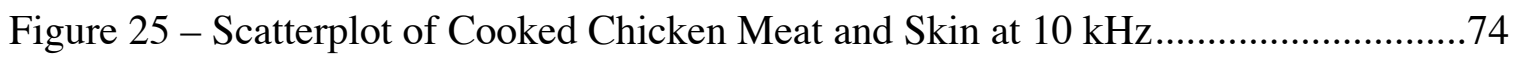

Figure 26 - Boxplot of Chicken Tissue Impedance .................................................76

Figure 27 - Boxplot of Chicken Tissue Impedances - Excluding Cooked Skin..............78

Figure 28 - Boxplot of Tissue Engineered Skin Analogues........................................80

Figure 29 - Electrode Device Bill Of Materials ...................................................... 107

Figure 30 - Electrode Holder Top Section Drawing ..............................................108

Figure 31 - Electrode Holder Middle Section Drawing .........................................109

Figure 32 - Electrode Holder Bottom Section Drawing ….......................................110

Figure 33 - LabVIEW Program Front Panel .......................................................111

Figure 34 - LabVIEW Block Diagram ................................................................ 112 


\section{List of Equations}

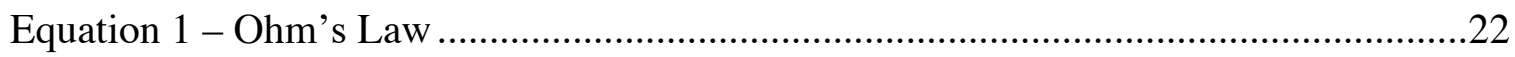

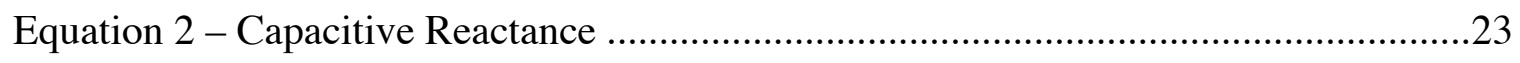

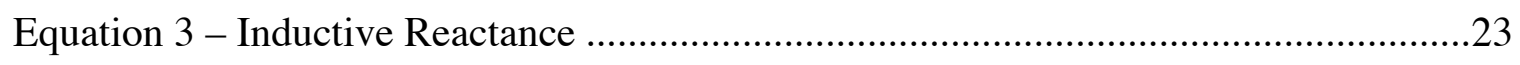

Equation 4 - Impedance Components ................................................................23

Equation 5 - Phase Angle ..................................................................................24

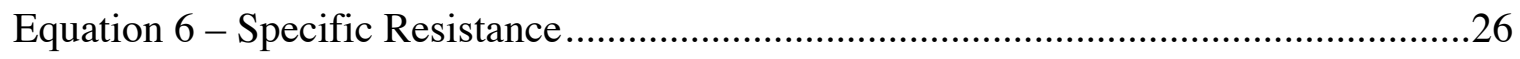

Equation 7 - Stratum Corneum Resistivity Profile .................................................26

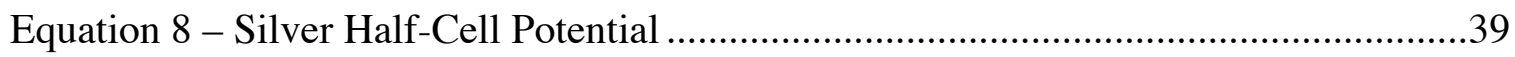

Equation 9 - Program Iteration Frequency ..............................................................48

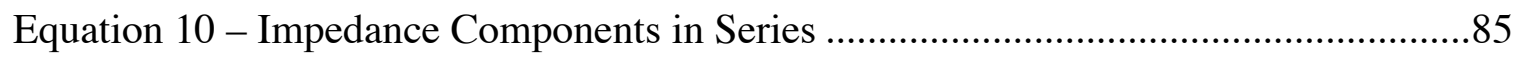




\section{Introduction}

\section{Thesis Objective}

The objective of this thesis is to manufacture, assemble, and test a device that uses a matrix of electrodes to measure the electrical impedance of skin tissue. This device will be used to measure the differences in electrical impedance between healthy tissue and cancerous tissue, specifically melanoma. Statistical differences in impedance can potentially provide a non-invasive diagnosis for melanoma and save the patient from unnecessary biopsies. The matrix of electrodes allows for the acquisition of impedance in multiple directions, which can help identify the boundaries of the tumor.

To ensure that this electrode device functions properly, the number of electrodes and electrode pattern have been kept small and simple, respectively. Thus, the objective of this thesis is also to review possible alterations to the device for future work, which may increase the resolution of the device and allow for accurate identification of tumor boundaries.

\section{Thesis Purpose}

The purpose of this thesis is to: 1) present information on skin cancer and provide current clinical practices in diagnosing, staging, and treating melanoma, 2) introduce a relatively new technique for non-invasive diagnosis of skin cancer, 3) validate this new technique by providing and analyzing experimental data using the constructed electrode matrix device, 4) draw practical and theoretical conclusions on the data, and 5) speculate on alterations for future work, clinical utilization, and possible interplay between radiofrequency tissue ablation treatment devices. 


\section{Background}

\section{Skin Anatomy and Physiology}

To understand the scientific theory behind impedance analysis of skin, it is important to understand the overall structure, cellular composition, and normal functioning of skin. Skin is considered the body's largest organ and serves multiple functions including thermoregulation, sensation, vitamin D synthesis, and barrier functions [1]. Thermoreceptors in the skin transmit signals to the brain, which can induce vasoconstriction or vasodilation when it is cold or hot, respectively [1]. Similar to thermoreceptors, there are an abundance of nerve endings in the skin that allow for the sensation of touch. Vitamin D synthesis begins in the skin from exposure to ultraviolet (UV) B rays and ultimately leads to calcitriol, which serves numerous functions as a hormone in the body [1]. Finally, the skin serves a barrier function to prevent bacteria, fungi, and water from entering the body through the skin. It also functions to retain the water in the body. Due to its large surface area and its location as a barrier to the external world, the skin receives the most physical injuries in the form of cuts, scraps, UV radiation and more [1]. However, with skins high regeneration rate, the physical traumas that occur are quickly repaired [1].

All of the aforementioned functions occur from the cellular makeup of skin.

Figure 1 shows the three main layers of skin, which are the hypodermis, dermis, and epidermis, in order from deepest to most superficial [1]. The hypodermis is the deepest layer of skin and is mainly comprised of adipose tissue [1]. It is highly vascularized and is thus an attractive sight for drug injections known as subcutaneous injection [1]. The 
adipose tissue connects the skin to underlying structures, insulates the body, and acts as padding in sensitive areas [1].

The dermis is the middle layer of the skin, superficial to the hypodermis, and is mainly connective tissue with collagen and elastin fibers and fibroblast cells [1]. Incorporated into the dermis are blood vessels, sweat glands, and nerve endings, which contribute to the functions of sensation and thermoregulation [1]. At the border between the dermis and the epidermis, there exist wave-like structures called dermal papillae [1]. These dermal papillae mesh with epidermal ridges and oppose shearing forces placed on the skin [1].

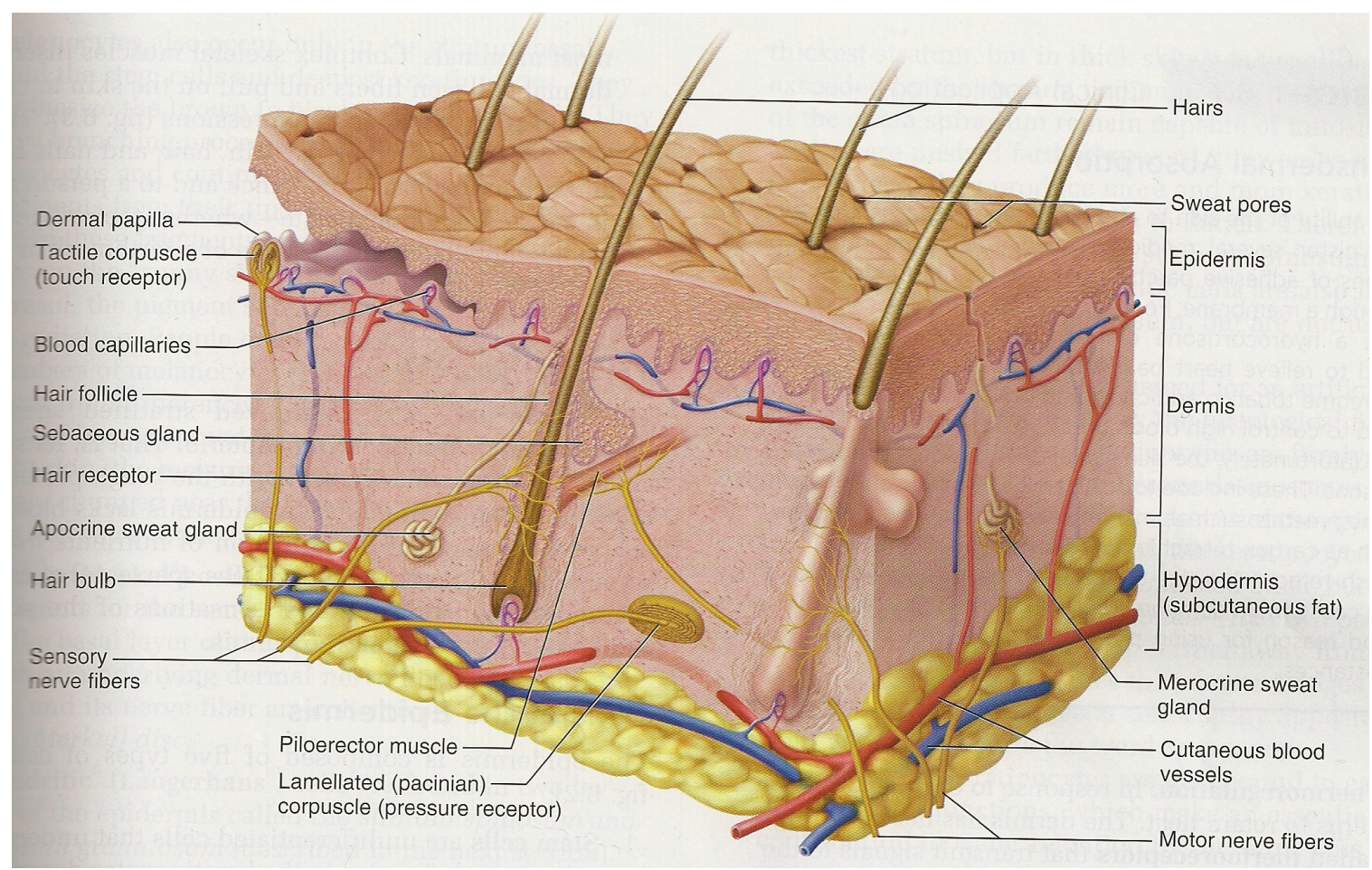

Figure 1: Skin Anatomy

\section{A cross section showing the three layers of skin and their components [1]}

The outermost (superficial) layer of skin is known as the epidermis. The epidermis is important to this thesis because it contains the cells that grow uncontrollably 
during formation of most common skin tumors [1]. The epidermis is broken down into further layers known as the stratum basale, stratum spinosum, stratum granulosum, stratum lucidum, and stratum corneum, from deepest to most superficial [1]. The stratum basale is uniquely comprised of stem cells, melanocytes, keratinocytes, and tactile cells [1]. Epidermal stem cells, found in the stratum basale, produce new keratinocytes and gradually push old keratinocytes to the surface of the skin in approximately 30-40 days [1]. Melanocytes are pigment-producing cells that release a brown to black pigment known as melanin [1]. This melanin is taken up through phagocytosis by keratinocytes and is accumulated on the side of the nucleus that receives the most UV rays [1]. Melanin absorbs these harmful UV rays and inhibits DNA damage [1]. Tactile cells are touch receptors and are coupled to nerve fibers found in the dermis to transmit pressure and texture information to the brain [1]. Keratinocytes are the most abundant cell in the epidermis and are found in all five layers. Keratinocyte secretion of lipids in the stratum granulosum and stratum spinosum is responsible for the hydrophobic barrier that retains water in the body [1]. Keratinocytes also have many desmosomes and tight junctions types of intercellular connections - that oppose shearing forces and relate to the toughness of skin [1]. The last cell, dendritic cells, are found in the stratum granulosum and stratum spinosum and act as macrophages for any pathogens that enter the epidermis through abrasions, scratches, etc [1]. Together, the intercellular connections, as well as the different layers of skin, influence the electrical properties of healthy skin tissue. Changes in the type and number of cells during tumorigenesis are discussed in the section Skin Cancer. 


\section{Cancer}

In general, a tumor is the term used to describe the uncontrolled growth of abnormal cells in the body [2]. A tumor may be slow growing masses that are encapsulated with fibrous tissues (benign) or fast growing masses that can release cells into the systemic circulation (malignant) [1]. The latter of these is the more dangerous type of tumor and is often referred to as cancer. The five major classes of cancer and the cells in which they originate from are carcinoma from epithelial cells, melanoma from melanocytes, sarcoma from bone or muscle, leukemia from blood forming tissues, and lymphoma from lymph nodes [1].

\section{Causes}

In normal, healthy cells, when the life cycle reaches its end, extrinsic (cytokines) and intrinsic (cytochrome-c) factors stimulate the cell to fragment the DNA and begin destroying itself [3]. This is known as apoptosis. Phagocytic cells, such as macrophages

or dendritic cells, remove and degrade the fragments of the apoptotic cells [3]. The death of cells is counteracted by the controlled generation of new cells from stem cells. For instance, in the stratum basale layer of the epidermis, stem cells continuously regenerate keratinocytes to renew the skin [1]. However, in tumorigenic cells, key genes that regulate differentiation are damaged in the DNA [1]. All of these genes are not known, but some of them include sis, ras, and p53, which, in their abnormal states, secrete excessive amounts of angiogenic growth factors, cause abnormally sensitive growth factor receptors, and fail to inhibit the enzymes of the cell cycle, respectively [1]. DNA damage occurs through various mutagens and mechanisms that include chemicals, excessive alcohol, environmental toxins, sunlight exposure, genetics, 
radiation, and viruses [4]. Some chemicals known for their carcinogenic potential are benzene, asbestos, ethylene oxide, formaldehyde, tobacco, and many more [4].

\section{Effects and Symptoms}

Cancer symptoms are highly dependent on the classification and location of the tumor. For these reasons, the effects and symptoms described in this section may not correspond to every cancer. One of the first symptoms of cancer is fatigue [2]. Fatigue stems from the fact that the tumors have a high metabolic rate due to the continuous differentiation of cells [2]. Tumors secrete angiogenic (capillary-forming) factors that increase the blood flow and nutrients to it [2]. The flow of more nutrients to the tumor depletes the resources used for other healthy cells; the result is a general feeling of weakness. Muscle and adipose tissue may even degrade to provide extra nutrients to the tumor, which leads to weight loss [2].

In some cancer cases, especially in leukemia, the immune system is either preoccupied with fighting the cancer or abnormal due to the cancer. This allows for opportunistic infections to overwhelm the weakened immune system and cause serious illness or death. The growth of the tumor itself has further implications than just metabolic need. Growing masses can infiltrate normal tissues and cause dysfunction [1]. If serious enough, the dysfunction can lead to death as in the inability to oxygenate blood in lung cancer [1]. Tumor growth may also place pressure on airways or blood vessels and can inhibit breathing and oxygenation to healthy tissues [1]. Finally, it is important to note that while the primary cancer is detrimental, in most cases, the metastatic tumors that infiltrate other regions of the body cause the more severe symptoms [1]. 


\section{Treatment}

Cancer treatment options are similar to symptoms in that they vary greatly with the classification and location of the mass. However, the three main treatments used in most cancers are chemotherapy, radiation therapy, and surgery [2]. Chemotherapy involves administering drugs that are cell cycle arresters (i.e. inhibit differentiation) [2]. Experimental chemotherapy drugs are tagged with certain proteins to hone directly to and affect only the cancerous cells [2]. Yet, most chemotherapy drugs still inhibit differentiation in all cells in the body and thus cause significant side effects, such as poor appetite, loss of hair, fatigue, bleeding, and mouth sores [2].

Radiation therapy uses multiple X-ray beams that meet at the tumor and produce a high amount of radiation at its location [2]. Just as radiation can damage DNA and cause cancer, high amounts of radiation can further damage DNA and cause cell death [2]. There are few side effects to radiation therapy, but may include irritation or damage to cells surrounding the tumor [2]. Radiation therapy and chemotherapy are often used synergistically to shrink the tumor for surgery [2]. Depending on the location of the cancer, a surgeon will cut into the body and remove all tumor cells in the area.

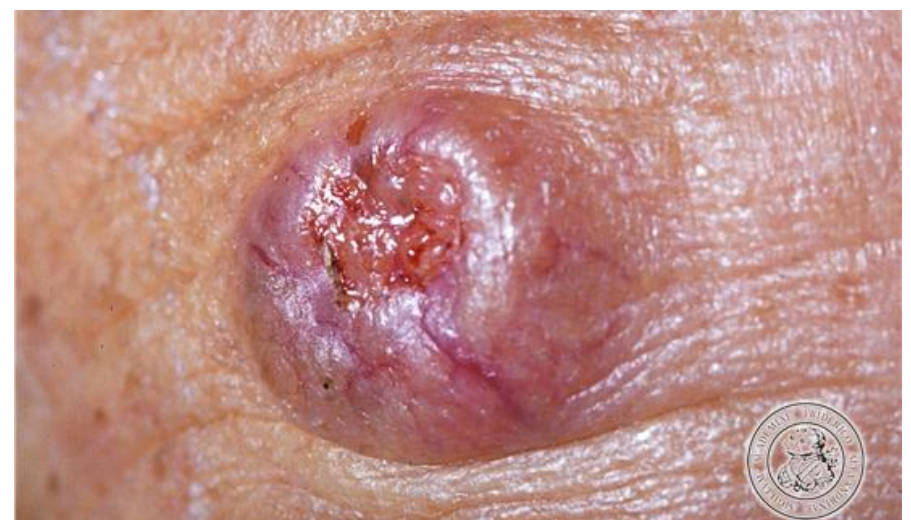

Figure 2: Basal Cell Carcinoma

A basal cell carcinoma lesion showing the beaded edge and central depression [5] 


\section{Skin Cancer}

Now with the knowledge of skin anatomy and an overview of cancer, we can specifically investigate the nuances of skin cancer. As of 2007, skin cancer is the most common type of cancer, although there is a high survival rate associated with the disease $[1,6]$. There are three common types of skin cancer that are classified by the cell type in which they originate. These classifications are further lumped into melanoma and nonmelanoma cancer categories.

\section{Non-Melanoma}

Basal cell carcinoma and squamous cell carcinoma are the most common types of non-melanoma skin cancer [7]. Non-melanoma cancers are generally less severe than melanoma cancers [7]. Basal cell carcinoma derives from the cells in the stratum basale the deepest layer of the epidermis [7]. While basal cell carcinoma is the most prevalent type of skin cancer, it is also the least hazardous to health because of the low risk of metastasis [7]. The lesion of basal cell carcinoma usually grows from a small, shiny bump to a larger one with a beaded edge and central depression as shown in Figure 2 [7]. Squamous cell carcinoma derives from keratinocytes in the stratum spinosum layer of the epidermis [7]. This form of skin cancer is more malicious but still controllable if diagnosed early. These lesions appear red and scaly and usually precede more ulcerative lesions as in Figure 3 [1]. Other forms of non-melanoma skin cancer that are less common include Kaposi's sarcoma, Merkel (tactile) cell carcinoma, and cutaneous lymphoma [7]. Even though the majority of these skin cancers are more prominent than melanoma skin cancer, they are often less dangerous and will not be investigated in this thesis. 


\section{Melanoma}

Melanoma skin cancer is considered the most deadly form of all skin cancers [8]. It was estimated in 2010 that 68,130 men and women would be diagnosed with melanoma and 8,700 men and women would die from melanoma [8]. Melanoma stems from the abnormal growth of melanocytes in the epidermis and may occasionally be found in the pigmented segments of the eyes and intestines [6].

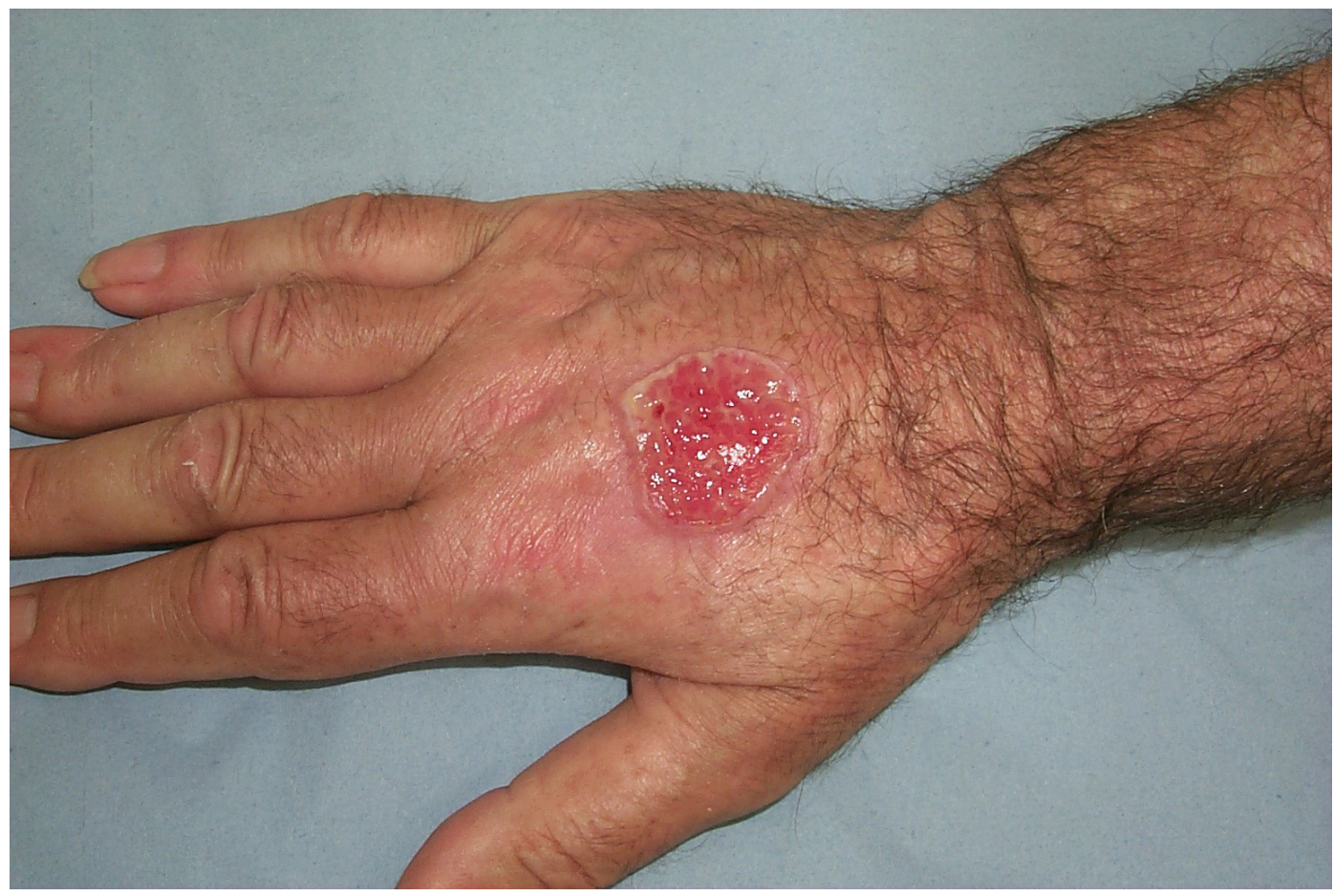

Figure 3: Squamous Cell Carcinoma

\section{A squamous cell carcinoma lesion with advanced ulcerative feature [9]}

\section{Risk Factors}

Abnormal growth of melanocytes occurs from damage to the DNA. Most scientists believe that UV rays damage the DNA directly, however, there are many other factors that have a role in the development of melanoma. Skin complexion is highly correlated to melanoma production [8]. Persons with fairer skin pigment cannot protect 
against the UV rays as well as persons with dark complexions. This results in an approximately 30 fold greater chance of melanoma in white persons compared to Asian and Black persons [8]. Similarly, increased sun exposures or intense sunburns will cause more UV ray damage and a greater likelihood of skin cancer development [10]. As such, areas of the body that experience the most sun exposure, which are the back, neck and face, have a higher probability of developing cancerous lesions [10]. Genetics also plays a role in melanoma development. Family members with previous history of melanoma are likely to pass the dysfunctional gene to their offspring [10]. Recent studies in melanoma etiology have found that mutations in the BRAF, p53, or Rb genes are often seen repeated among family members that exhibit the disease [11]. These genes are thought to control the suppression of growth, which, when mutated, cause immortalized cancer cells [11]. Age is also responsible for development of the disease considering that the median age of melanoma diagnosis is 60 years [8]. One article believes that the manifestation of melanoma in later years is due to a gradual buildup of oxidative stress caused by melanin-derived reactive oxygen species [11]. Finally, individuals should scrutinize the appearance of dysplastic nevi, or moles. Nevi, which are benign growths, have the capability to begin changing into melanoma or other skin cancer lesions [10]. Tips for identifying malicious lesions are discussed in the Diagnosis section next.

\section{Diagnosis}

Early diagnosis of melanoma is critical in survival rates. When the cancer is diagnosed early - before the lesion has spread to lymph nodes or other tissues - the relative survival percentage at 5 years after the diagnosis is $98 \%$ [8]. However, when the cancer has metastasized, the relative survival percentage at 5 years is $15.9 \%$ [8]. Current 
diagnosis techniques utilize a combination of visual inspection and histological testing. The visual inspection of the nevi is governed by the ABCDE rules - an updated version of the $\mathrm{ABCD}$ rules. A physician uses these rules during an examination, but they recommend annual self-examinations using mirrors [12]. The following rules are as follows [10]:

- $\mathrm{A}=$ Asymmetry - Two halves of the nevus do not match

- $\quad \mathrm{B}=$ Border - The borders of the nevus are uneven or blurred

- $\mathrm{C}=$ Color - Two or more distinct colors are found. These colors may be brown, tan, black, red, or blue.

- $\mathrm{D}=$ Diameter - The diameter of the nevus is larger than $1 / 4$ " or $6 \mathrm{~mm}$

- $\mathrm{E}=$ Evolving - Any change in rules A, B, C, or D, or any bleeding, itching, or crusting, is cause for concern.

Images depicting benign and malignant lesions for all aspects of the ABCDE rules are shown in Figure 4. If any of the rules are satisfied and a nevus appears to be malignant, then a biopsy is performed. The biopsies performed depend on the appearance of the lesion and the location. Most commonly, excisional biopsies are performed, which includes cutting away the entire lesion, as well as some surrounding healthy tissue [4]. Incisional biopsies are similar to excisonal biopsies, but only incorporate cancerous cells - no healthy tissue is removed [4]. Punch biopsies remove a cylindrical section of the epidermis and dermis similarly to a circular cookie cutter [4]. Punch biopsies are beneficial because they incorporate dermis tissue that is helpful for staging [4].

After the biopsy, a sample of the tissue is sent to the laboratory where histology is performed by staining the sample and viewing cells with a microscope [4]. Trained 
laboratory technicians subjectively analyze the cell morphology of the sample and determine if cancer is a proper diagnosis. Often, multiple technicians view the histology slides to reduce error from technician subjectivity [4]. If cancer is determined to be an appropriate diagnosis, trained professionals stage the cancer and determine a prognosis. Many times, further excisional biopsies are needed to remove all cancerous cells.

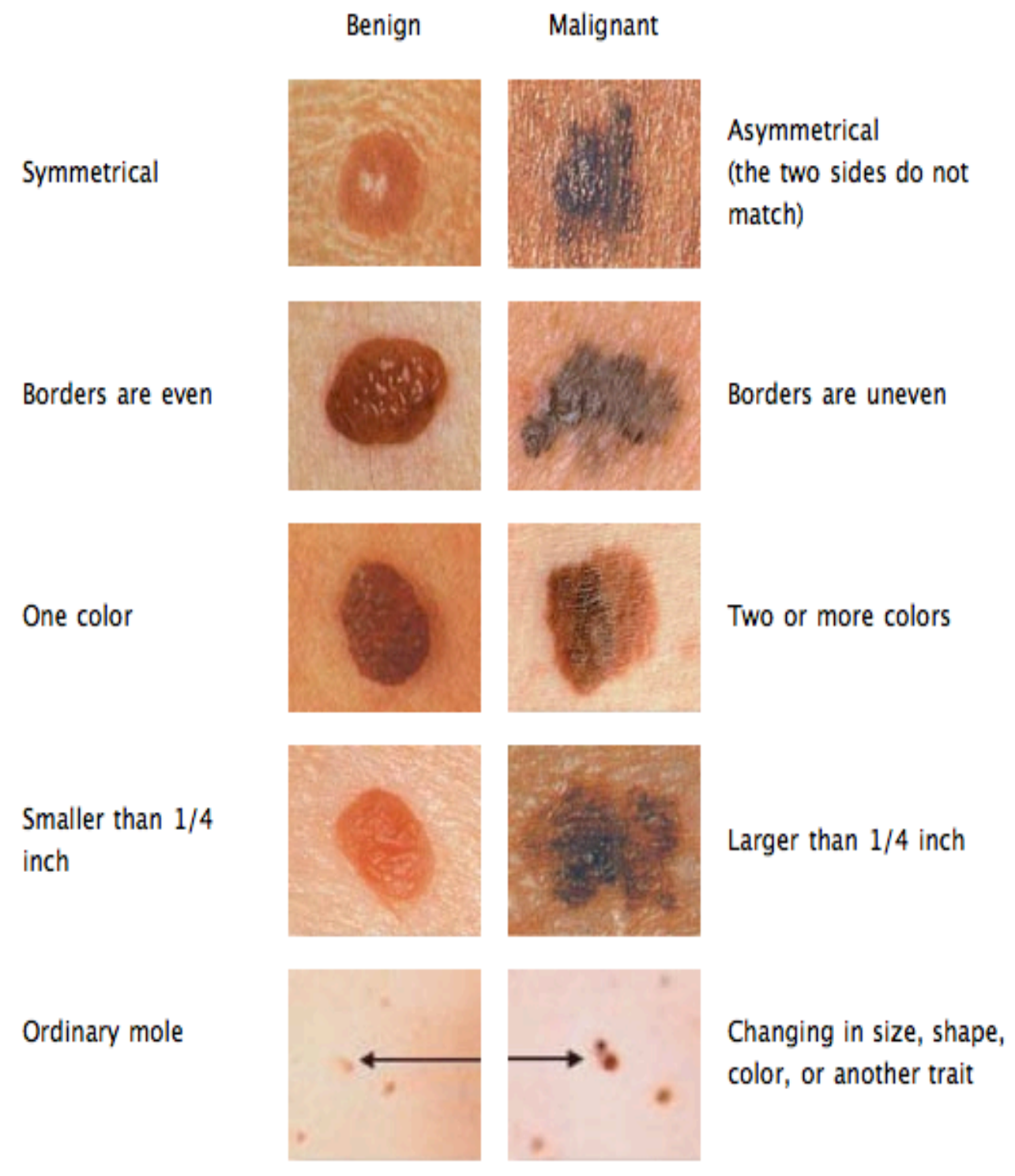

Figure 4: ABCDE Rules

Example images of the difference between benign nevi and malignant melanomas in reference to the $\mathrm{ABCDE}$ rules of diagnosis [10] 
Since the ABCDE rules and histological inspections are based on the physician or technician's subjectivity, the consistency of results may vary between persons. Thus it is important to create a diagnostic technique that eliminates subjectivity. Even more important, is creating a diagnostic technique that is non-invasive so that surgery does not have to be performed. For example, scarring will occur from an excisional biopsy, while the results of the biopsy may yield benign results. Besides scarring, with diagnostic techniques being invasive, physicians may decide that a lesion does not appear severe enough to justify surgery. The physician attempts to eliminate unnecessary scarring while balancing the risk of overlooking a malignant tumor. This risk would be nearly nonexistent if an accurate non-invasive diagnostic technique could provide objective results.

Attempts at producing new diagnostic techniques include multispectral digital dermoscopy, confocal scanning laser microscopy, and cellular electrical bioimpedance [12]. Multispectral digital dermoscopy uses a camera that has the ability to project electromagnetic waves at different wavelengths and record the reflected signals [12]. Different wavelengths of electromagnetic radiation can penetrate different thicknesses of skin and obtain images of a lesion that physicians cannot see [12]. The color of the lesion is also recorded and a computer algorithm analyzes all of the data to determine if the lesion is likely malignant; this technique yields a sensitivity of 95-100\% [12]. Confocal scanning laser microscopy is similar to multispectral digital dermoscopy, except that it uses a pinhole to focus a low-intensity infrared laser beam [12]. This highly focused laser beam is able to penetrate the skin and record structures at different levels [12]. Thus, it provides slices of tissue, like a digital rendition of histology, to allow for diagnosis. The confocal microscopy technique allows for $98 \%$ sensitivity [12]. Cellular electrical 
bioimpedance is the diagnostic technique that will be investigated further in this thesis.

The theory behind cellular bioimpedance measurements and its application toward melanoma skin cancer diagnosis are discussed further in Electrical Properties $\rightarrow$ Cancer and Practical Uses.

Staging

After successful diagnosis and identification of the type of skin cancer, staging of the lesion begins. Staging includes a series of parameters that can be followed objectively. There are two divisions to staging. The first division encompasses the $\mathrm{T}, \mathrm{N}$, and $\mathrm{M}$ parameters. These parameters are broken down even further into numbers that relate to the number or size of each parameter. The second division of staging groups the $\mathrm{T}, \mathrm{N}$, and $\mathrm{M}$ values together to assign a comprehensive value to the stage of the cancer. This comprehensive value will determine the likely prognosis of the patient. The parameters are explained as follows [13]:

○ $\quad \mathbf{T}=$ Primary Tumor. This parameter of staging mainly deals with the thickness of the lesion. The thickness of the lesion is defined as the distance from the top layer of the epidermis to the bottom of the lesion. These measurements are usually performed with micrometers after excision or during the histological sections of the tissue. Imaging technologies, such as confocal microscopy or ultrasound, may also accurately gauge the thickness of the tumor. In addition to the thicknesses, appearances of microscopic ulcerations are taken into account, as well as the rate of mitosis. The rate of mitosis only corresponds to staging in T1 lesions and is given an ' $\mathrm{a}$ ' for mitosis rates less than 1 event $/ \mathrm{mm}^{2}$ or a ' $b$ ' for rates greater than or equal to 1 event $/ \mathrm{mm}^{2}$.

- TX - Primary tumor cannot be assessed

- T0 - No evidence of primary tumor

- Tis - Melanoma in situ (still in original place)

- $\mathbf{T 1}$ - Melanoma is $1.0 \mathrm{~mm}$ or less in thickness

- T2 - Melanoma is $1.01-2.0 \mathrm{~mm}$

- $\mathbf{T 3}$ - Melanoma is $2.01-4.0 \mathrm{~mm}$

- T4 - Melanoma is greater than $4.0 \mathrm{~mm}$

- $\mathbf{a}$-Lesion contains no ulceration

- b-Lesion contains ulceration 
$\circ \quad \mathbf{N}=$ Regional Lymph Nodes. This parameter identifies the number of lymph nodes affected by metastasis of the lesion. Metastasis occurs when cellular adhesion molecules break down in the lesion. This allows surface cancerous cells to dislodge from the mass and travel either by the lymphatic system to the lymph nodes or by the circulatory system to distant tissues. Lymph nodes are tested by palpating downstream lymph nodes for inflammation. Lymph fluid is also retrieved from the lymph nodes under local anesthesia as shown in Figure 5. The lymph fluid is stained to look for leukocytes or cancer cells. Further differentiation into ' $a$ ' and ' $b$ ' are used to describe the size of the metastasis.

- $\mathbf{N X}$ - Regional lymph nodes cannot be assessed

- No - No regional metastases detected

- N1-3 - Metastases related to the number of nodes affected

- a-Micrometastasis

- b-Macrometastasis

○ $\quad \mathbf{M}=$ Distant Metastases. This parameter identifies the tissues affected by melanoma metastases and are ranked from ' $a$ ' to 'c' based on the type of tissue affected most frequently. Since skin and subcutaneous tissue is adjacent to the original location of the lesion, it is common to get metastasis in these locations. The lungs are also a frequent location for metastatic melanoma. Metastases are imaged by using X-rays, PET scans, and MRIs that allow for visualization of the body. This parameter can also be further differentiated by the serum levels of Lactate Dehydrogenase (LDH).

- M0 - No detectable evidence of distant metastases

- M1a - Metastases to skin, subcutaneous, or distant lymph nodes with normal LDH

- M1b - Metastases to lung with normal LDH

- M1c - Metastases to all other visceral sites or elevated LDH

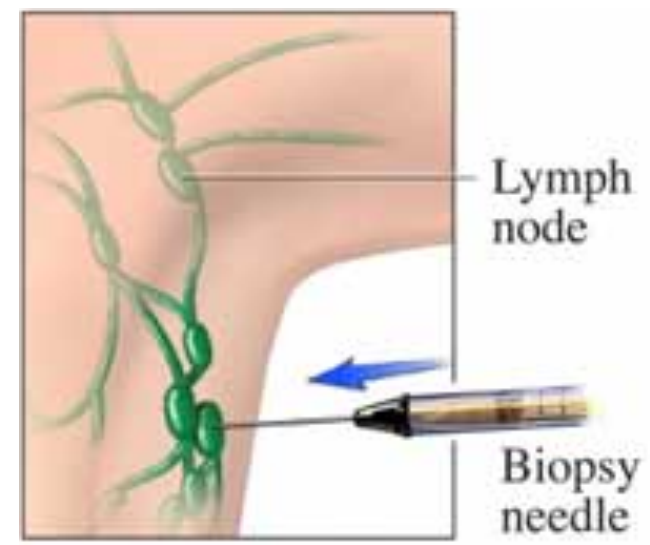

Figure 5: Lymph Node Biopsy

An example of a lymph node biopsy to determine the $\mathbf{N}$ stage of melanoma [14] 
Given the definitions and parameters for the staging of melanoma, a table compiling the comprehensive stages with the parameters is provided in Table 1 [13].

There are two headings for the stages of melanoma: clinical and pathologic staging. The only difference between the two headings is that pathologic staging incorporates surgical findings of melanoma metastases to lymph nodes.

Table 1: Melanoma Skin Cancer Staging [13]

\begin{tabular}{|c|c|c|c|c|c|c|c|}
\hline \multicolumn{8}{|c|}{ ANATOMIC STAGE/PROGNOSTIC GROUPS } \\
\hline \multicolumn{4}{|c|}{ Clinical Staging $^{3}$} & \multicolumn{4}{|c|}{ Pathologic Staging ${ }^{4}$} \\
\hline Stage 0 & Tis & No & MO & 0 & Tis & NO & MO \\
\hline Stage IA & T1a & No & MO & IA & T1a & No & MO \\
\hline \multirow[t]{2}{*}{ Stage IB } & $\mathrm{T} 1 \mathrm{~b}$ & No & MO & \multirow[t]{2}{*}{ IB } & $\mathrm{T} 1 \mathrm{~b}$ & No & MO \\
\hline & T2a & No & MO & & T2a & No & MO \\
\hline \multirow[t]{2}{*}{ Stage IIA } & $\mathrm{T} 2 \mathrm{~b}$ & No & Mo & \multirow[t]{2}{*}{$\|$ IA } & $\mathrm{T} 2 \mathrm{~b}$ & No & MO \\
\hline & ТЗа & No & MO & & ТЗа & No & MO \\
\hline \multirow[t]{2}{*}{ Stage IIB } & $\mathrm{T} 3 \mathrm{~b}$ & No & MO & \multirow[t]{2}{*}{ IIB } & T3b & No & MO \\
\hline & T4a & No & MO & & T4a & No & MO \\
\hline Stage IIC & T4b & No & MO & IIC & T4b & No & MO \\
\hline \multirow[t]{11}{*}{ Stage III } & Any $T$ & $\geq \mathrm{N} 1$ & M0 & \multirow[t]{2}{*}{ IIIA } & T1-4a & N1a & MO \\
\hline & & & & & T1-4a & $\mathrm{N} 2 \mathrm{a}$ & Mo \\
\hline & & & & \multirow[t]{5}{*}{ IIIB } & T1-4b & Nla & MO \\
\hline & & & & & T1-4b & $\mathrm{N} 2 \mathrm{a}$ & MO \\
\hline & & & & & T1-4a & $\mathrm{N} 1 \mathrm{~b}$ & MO \\
\hline & & & & & T1-4a & $\mathrm{N} 2 \mathrm{~b}$ & MO \\
\hline & & & & & T1-4a & $\mathrm{N} 2 \mathrm{C}$ & MO \\
\hline & & & & \multirow[t]{4}{*}{ IIIC } & T1-4b & $\mathrm{N} 1 \mathrm{~b}$ & MO \\
\hline & & & & & T1-4b & $\mathrm{N} 2 \mathrm{~b}$ & MO \\
\hline & & & & & T1-4b & $\mathrm{N} 2 \mathrm{C}$ & MO \\
\hline & & & & & Any T & N3 & MO \\
\hline Stage IV & Any T & Any N & M1 & IV & Any $T$ & Any N & M1 \\
\hline
\end{tabular}


To summarize the table, Stages I and II include in-situ tumors. These tumors are the ones that are most likely survivable if removal of the cancerous cells begins immediately. The letters 'a', 'b', and 'c' that are associated with stages I and II provide the information on the thickness of the tumor. The thicker the tumor, the more likely it is that the mass will penetrate into the dermis and begin metastasis. Stage III incorporates all melanoma metastases to distant lymph nodes. As the number of lymph nodes affected increases, so does the risk of death or other severe complications. Stage IV takes into account metastases to other tissues, which is considered the worst prognosis, depending on the locations of the metastases.

\section{Treatment}

With staging of the tumor known, the physician and the patient discuss treatment options. With stage I and II melanoma, there is no involvement of distant tissues or lymph nodes and thus the tumor itself can specifically be targeted for the treatment. One benefit of having a skin cancer is that the mass is found on the surface of the body. Thus, surgical intervention is often easy and fast. Excisional surgery, related to the technique used in the diagnosis of cancer, is often used to treat patients with skin cancer. In this technique, the physician merely cuts away the tumor along with a specified margin of healthy tissue to ensure the removal of all tumor cells [10]. For in situ melanomas, $0.5-1$ $\mathrm{cm}$ of healthy tissue surrounding the tumor is removed during surgery [10]. Melanomas that are $1 \mathrm{~mm}$ or less, 1.01 to $2 \mathrm{~mm}$, or $2.01 \mathrm{~mm}$ or greater in thickness will have approximately $1 \mathrm{~cm}, 1$ to $2 \mathrm{~cm}$, or $2 \mathrm{~cm}$ of healthy tissue removed during the surgery, respectively [10]. 
One advanced surgical technique that correlates to reduced margins of healthy tissue removed is called Mohs micrographic surgery [6]. In this technique, a thin layer of the tumor is removed and investigated for the presence of tumor cells at the border [6]. These investigations include staining the tissue sections and viewing slides under a microscope. If tumor cells are found in the middle of the section, then more cuts along the thickness of the tumor are needed [6]. If tumor cells are found at the border of the section, then it is likely that all tumor cells are not resected from the skin. Thus, the surgeon removes more marginal healthy tissue until the presence of tumor cells at the border of the sections is non-existent [6]. This surgery is longer then the simple excisional technique but reduces the amount of healthy tissue lost and softens the presence of a scar afterward [6]. However, looking at Figure 6, a scar is typically still noticeable from the surgery.

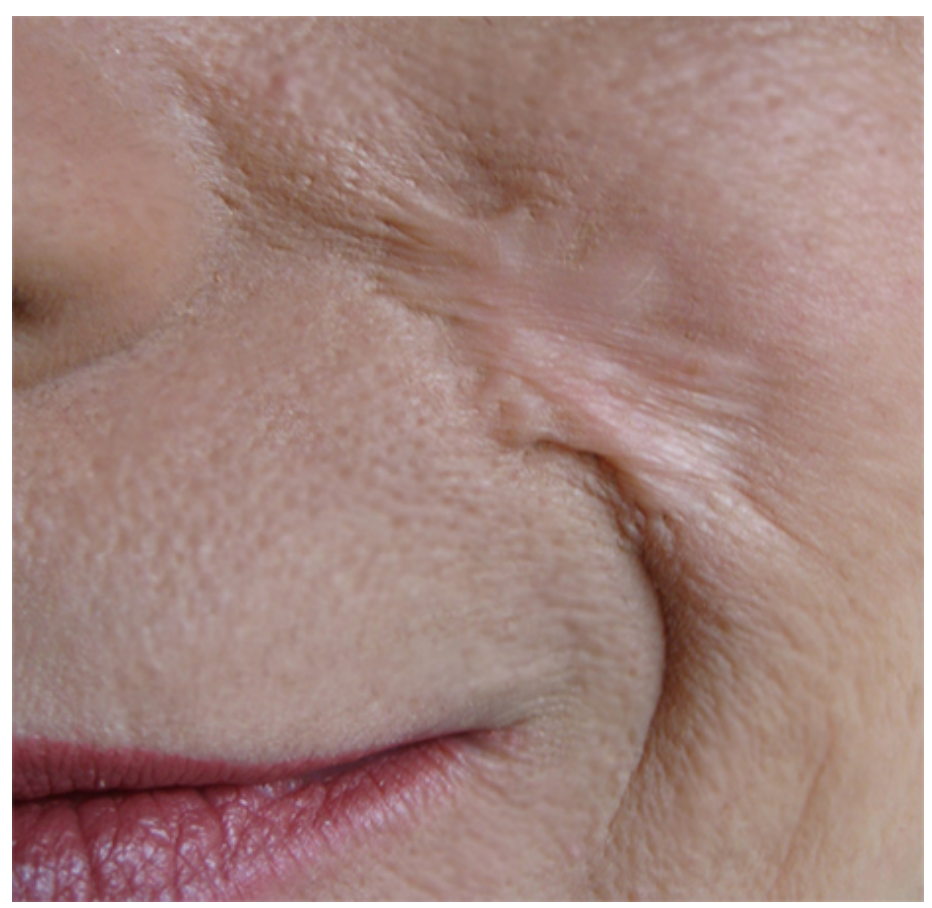

Figure 6: Mohs Surgery Scar A noticeable scar created from Mohs micrographic surgery [15] 
Another surgical treatment that causes heavy scarring is called electrodessication and curettage [16]. Here, the surgeon uses a spoon-like instrument, known as a curette, and scoops the tumor away from the skin [16]. Due to heavy bleeding, an electrode is placed in the crater of the removed tumor and electric current is passed to the tissue to cauterize blood vessels and kill any remaining tumor cells in the area [16]. This technique is quick and easy, but the removal of all tumor cells is not confirmed and scarring is typically present [16].

Techniques that prevent or markedly reduce the appearance of scars are needed as skin cancer treatments. One such technique is known as cryosurgery and is similar to wart removal. Liquid nitrogen is sprayed or applied to the tumor and the intense cold freezes the cells and stops cellular processes, effectively killing the tumor cells [17]. While this may prevent or reduce the appearance of scars, the technique is not effective in killing tumors that have advanced beyond in situ/thin melanoma [17].

Radiofrequency tissue ablation has been suggested as a possible non-invasive treatment for skin cancer, although there are no current publications testing the capabilities of this technique. It is suggested that the principles behind the use of radiofrequency ablation should also work equally well, if not better, in skin cancer due to its location on the surface of the body [18]. This technique sends radiofrequency waves at 300 to $500 \mathrm{MHz}$ frequencies to the tumor [18]. The waves interact with each other at the tumor location and cause the tissue to heat up. The excessive heat damages the cells and causes cell death. If a shape of the tumor is identified using imaging technologies, the radiofrequency waves can be directed to cancerous tissue only [18]. This technique may reduce the appearance of scars and healthy tissue damaged during treatment [18]. 
There are also treatment techniques that usually treat metastatic cancers but can be used to shrink the tumor. For example, radiation therapy and chemotherapy may be administered to shrink the tumor, which allows for smaller scar development after surgical excision [4]. These techniques are also often used after surgical excision to ensure that all cancer cells are destroyed and that relapses do not occur [4]. Furthermore, these techniques are used to treat melanomas that have metastasized to lymph nodes and distant tissues [4].

Radiation therapy, similar to radiofrequency ablation, uses directed X-ray beams that are shaped from Computer Tomography (CT) images of the tumor to cause extensive DNA damage in cancerous cells [4]. These directed beams enter the body at different locations and intersect at the tumor to cause maximal damage, while leaving the healthy tissue unharmed [4]. While radiation is a cause of cancer, it can also disturb DNA enough at high doses to kill the tumor cells [6].

Chemotherapy uses chemical agents to attack DNA. Some topical agents, such as Fluorouracil and Imiquimod, can be applied to skin to kill cancer cells in the epidermis [6]. These topical agents, however, are only directed toward basal cell and squamous cell carcinomas [6]. There are also systemic chemotherapy drugs that are cell cycle inhibitors [6]. These arrest cells in their cell cycle and prevent them from differentiating. Cancerous cells often cannot handle the cell cycle inhibitors and they die before healthy tissues do. Chemotherapy is a harsh treatment with many side effects due to the non-specific nature of cell cycle inhibitors [6].

Lastly, immunotherapy and gene therapy have been investigated as possible treatments. Immunotherapy utilizes chemicals and compounds in the body to treat the 
cancer [4]. The body has many natural defenses but can often times be shut off by the tumor. By isolating these natural defenses, amplifying their numbers, and reinjecting them into the body, we can effectively enhance our immune systems [4]. Interferon (IFN) alpha-2b is an FDA approved therapy indicated for use in high-risk (Stage II, III) melanomas with a high chance of recurrence [4]. Other immunotherapies in research include tumor necrosis factor (TNF) and high dose IL-2. TNF is not FDA approved but may show promise due to its natural tumor fighting capabilities and anti-angiogenic properties [4]. IL-2 is currently FDA approved for stage IV metastatic melanoma. It is known by the name proleukin and activates the body's innate immune system to fight the cancer [4]. Gene therapies seem to still be premature, but consist of delivering genes to cells to enhance or inhibit certain functions. For example, inhibiting the functions of mitogenic genes may slow cancer cell differentiation or inhibiting angiogenic factors from generating capillaries may prevent the delivery of nutrients to the tumor [10].

With all of this in mind, it is important to protect one's self from harmful UV rays. Wearing sun block, long sleeved shirts, long pants, and sunglasses and clothing that absorb UV radiation can help prevent the occurrence of cancer [6]. With that said, 1 in 52 people of white complexion will get skin cancer in their lifetime [8]. Thus, it is important to consistently perform self-examinations in order to find suspicious nevi in early stages of development. Better, non-invasive, objective diagnostic techniques may increase the ability to diagnose early tumors. For this reason, one diagnostic technique in particular, multi-electrode impedance analysis, will be investigated further in this thesis. 


\section{Electrical Properties}

When describing the theory behind multi-electrode impedance analysis, it is important to have an understanding of basic electrical properties. This section will begin with a brief overview of electrical theory, followed by a discussion of electrical properties of healthy and cancerous skin tissue, and ending with a summary of previous work accomplished in the field of Electrical Impedance Spectroscopy (EIS) as a diagnostic technique for cancer.

\section{Introduction to Electrical Theory}

There are various electrical parameters that describe circuits and circuit components. This thesis will focus exclusively on the impedance of skin cells. Impedance (Z) describes the amount of opposition to the flow of current and is associated with a phase angle $(\theta)$; the phase accounts for the difference in cycles of the voltage waveform compared to the current waveform [19]. A phase difference results from the retardation of the current waveform as it travels through the measurement medium. Current (I) is the flow of electric charges through a medium and is traditionally defined as the flow of positive charges. Impedance is related to current through Ohm's law, which states that the voltage $(\mathrm{V})$ divided by the current equals the impedance, where the voltage is the potential energy that drives the current [19].

Equation 1 - Ohm's Law

$$
Z=\frac{V}{I}
$$

Impedance may be broken down into separate vectors along a real and imaginary (complex) coordinate plane [19]. The real (X-axis) component of impedance is the resistance [19]. Resistance (R) is the opposition to DC current in a circuit and thus does 
not depend on frequency. The imaginary ( $\mathrm{Y}$-axis) component of impedance is the reactance $(\mathrm{X})$ and is the opposition of capacitance and inductance to current [19]. Capacitance (C) is the measure of a components ability to store charge across separated conductive plates and is measured in Farads (F) [19]. Equation 2 gives the reactance associated with the capacitive component of a circuit [19]. The capacitive reactance at low frequencies (DC) causes the capacitor to behave as an open switch. Conversely, with high frequencies, a capacitor behaves as a short.

Equation 2 - Capacitive Reactance

$$
X_{C}=-\frac{1}{2 \pi f C}
$$

Where:

$$
\begin{aligned}
& \mathrm{f}=\text { Frequency }(\mathrm{Hz}) \\
& \mathrm{C}=\text { Capacitance }(\mathrm{F})
\end{aligned}
$$

Inductance (L) is the measure of a components ability to store charge through coil-induced electric fields and is measured in Henrys (H) [19]. Equation 3 gives the reactance associated with the inductance of a component [19]. At low (DC) and high frequencies, an inductor acts as a shorted wire and open switch, respectively.

$$
\begin{gathered}
\text { Equation } 3 \text { - Inductive Reactance } \\
\qquad X_{L}=2 \pi f L
\end{gathered}
$$

where $\mathrm{L}$ is the inductance in Henrys. Impedance, phase, resistance, and reactance are measured in Ohms and related by the following geometric relationships [19]:

$$
\begin{aligned}
& \text { Equation } 4 \text { - Impedance Components } \\
& \qquad Z=\sqrt{R^{2}+X^{2}}
\end{aligned}
$$




$$
\begin{gathered}
\text { Equation } 5 \text { - Phase Angle } \\
\qquad \theta=\arctan \left(\frac{X}{R}\right)
\end{gathered}
$$

\section{Skin Electrical Properties}

As discussed in the section Skin Anatomy and Physiology, skin consists of three main layers. Within the dermis and epidermis layers are various distributions of hair follicles, pores, and sweat ducts [20]. Furthermore, moving from deep to most superficial the cellular shape, structure, and composition changes, producing a dense, scaly layer of dead keratinocytes at the stratum corneum [1]. For these reasons, the skin is considered to be anisotropic and heterogeneous [20]. These features of skin can make electrical measurements in various directions particularly troublesome. However, there exists simplified equivalent circuit and mathematical models that aid in predicting electrical properties.

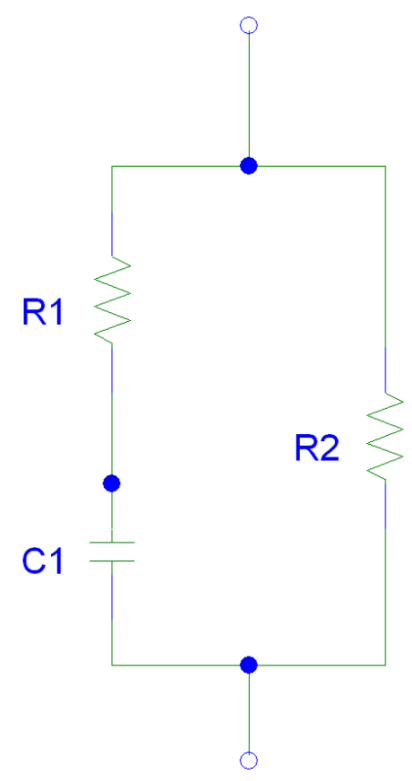

Figure 7: Skin Tissue Equivalent Circuit Model

The skin equivalent circuit model consists of intra and extracellular fluid resistances (R1 and R2) and a capacitance associated with the cell membrane (C1) [21]. 
A common equivalent circuit model of a single cell that can also be used for skin tissue is shown in Figure 7 [21]. For single cells, the intra and extracellular fluid resistances are denoted $\mathrm{R} 1$ and $\mathrm{R} 2$, respectively [21]. There is also a capacitive element to the circuit (C1) due to the cellular membrane [21]. The cellular membrane is composed of a phospholipid bilayer, which is impenetrable by many ions and molecules [22]. The separation of ions on either side of the membrane, established in large part by ATPdependent sodium-potassium pumps, mimics the function of parallel-plate capacitors [22]. The capacitance of the cellular membrane is usually taken as $1 \mathrm{uF} / \mathrm{cm}^{2}$ of membrane surface area [22].

When dealing with skin tissue as a whole, Figure 7 is used again, but the values of the three components change to accommodate a lumped sum of all the intracellular and extracellular fluid resistances. The capacitive component value changes to reflect an increased capacitance associated primarily with the stratum corneum. As discussed earlier, an important function of the skin is to retain water and prevent bacteria, fungi, and water from entering the body [1]. This is accomplished by keratinocytes between the stratum granulosum and spinosum [1]. In this region, tight junctions interconnect keratinocytes [1]. Secretion of lipids and the formation of an insoluble protein layer on the inner surface of plasma membranes further enhance the function of the epidermal water barrier [1]. Superficial to this barrier, keratinocytes undergo apoptosis [1]. All of these aspects of the epidermal water barrier create high impedance regions, which may detract from reliable impedance measurements of deep tissues and tumors [23].

A study performed by Yamamoto and Yamamoto in 1976 derives an equation to represent the resistivity of skin at different layers in the stratum corneum [23]. The 
resistivity, also known as the specific resistance, is a way to normalize resistance measurements based on the distance between, and the surface area of, electrodes (Equation 6) [18]. Equation 7 represents an exponential decay of the resistivity from the most superficial layer of the stratum corneum to deeper regions [23]. This is determined empirically by consecutive impedance measurements after cellulose tape stripping of a few layers of stratum corneum [23].

Equation 6 - Specific Resistance

$$
R_{S}=R_{M} * S_{A} / D_{E}
$$

Where:

$\mathrm{R}_{\mathrm{S}}=$ Specific resistance

$\mathrm{R}_{\mathrm{M}}=$ Measured resistance

$\mathrm{S}_{\mathrm{A}}=$ Electrode surface area

$\mathrm{D}_{\mathrm{E}}=$ Distance between electrodes

Equation 7 - Stratum Corneum Resistivity Profile

$$
\rho(x)=\rho_{o} e^{-\alpha x}
$$

Where:

$\varrho_{\mathrm{o}}=$ Initial resistivity found as $7.7 \times 10^{5} \Omega-\mathrm{m}$

$\alpha=$ Attenuation factor found as $2 \times 10^{5} \mathrm{~m}^{-1}$

$\mathrm{x}=$ Depth into stratum corneum

The resistivity of a tissue is an important parameter in electrical impedance measurements because it serves as a normalized value to compare to other studies using different electrodes and electrode separations. A critical question in electrical impedance studies is determining the frequency of the source signal. One factor in determining frequency is the desired depth of the measurement. High frequencies allow for greater current depth penetration, while lower frequency currents remain superficial [24]. Thus, in investigated deep melanomas, higher frequencies may be desired. In addition, the 
depth of penetration is partially determined by the separation of electrodes - usually taken to be half the distance between electrodes [25]. High frequencies also have another inherent advantage in impedance measurements. Since the equivalent circuit model of skin tissue consists of a capacitive element, it may be short-circuited with a high frequency signal. With the capacitive element shorted, impedance measurements are comprised primarily of the intracellular and extracellular fluid resistances; this provides a method of measuring the hydration of the tissue [26]. The effective shorting of the capacitive element is known as a beta dispersion and can occur anywhere from $\mathrm{kHz}$ to $\mathrm{MHz}$ [25]. The frequency at which the beta dispersion occurs is dependent on the shape and structure of the cells, as well as the intra and extracellular water content [25].

It is important to note that impedance measurements of skin are dependent on numerous parameters. For instance, the location of the measurement on the body, the age and gender of the subject, and the season (time of year) all influence impedance readings $[25,27]$. Also, the length of time of the measurement was found to skew the results; skin resistance decreases over long testing periods [28]. To ensure that as many variations of skin impedance measurements are filtered out, an ipsilateral skin site - one on the same side of the body as the suspicious lesion - is used as a reference point [29].

\section{Cancerous Electrical Properties}

All of the previously discussed details of skin electrical properties hold true for cancerous electrical properties with the exception that the cell shape, size, and orientation of cancerous cells differs from that of healthy, benign cells [30]. The permeability of cancer cells to ions increase due to an unknown mechanism in cancer physiology [31]. The increased permeability of the cellular membrane allows increased flow of potassium, 
magnesium, and calcium out of the cell, and sodium and water into the cell [31]. The increase in water content due to the change in osmotic pressure causes a spherical shape in cancer cells [31]. A sphere represents the greatest possible volume to surface area ratio and as a result, cancer cells contain increased intracellular fluids. Since the intracellular fluid is a more conductive (less resistive) medium, the impedance of cancerous tissue, especially at the beta dispersion, will decrease [32].

\section{Impedance Device Characteristics}

Differences in the physiology and anatomy of cancerous and healthy cells are exploited during diagnosis of melanoma. There are a few variations in the impedance diagnostic techniques that are utilized in the literature; these include degrees of invasiveness, electrode material, and electrode pattern. For their impedance-measuring device, some investigators use a micro-invasive setup [29]. This consists of spiked electrodes that penetrate the thin 10 - 40 um stratum corneum, which provides the advantage of bypassing a high impedance region [29]. Aberg et al. discovered that microinvasive electrodes allowed for accurate impedance measurements of deep tissues, in which malignant melanomas usually reside [29]. Although considered micro-invasive, the electrodes still penetrate the skin and may cause pain, irritation or other effects, which are not specified by the authors. The non-invasive technique, in which this report will focus, suffers from the high stratum corneum impedance; this may skew results for deeper tissues [33]. Mechanisms around the effects of the stratum corneum consist of sourcing high frequency signals to short the capacitor, scrubbing, cleaning, abrading, or moisturizing the skin to remove layers of stratum corneum or increase conductance of the dead keratinocyte layers, or normalizing measurements to an ipsilateral skin site [33]. 
Electrode material for impedance devices usually consists of either gold or silversilver chloride $(\mathrm{Ag} / \mathrm{AgCl})[28,34]$. Gold is a good conductor and used frequently in microelectrode devices. However, gold electrodes tend to be polarizable [35]. Polarizable electrodes are those in which the material is difficult to oxidize [35]. For this reason, ions concentrate around the electrode and create a capacitive area [35]. An overpotential is needed to adjust for the voltage drop across the concentrated ion capacitor [35]. This overpotential may change with time and magnitude of voltage applied creating offsets in the measurements [35]. $\mathrm{Ag} / \mathrm{AgCl}$ is considered a non-polarizable electrode and allows current to pass from the electrode-electrolyte interface with no capacitive influence [35]. $\mathrm{Ag} / \mathrm{AgCl}$ electrodes undergo a chemical reaction in which silver oxidizes and binds with $\mathrm{Cl}^{-}$to form a water-stable $\mathrm{AgCl}$ molecule [35]. The chlorine ion is abundant in biological tissues and thus creates a stable reaction. Electrical noise in measurements is also less for $\mathrm{Ag} / \mathrm{AgCl}$ than with other metallic electrodes [35].

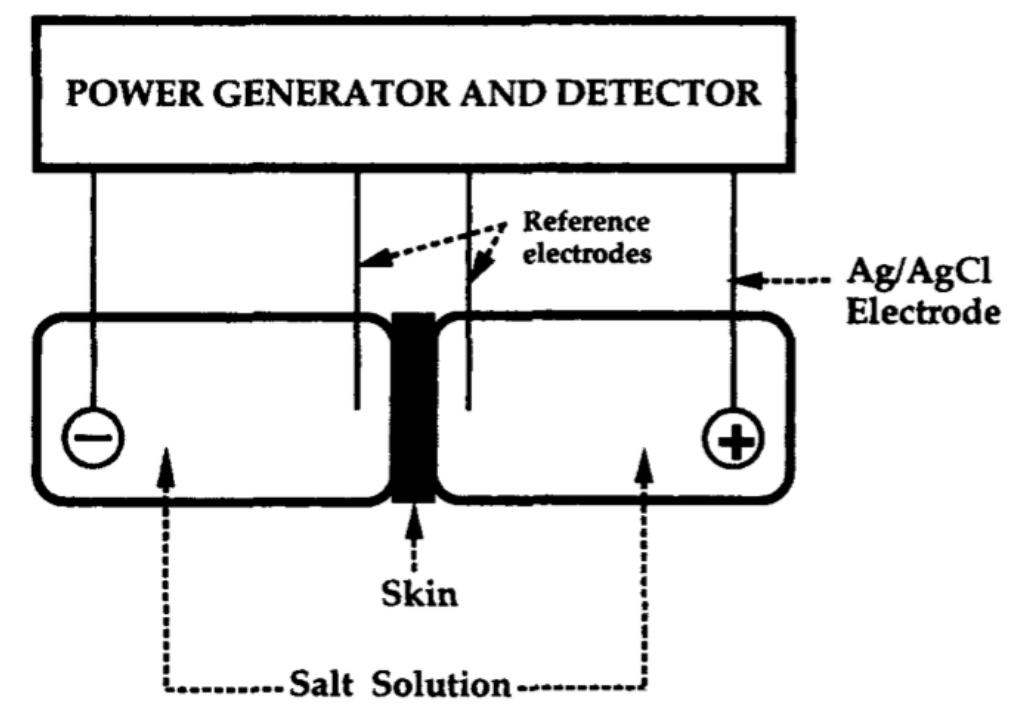

Figure 8: Dinh et al. Electrode Pattern

Depicts a linear electrode pattern with the source and sink electrodes surrounding the reference electrode [28]. 
Finally, the electrode pattern differs between investigators and depends mostly on the desired measurement depth, resolution, and coverage of the device. Glickman et al. and Har-Shai et al. utilize rectangular matrices of $8 \times 8$ and $8 \times 16$ pointed gold electrodes with a footprint of $4 \times 4$ and $5 \times 10 \mathrm{~mm}^{2}$, respectively $[33,34]$. Dinh et al. use a fourelectrode setup with the source and sink electrodes linearly bounding two reference electrodes; this alignment is shown in Figure 8 [28]. The last electrode pattern variant consists of ring-type electrodes. Aberg et al. use four concentric electrode rings where the central electrode performs as the sink and second electrode from the center acts as a guard electrode to direct the current [25]. The outer two rings act in unison as the source electrodes and create a "virtual electrode" between the two rings depending on their voltages [25].

\section{Previously Recorded Data}

This section provides previously recorded impedance data on both skin and cancerous tissues from the literature. This information is important because it allows for comparison of data generated during this thesis. The type of data provided depends on the investigators. In some instances, specific resistances and capacitances are given, while others supply only normalized conductance values and sensitivity/specificity measures.

Glickman et al. recorded conductivity and capacitance values at $2 \mathrm{kHz}$ for normal and cancerous skin tissue from nude mice injected with human melanoma cells. The conductance and capacitance of normal skin were $0.44 \mathrm{uS}$ and $0.017 \mathrm{nF}$, respectively. The conductance and capacitance of a malignant tumor were $2.65 \mathrm{uS}$ and $0.05 \mathrm{nF}$, respectively. They used a normalized conductance (GN) value of 6.32 to reach $95 \%$ sensitivity and $67 \%$ specificity [34]. 
Aberg et al. recorded conductance values for 31 frequencies over the range 1 $100 \mathrm{kHz}$. They used a principal components analysis (PCA), which used two statistical principal components to compare values. Their sensitivity and specificity were $92 \%$ and $80 \%$, respectively [29].

Har-Shai et al. used normalized conductance at $2 \mathrm{kHz}$ to determine differences in measurements. Control skin conductance measured on the head and neck was $2.23 \mathrm{uS}$, while the control skin elsewhere was $0.96 \mathrm{uS}$. A GN of 6.2 was used to obtain a $100 \%$ sensitivity [33].

Dinh et al. measured skin resistances at equilibrium and recorded a maximum value of $583,179 \Omega$. As the salt concentration of the electrolyte increased, the measured resistance decreased [28].

Pethig et al. determined specific capacitance and resistance for the stratum corneum at $1-10 \mathrm{kHz}$ as $4.6 \mathrm{nF} / \mathrm{cm}^{2}$ and $34.9 \mathrm{k} \Omega / \mathrm{cm}^{2}$, respectively. At 13.56 $\mathrm{MHz}$, skin conductance was $0.25 \mathrm{~S} / \mathrm{m}$ [32].

Gabriel et al. compiled conductivity and permittivity values of skin from multiple sources. At $10 \mathrm{kHz}$, the conductivity, dependent on the hydration of the skin, ranged from $1.0 \mathrm{E}-4$ to $0.5 \mathrm{E}-1 \mathrm{~S} / \mathrm{m}$. At the same frequency, the permittivity ranged from $2.0 \mathrm{E} 3$ to $1.0 \mathrm{E} 5$ [36].

Hemingway et al. averaged specific resistances of human skin and muscle measured at $500-3000 \mathrm{kHz}$. The specific resistances of skin and muscle were 289 and $110 \Omega$, respectively. At a lower frequency ( $\mathrm{f}=1000 \mathrm{~Hz}$ ), the resistance of cadaveric skin immediately after death was $59 \Omega$ [37].

Stante, a previous graduate student at the California Polytechnic State University in San Luis Obispo, initiated campus research on impedance-based measurements to diagnose melanoma skin cancer. Two $\mathrm{Ag} / \mathrm{AgCl}$ electrodes spaced $1 \mathrm{~cm}$ apart 
were used as the testing device. The impedance of raw and cooked chicken thigh skin, fat, and meat were measured at $10 \mathrm{kHz}$. The average impedance values for raw chicken skin, fat, and meat were 3.897, 2.945, and 1.801 k-ohms, respectively. The average impedance values for cooked skin, fat, and meat were $8.455,27.273$, and $2.784 \mathrm{k}-\mathrm{ohms}$, respectively. Tissue engineered skin constructs of Epiderm ${ }^{\mathrm{TM}}$ and Melanoma, from MatTek Corporation, were also measured at $10 \mathrm{kHz}$. The average impedance for Epiderm ${ }^{\mathrm{TM}}$ and Melanoma were 3.088 and 12.856 k-ohms, respectively [18].

The above values differ considerably from each other. This is expected because of the differences in electrode material, measurement site, test preparation techniques, and age and gender of the subject. However, these values, aside from Stante's work, have a similar trend that may serve as a starting point for a comparison with the values found in this thesis. In general, the conductance of melanoma tissue was greater than that of healthy skin tissue. This means that the resistance of melanoma tissue was less than the resistance of healthy skin tissue. While the values of resistance and capacitance for melanoma and healthy skin tissue differ between authors, the normalized conductance values remain consistent at approximately 6.2 to 6.4 . Normalizing the measurements is beneficial because it removes the inconsistencies associated with the different experiments and allows for a straightforward comparison to other data. If possible, the normalized conductance values will be compared to the data found in this thesis. 


\section{Methods}

As indicated in the Introduction, this thesis will focus on electrical impedance measurements as a non-invasive, objective technique for diagnosing melanoma skin cancer. To do this, a multi-electrode device was constructed and tested for its ability to differentiate between tissue types and tissue health. This project serves merely as a proof of concept that multi-directional impedance detection has the potential to distinguish between normal and melanoma skin and provide reliable results.

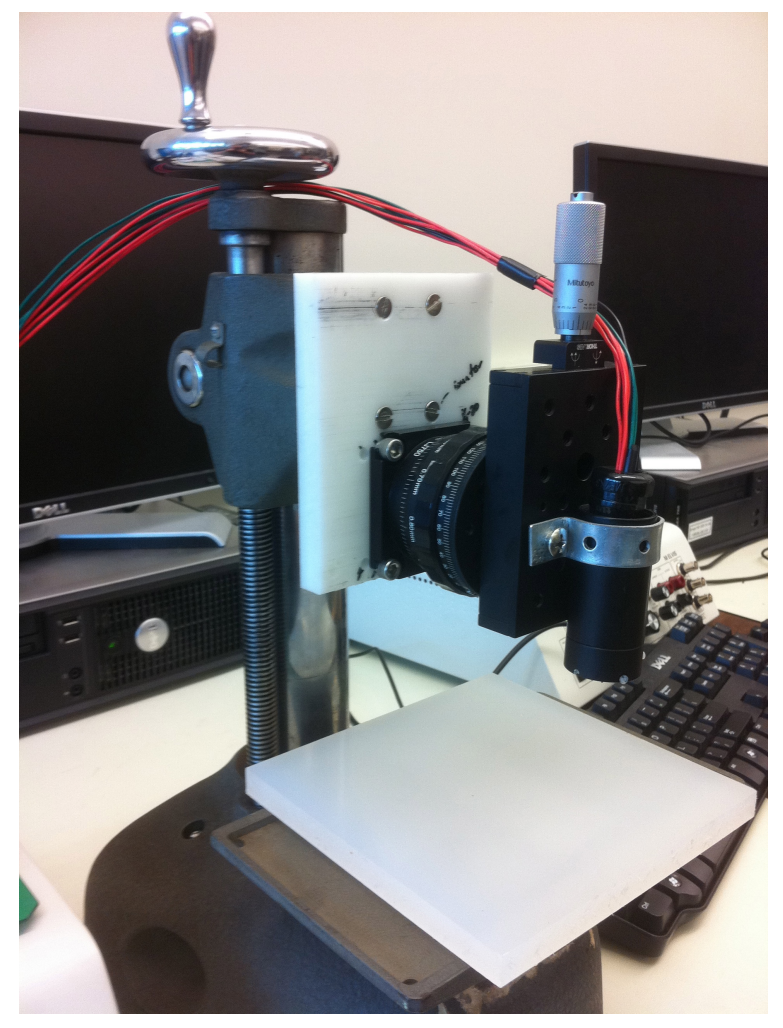

Figure 9: Electrode Device Assembly

The electrode device and fixture system used for impedance measurements.

In this section, a description of the device, shown in Figure 9, and the system used in this thesis for impedance measurements will be presented. The use of certain materials and dimensions will be explained, as well as the software, hardware, and program 
running the measurement algorithm. The methods used to validate the hardware, program, and device will be discussed. Finally, the methods used in the acquisition of impedance data for cooked and raw chicken tissue and melanoma and healthy tissue engineered skin analogues will be presented.

Briefly, the measurement system consists of the electrode device that houses and secures the electrodes, the device fixture that secures and actuates the electrode device, the breadboard circuit that routes the measurement signals, National Instruments' Educational Laboratory Virtual Instrumentation Suite (ELVIS) and USB-6251 that generates the measurement signals and acquires data, and National Instruments' LabVIEW that controls the signals and flow of data. During measurement, the electrodes are placed on the surface of tissue and electrical current is passed between two electrodes. The returning voltage is recorded and the impedance of the tissue between the two electrodes is calculated automatically within LabVIEW. Further detail is provided in the following sections.

\section{Electrode Device}

The device used in this thesis consisted of four main parts shown in Figure 10: the shaft, the electrode holder, the electrodes, and the device fixture. The composition, design, assembly, and purpose of each main part will be described in individual sections that follow.

\section{Shaft}

The shaft housed the electrodes and associated wires to prevent damage from external factors and provided a strain relief point for the wires. The shaft also provided a larger area for gripping if the electrode device was used by hand. It was composed of four 
1" diameter, stackable lens tubes from ThorLabs. The lengths (part numbers) of the four stackable tubes in order from tip to tail of the device were 0.5" (SM1L05), 2" (SM1L20), 1" (SM1L10), and 0.3" (SM1L03). These lens tubes all contained external and internal custom threads of $1.035 "-40$ at the tip and tail of each tube, respectively. This allowed for the simple joining of shaft members that made various assembly tasks, such as soldering electrodes, more accessible. Some alterations were made to the 0.5 " and 1 " lens tubes to accommodate some features of the entire device.

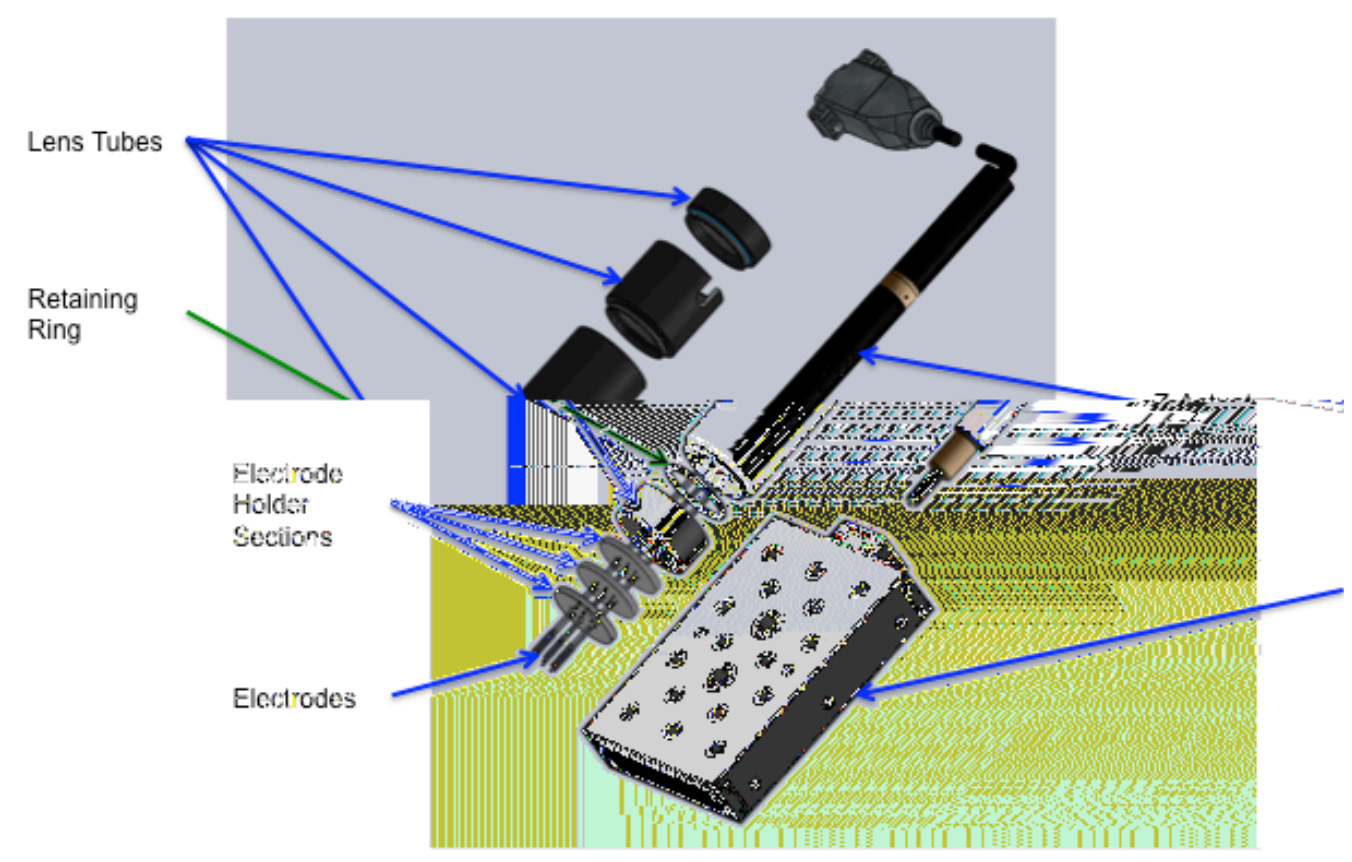

Figure 10: Electrode Device Exploded View

\section{An exploded view of the electrode device and translational stage with components labeled.}

The 0.5 " lens tube tip, where the external threads resided, was turned down with a lathe to remove the regions with diameters less than 1". Removing this feature allowed for the insertion of the electrode holder into the tube. Inside the tube, approximately 7 $\mathrm{mm}$ from the tip, was a retaining ring with external threads of 1.035 "- 40 . The bottom of 
the electrode holder, once inserted into the tube, rested on the retaining ring to prevent further movement into the tube. There were also three holes drilled into the sides of the tube, one of which was tapped with \#1-64 threads. The two non-tapped, clearance holes of gauge 50 rested 180-degrees from each other at $1.165 \mathrm{~mm}$ from the tip of the tube. The tapped hole was located 90-degrees from the clearance holes and $3.495 \mathrm{~mm}$ from the tip of the tube. The clearance holes passed \#1-64 nylon screws to interact with the top member of the electrode holder (discussed in the next section); this effectively prevented movement of the electrode holder out of the tube. The tapped hole allowed interaction of a \#1-64 screw with the middle member of the electrode holder; this effectively moved the middle member relative to the top and bottom members to act as a vice to the electrodes.

In order for the electrodes to interface with the data acquisition system, wires passed out of the shaft. To accomplish this, a 0.25 " by 0.25 " square was milled out of the 1"-diameter tube wall at the tail end. The reason the hole was cut at the tail of the tube rather than in the middle was to avoid twisting the wires and electrodes during connection of the 0.3 " tube to the 1 " tube. Furthermore, the action of screwing the 0.3 " tube onto the shaft applied pressure to the wires to prevent moving and tension on the electrode-wire joints.

\section{Electrode Holder}

The electrode holder, as alluded to in the previous section, consisted of three components that functioned together to clamp the electrodes in place. The diameter and length of all components were 1" and $2.33 \mathrm{~mm}$, respectively. The three sections were parted with a lathe from a 1" stock Delrin rod. Delrin was used because of its electrical insulation properties, machinability, and availability. Nine $0.0335 "$ diameter holes were 
match drilled into the face of all three sections to a total depth of $6.75 \mathrm{~mm}$. The remaining $0.25 \mathrm{~mm}$ of material in the bottom section was match drilled with a 0.0325 " drill bit. These holes held the 9 electrodes used in this device and were patterned into the section faces such that 8 electrodes circumferentially surrounded 1 central electrode in 45-degree increments at a $5 \mathrm{~mm}$ radius (see Figure 11 for clarification). The step in drill bit diameters provided a small ridge for the electrodes to rest. Thus, if the electrodes were manufactured with appropriate tolerances, the extension of the electrodes from the device would be roughly the same length. The pattern of electrodes allowed for impedance measurements in 8 different directions and kept the amount of tissue between an outer electrode and the central electrode constant at $5 \mathrm{~mm}$. A small distance between electrodes also increased the resolution of the device and prevented impedance values from exceeding the measurement capabilities of the hardware. Specifically, a $5 \mathrm{~mm}$ radius was used so that measurements could be conducted on the $1 \mathrm{~cm}$ diameter tissue engineered skin constructs, which are described in more detail in the Tissue Engineered Skin Analogues section.

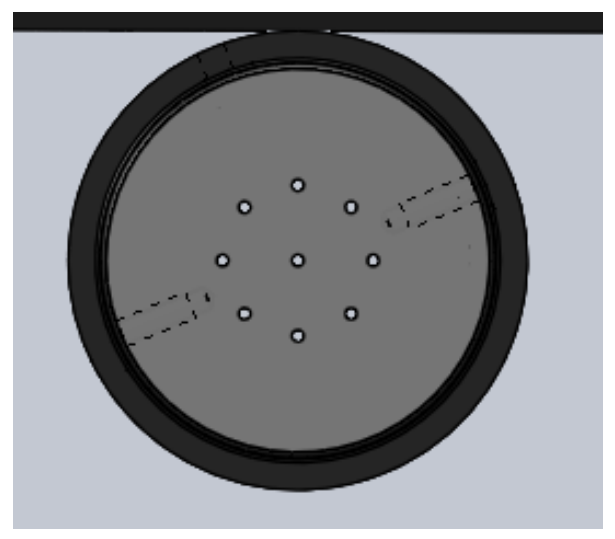

Figure 11: Electrode Pattern

The eletctrode pattern of 8 outer electrodes surrounding a central one at a $5 \mathbf{~ m m}$ radius. This is match drilled into the face of all electrode holder sections. 
The three separate sections of the electrode holder were needed to act like a vice. The top section's cylindrical face had two \#1-64 tapped holes that were 180-degrees from each other and aligned with the clearance holes on the 0.5 " lens tube. As mentioned before, the screws held the top section in place and prevented the electrode holder assembly from moving within the shaft. The middle section diameter was slightly turned down on a belt sander to allow for movement within the shaft. The turning of a screw in the threaded hole of the 0.5 " lens tube caused translation of the middle section in reference to the top and bottom sections; this effectively pinched each electrode and fixed them in place.

\section{Electrodes}

Silver-silver chloride $(\mathrm{Ag} / \mathrm{AgCl})$ electrodes were used as the measurement electrodes for this device. They consist of a silver wire coated in silver chloride precipitate. As described in the Introduction, $\mathrm{Ag} / \mathrm{AgCl}$ electrodes are nearly perfectly nonpolarizable and allow current to pass freely from electrode to electrolyte. The chemical reactions responsible for the electrode function are:

$$
\begin{aligned}
& A g \leftrightarrow A g^{+}+e^{-} \\
& A g^{+}+C l^{-} \leftrightarrow A g C l
\end{aligned}
$$

The oxidation of bulk silver and the release of an electron and silver ion are followed by the synthesis of silver chloride from the silver ion and a chloride ion found in the electrolyte. Since $\mathrm{AgCl}$ is stable and only slightly soluble in water, it precipitates out of solutions and deposits onto the silver wire [35].

The half-cell potential of the $\mathrm{Ag} / \mathrm{AgCl}$ electrode is determined by the following governing equation: 
Equation 8: Silver Half-Cell Potential [35]

$$
E=E_{A g}^{0}+\frac{R T}{n F}\left(\ln K_{s}-\ln a_{C l^{-}}\right)
$$

where $\mathrm{E}$ is the half-cell potential, $\mathrm{E}_{\mathrm{Ag}}^{0}$ is the standard half-cell potential of silver, $\mathrm{R}$ is the gas constant, $\mathrm{T}$ is temperature, $\mathrm{n}$ is the valence of silver, $\mathrm{F}$ is Faraday's constant, $\mathrm{K}_{\mathrm{s}}$ is the solubility product, and $\mathrm{a}_{\mathrm{Cl}}$ is the activity of the chloride ion. The standard half-cell potential of silver is found in a standard table. The solubility product is the rate of precipitation out of solution at equilibrium and is constant. All other symbols are constants except for the activity of the chloride ion. However, in biological applications, the chloride ion remains stable [35]. Thus, the half-cell potential of $\mathrm{Ag} / \mathrm{AgCl}$ electrodes is stable and will not change during experimentation. This reduces transient errors in impedance determination [35].

Furthermore, nonpolarizable electrodes do not develop double charge layers associated primarily with polarizable electrodes [35]. The double charge layer is created by the buildup of ions attracted to the surface of a polarizable electrode [35]. As current passes between electrode and electrolyte, the concentration of ions at the surface of the electrode changes and creates an overpotential [35]. The double charge layer is also responsible for motion artifacts that cause errors in measurements [35]. If an electrode moves, the ions in the double charge layer are disturbed and the half-cell potential of the electrode changes momentarily [35]. Since nonpolarizable electrodes do not have a double charge layer, overpotentials, stability, and electrode noise are avoided.

For this thesis, $\mathrm{Ag} / \mathrm{AgCl}$ pellet electrodes (E255) were purchased from Warner Instruments. The length and diameter of the active tip of the electrode was $10 \mathrm{~mm}$ and 0.8 $\mathrm{mm}$, respectively. This size was chosen primarily for consistency with a previous thesis 
entitled "The Electrical Properties of Human Tissue For the Diagnosis and Treatment of Melanoma Skin Cancer" by Glenn Stante. Keeping the electrode dimensions similar allowed for quick cross-referencing to previous results. The small diameter also allowed for more accurate measurements because less tissue was underneath the electrode; the tissue of interest should be between electrodes, rather than underneath, so that the current passes through it. Furthermore, these electrodes were determined to be "suitable for probing tissue" by the manufacturer [38]. Each electrode was soldered to a 20 gauge insulated wire for coupling to the measurement hardware. When needed, electrode tips were placed in $100 \%$ ethyl alcohol for three minutes and deionized water for five minutes to clean the surface.

\section{Device Fixture}

The electrode device was compact enough for handheld use. However, for experimental purposes, the electrode device was fixed to a micrometer-actuated surface to alleviate motion artifacts and similar user errors. The main device fixture component was a height gauge as shown in Figure 12. This height gauge provided a table for sample placement and a Delrin backing for securing the shaft of the device. A wheel, when turned, allowed for coarse adjustment of the device in the vertical direction. Attached to the Delrin backing was a rotational stage that allowed for rotation of the electrode device. The rotation was necessary for specimens with uneven surfaces, because it evenly distributed the pressure; this was important for reliable measurements. Attached to the rotational stage was a 1" translational stage (PT1) from ThorLabs that allowed for fine adjustment in the vertical direction of the electrode device with a micrometer. The electrode device was affixed to the translational stage with an altered steel bar that was 
bent in a way to encircle the device shaft. Screws $(0.25 "-20)$ secured the steel bar to the translational stage and applied pressure so that the device did not move during experimentation.

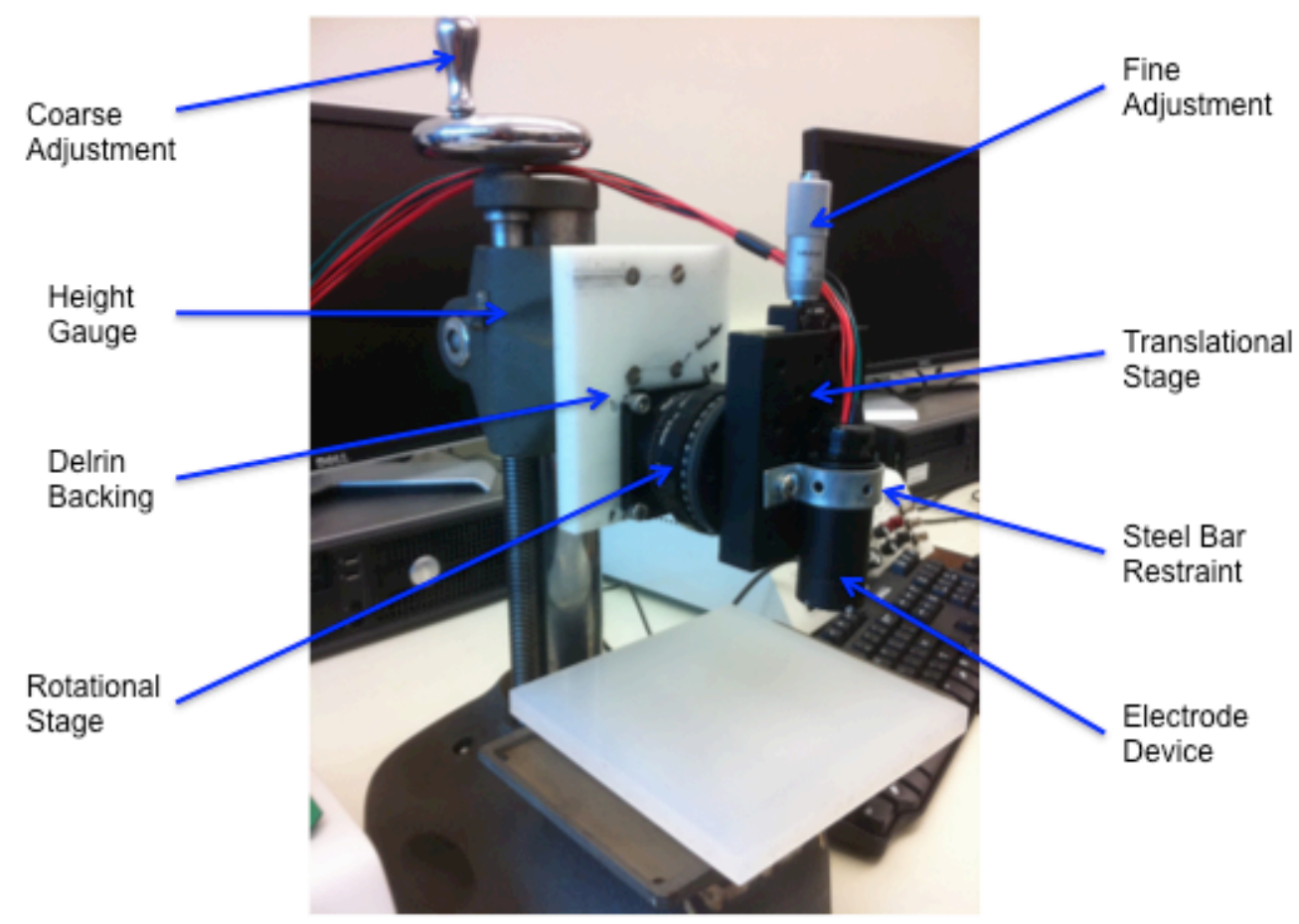

Figure 12: Electrode Device Fixture

The electrode device and fixture system with components labeled.

\section{Device Summary}

With an understanding of the anatomy of the electrode device, its function will be discussed briefly to familiarize the reader with its intended use before continuing to the control and data acquisition of the system. The electrodes that protrude from the face of the electrode holder were placed perpendicular to the surface of the tissue. The device fixture was rotated as needed so that each electrode reached the surface of the skin at the same moment. When the program was started, a sinusoidal signal traveled from the central electrode to one of the 8 outer electrodes. The impedance was recorded and the 
next outer electrode was selected. This continued, holding the central electrode active and switching between the outer electrodes, until all 8 outer electrodes were selected. The details of the program, hardware, and circuit used to perform these measurements are discussed in the next section.

\section{Device-Computer Interface}

Measurements from the electrodes were coupled to a computer through National Instruments ELVIS and USB-6251 data acquisition systems, a breadboard circuit, and National Instruments LabVIEW software. Figure 13 shows the complete device-computer interface, which will be described in more detail in the following sections.

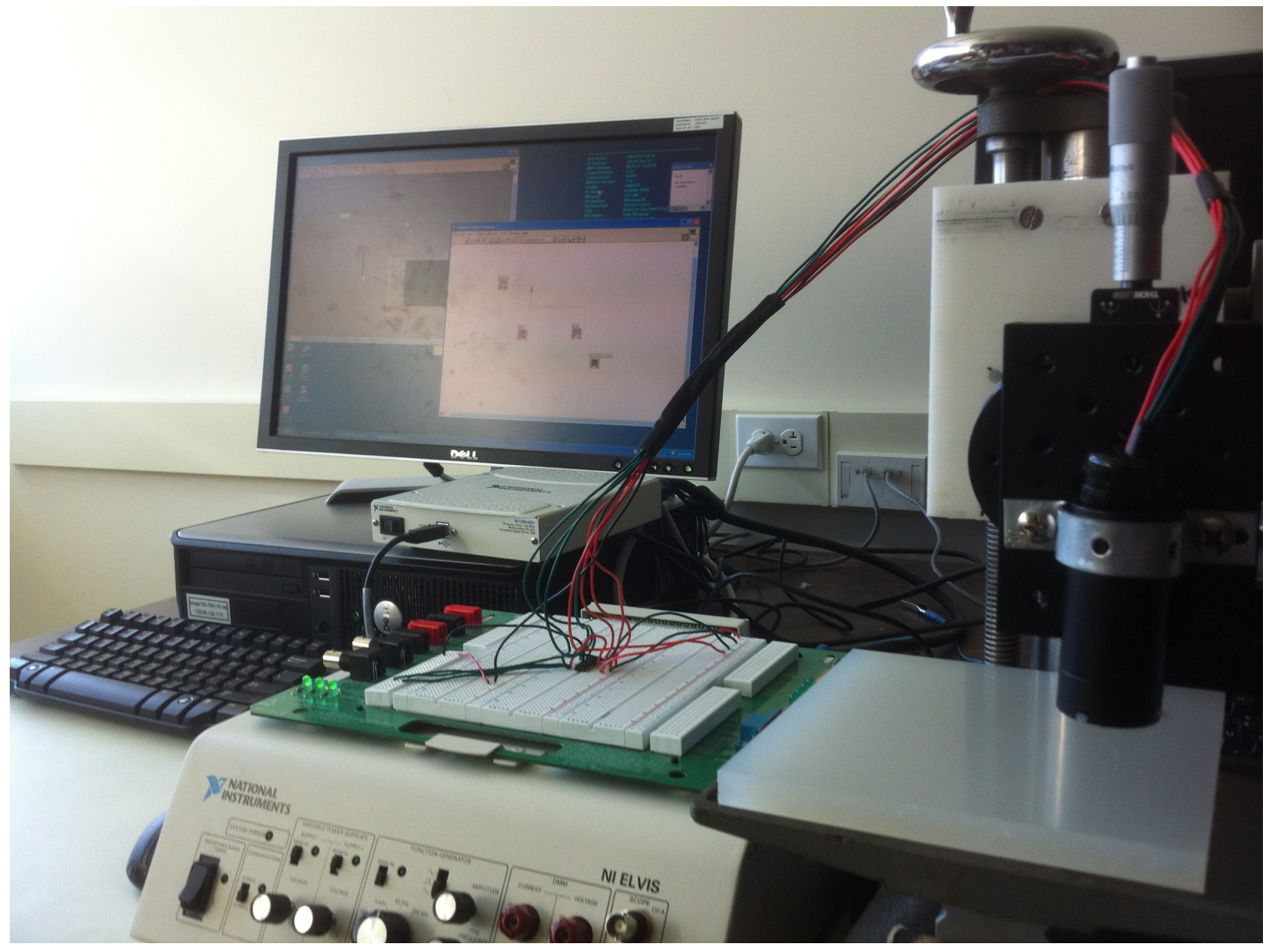

Figure 13: Device-Computer Interface

The device-computer interface showing the device, ELVIS system, multiplexer circuit, USB-6251, and LabVIEW software. 


\section{National Instruments ELVIS}

ELVIS, shown in Figure 14, stands for Educational Laboratory Virtual Instrumentation Suite and is a National Instruments product that contains 12 different instruments in one integrated suite. It was selected for use in this thesis because of its availability, its economical advantages in having 12 integrated instruments, and its simple integration with National Instruments LabVIEW that allowed for experimentation control, measurement, automation, and most importantly, flexibility [39]. The ELVIS instruments used in this thesis were the Digital Bus Writer, Variable Power Supplies, and Impedance Analyzer. The Digital Bus Writer wrote digital data to the digital output terminal on the ELVIS breadboard and was capable of user-created patterns, ramp, or toggle, and could either produce single or continuous writes. The Variable Power Supplies were capable of supplying -12 to 12 volts DC and supplied a maximum current of approximately $280 \mathrm{~mA}$ at $5 \mathrm{~V}$. The Impedance Analyzer provided the resistance, reactance, impedance, and phase at frequencies between 5 and $35,000 \mathrm{~Hz}$. Since most of the literature suggested differences in tissue impedances at 2 and $10 \mathrm{kHz}$, the ELVIS Impedance Analyzer was sufficient for this project [40]. 


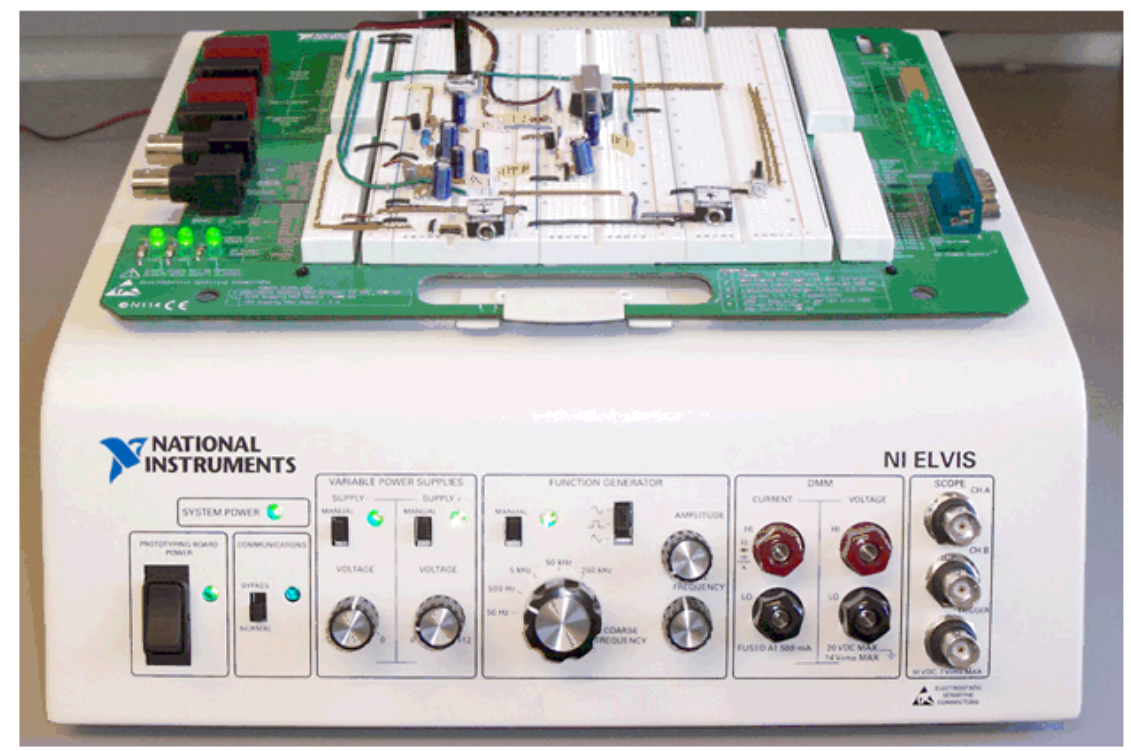

Figure 14: National Instruments ELVIS

\section{An example NI ELVIS system showing the front panel (dials/switches) and prototyping board [40].}

The ELVIS system has a front panel and a prototyping board. The front panel contains dials, switches, BNC connectors, and banana jacks to simulate a traditional analog instrument interface. The prototyping board provides perforations that allow for building temporary circuits that can be easily altered if changes are needed. The board also provides input/output pins for all integrated ELVIS instruments. Using the prototyping board, one could couple an external circuit with the integrated instruments.

\section{National Instruments USB-6251}

While the ELVIS system is responsible for the actual control and measurement of the experiment, a data acquisition system is needed to send and receive the data to and from the computer. National Instruments USB-6251 is a 16 bit, M series data acquisition system that includes 16 analog inputs, 2 analog outputs, 24 digital I/O, two 32-bit counters, and is compatible with the NI ELVIS device. The USB-6251 connects to the computer through USB and has transfer speeds of 1.25 and 2.8 mega-samples/second for 
the analog input and output, respectively [41]. The transfer speeds, number of available channels, resolution of the signals, and compatibility with the ELVIS system justifies the USB-6251 as a proper data acquisition system for this thesis.

\section{Multiplexer}

The ELVIS prototyping board was used to construct a circuit to control the selection of the outer electrodes and to couple the circuit to the integrated instruments. Wire connected the Current $\mathrm{Hi}$ pin of the Impedance Analyzer to the central electrode of

the device. To control which outer electrode was selected for measurement, an 8:1 analog multiplexer (NXP HEF4051BP, 652) was used.

Multiplexers (mux) take one of many inputs, dependent on the digital address, and direct it to a common output [42]. The mux used in this project, the HEF4051B purchased from Avnet, allowed for 8 analog inputs, corresponding to the 8 outer electrodes, and directed the signal to the common output, which was connected to the Current Lo pin on the ELVIS prototyping board. This completed the electrical loop from the Current Hi pin. With 8 possible inputs, three digital pins determined the active channel. A table of the power states for each digital pin and the corresponding active channel is provided in Table 2. S1, S2, and S3 are the three digital pins, $\mathrm{E}$ is an on/off pin that can cause high impedance states in all channels regardless of the states of the digital pins, $\mathrm{L}$ is low power $(\sim 0 \mathrm{~V}), \mathrm{H}$ is high power $(\sim 5 \mathrm{~V})$, and $\mathrm{X}$ does not matter [43]. 
Table 2: HEF4051BP, 652 Function Table [43]

\begin{tabular}{|c|c|c|c|c|}
\hline \multicolumn{4}{|c|}{ Input } & \multirow[t]{2}{*}{ Channel ON } \\
\hline$\overline{\mathrm{E}}$ & S3 & S2 & S1 & \\
\hline L & L & L & L & $Y 0$ to $Z$ \\
\hline L & L & L & $\mathrm{H}$ & Y1 to $Z$ \\
\hline L & L & $\mathrm{H}$ & $\mathrm{L}$ & $Y 2$ to $Z$ \\
\hline L & L & $\mathrm{H}$ & $\mathrm{H}$ & Y3 to $Z$ \\
\hline L & $\mathrm{H}$ & L & L & $Y 4$ to $Z$ \\
\hline L & $\mathrm{H}$ & L & $\mathrm{H}$ & Y5 to $Z$ \\
\hline L & $\mathrm{H}$ & $\mathrm{H}$ & $\mathrm{L}$ & $\mathrm{Y} 6$ to $\mathrm{Z}$ \\
\hline L & $\mathrm{H}$ & $\mathrm{H}$ & $\mathrm{H}$ & $Y 7$ to $Z$ \\
\hline $\mathrm{H}$ & $x$ & $x$ & $x$ & switches off \\
\hline
\end{tabular}

The specific pinouts for this device are shown in Figure 15. The device has two negative power supplies, one for the analog inputs $\left(\mathrm{V}_{\mathrm{EE}}\right)$ and the other for the digital inputs $\left(\mathrm{V}_{\mathrm{SS}}\right) . \mathrm{V}_{\mathrm{SS}}$ must be grounded, while $\mathrm{V}_{\mathrm{EE}}$ is either grounded or set to $-5 \mathrm{~V}$ dependent on whether the analog inputs are positive or both positive and negative, respectively [42]. Considering that the Impedance Analyzer signal is a sinusoidal waveform, a -5 V supply was used for $\mathrm{V}_{\mathrm{EE}}$.

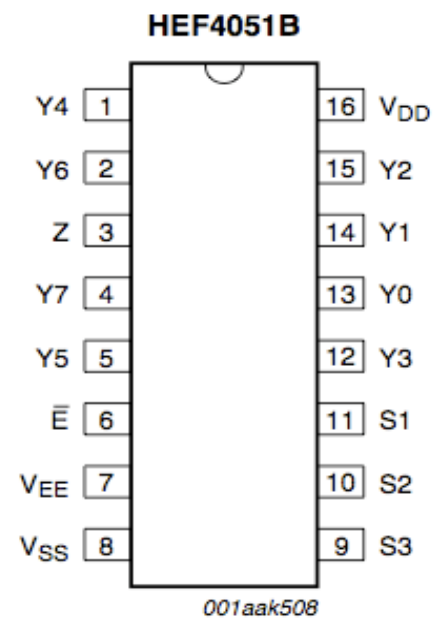

Figure 15: HEF4051BP Pinout Diagram

The diagram shows the specific pins for the multiplexer. Y prefixes indicate analog inputs, $S$ prefixes indicate digital addresses, $V$ prefixes indicate power supplies, and $\mathrm{Z}$ is the common output [43]. 


\section{Breadboard Circuit}

The ELVIS system contains some hardware resource conflicts depending on which integrated instruments are used at the same time. The conflicts also depend on the capabilities of the data acquisition system. Fortunately, the Impedance Analyzer, Digital Write Bus, and Variable Power Supplies can be used simultaneously. The prototyping board mainly consists of the multiplexer and the connections between it and the integrated instruments. The central electrode of the device connects to the Current $\mathrm{Hi}$ pin, the outer electrodes connect to the 8 analog inputs of the multiplexer, and the $\mathrm{Z}$ pin (common output) of the multiplexer inserts into the Current Lo pin. The $\mathrm{V}_{\mathrm{SS}}$ and $\mathrm{V}_{\mathrm{EE}}$ pins of the multiplexer are attached to the common ground of the ELVIS system and the negative supply voltage of the Variable Power Supplies, respectively. The positive variable power supply pin on the ELVIS is wired to the $V_{D D}$ pin on the multiplexer. The negative and positive supply voltage dials on the ELVIS front panel are set to approximately -5 and $5 \mathrm{~V}$, respectively. Four pull-up resistors of $10 \mathrm{k}$-ohms are used to "pull-up" the current from the digital output bus. The first four channels of the digital output bus connect to the S0, S1, S2, and E pins of the multiplexer. The signals and timing of this circuit are controlled by the NI LabVIEW software and the custom program developed for this thesis.

\section{NI LabVIEW Program}

LabVIEW is a programming environment that uses graphical icons and wires to create a flowchart of code execution. LabVIEW comes with large libraries of predefined graphical icons that can be easily altered to create virtual instruments (VI) that have the 
proper functionality for the project [44]. Furthermore, many external products have downloadable drivers that can be installed and integrated into the code fairly easy.

The custom program developed for this thesis, found in Appendix B, controlled the ELVIS system and required the following user inputs: device name, number of points, high frequency, low frequency, and the time delay between electrode measurements. Overall, the program calculated the variables used in the impedance analyzer, activated the impedance analyzer, and controlled the active channel of the multiplexer. Specifically, the number of points, high frequency, low frequency, and For loop iteration entered a function node with the equation:

$$
\begin{aligned}
& \text { Equation 9: Program Iteration Frequency } \\
& F_{i}=\frac{F_{h}-F_{l}}{N-1} i+F_{l}
\end{aligned}
$$

where $F_{i}$ was the specific iteration frequency, $F_{h}$ was the high frequency, $F_{1}$ was the low frequency, $\mathrm{N}$ was the number of points, and $\mathrm{i}$ was the iteration number. A second For loop commenced to control the selection of the outer electrodes. Inside, the digital write function was initiated and the digital address of the multiplexer channel was written dependent on the second For loop iteration value. The iteration frequency and device name entered the second For loop and the ELVIS Impedance Analyzer subVI, where an algorithm produced the impedance, phase, resistance, and reactance. After storing the data in memory, the digital write function was closed and the second For loop iterated to record all 8 directions. When the second For loop finished execution, the stored recordings were written to a Microsoft Excel file that was named for the first For loop 
iteration. This process was repeated in the first For loop until the number of data points requested was reached.

\section{System Validation}

The hardware, software, custom program, device, and device fixture worked together to measure the impedance of various tissues. However, it was important to verify the functionality of individual pieces to ensure the system as a whole was working properly. To do this, the ELVIS system, the multiplexer, and the electrode device were tested. The details of each test are described in the sections to follow.

\section{ELVIS Validation}

The purpose of this test was to confirm that the ELVIS system could correctly identify the impedance of various resistors and capacitors to within the tolerance thresholds provided by the manufacturer of the electrical components. If the ELVIS system was able to accomplish this task, then we could consider all values recorded on biological tissues to be reliable as well.

The electrical components (Vishay BCcomponents) were inserted directly into the Current Hi and Current Lo pins of the Impedance Analyzer so that the impedance measured would be from the ELVIS system and the electrical component only. The seven values of resistors used for validation were $1,10,100,1 \mathrm{k}, 10 \mathrm{k}, 100 \mathrm{k}$, and $1 \mathrm{M}$ $\mathrm{ohm}$. Three different resistors for each value were used. Three capacitors for each of five capacitor values were utilized for validation. The capacitor values were $10 \mathrm{u}, 1 \mathrm{u}, 0.1 \mathrm{u}$, $10 \mathrm{n}$, and $1 \mathrm{n}$-farad. The resistors and capacitors had a threshold accuracy of $\pm 5 \%$ and $\pm 10 \%$ based on the specifications given by the manufacturer, respectively. 
The main custom program was altered for the purposes of this validation. The second For loop was removed because outer electrode selection was not necessary for the ELVIS system alone. Two points were recorded - one each at 2 and $10 \mathrm{kHz}$ frequency. The $2 \mathrm{kHz}$ frequency was selected because of its expected position at the $\beta$-dispersion point for skin and its use by Glickman and Har-Shai [33, 34]. The $10 \mathrm{kHz}$ frequency was chosen for its use by Gabriel and Stante $[18,36]$. The data recorded by the Impedance Analyzer were compared to the value ranges provided by the manufacturer.

\section{Multiplexer Validation}

Multiplexers inherently increase the impedance of the load because of the way they are constructed. For certain applications, like this thesis project, sources of impedance other than the tissue or electrical component being measured can cause errors in the data. Thus, the multiplexer must be validated to ensure that reliable impedance readings are still possible. If not, some post-processing techniques can be applied to eliminate the added impedance from the multiplexer. Since impedances in series act as resistors in series, any component's impedance can be added to arrive at the total system impedance. Therefore, if the impedance of the multiplexer without a load is known, then it can be subtracted from the impedance of the multiplexer with a load to obtain the impedance of the load only.

The multiplexer, pull-up resistors, and all connections were placed onto the prototyping board as described in the Breadboard section, except the connections to the electrode device were removed. Instead, the Current $H i$ wire was split into 8 wires leading to the 8 multiplexer inputs as shown in Figure 16. Before each connection to the multiplexer input, a resistor or capacitor was placed. The same amount and value of 
resistors and capacitors used in the ELVIS validation were employed again in this validation. An additional test was performed with bare wires connecting the multiplexer inputs to record the intrinsic impedance of the multiplexer; this test was performed three times. All tests were performed at 2 and $10 \mathrm{kHz}$ frequencies. The data recorded for each resistor and capacitor at the two frequencies was compared to the values supplied by the manufacturer to determine the reliability of the system. Then, the average intrinsic impedance was subtracted from the recorded data and compared to the values supplied by the manufacturer.

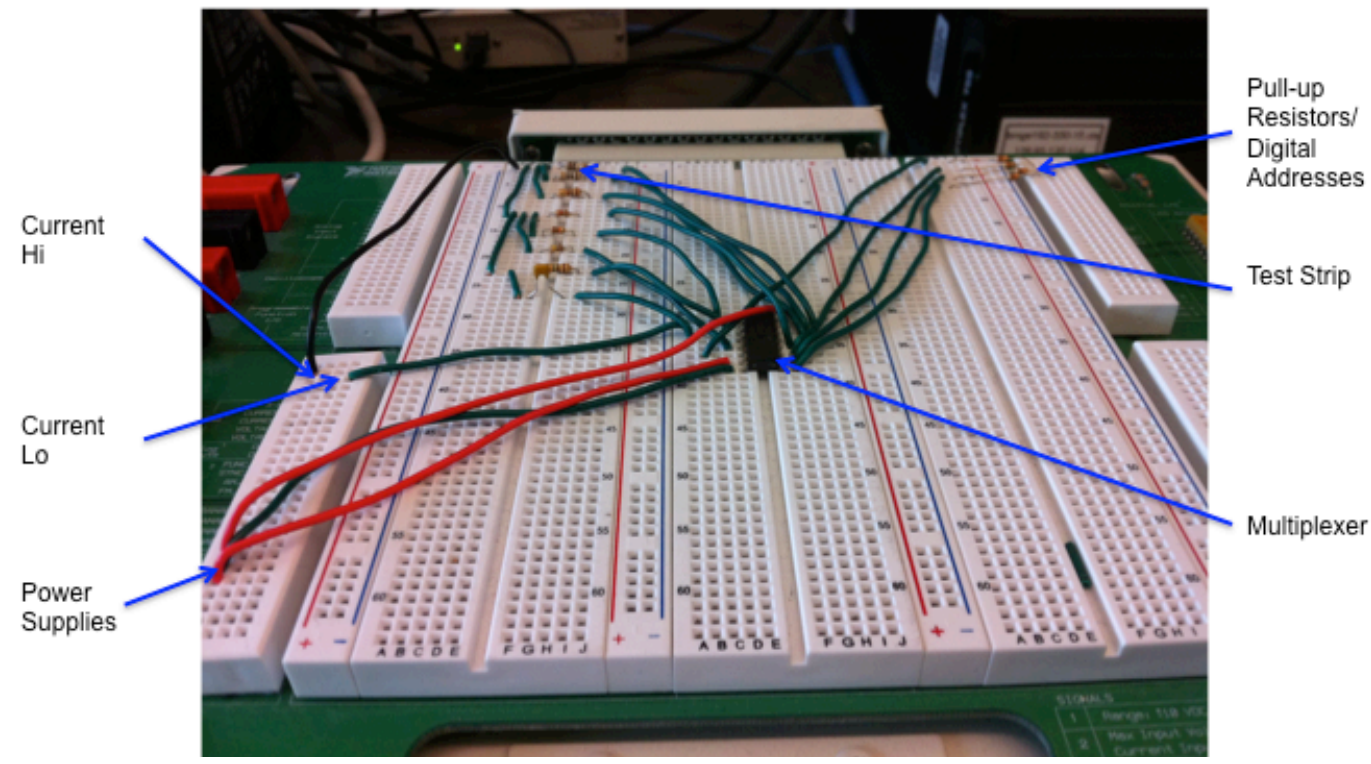

Figure 16: Multiplexer Validation Setup

Shows the setup for the multiplexer validation tests with a series of resistors in the test strip.

\section{Device Validation}

After validating the ELVIS system and the multiplexer, the electrode device was tested to ensure that all electrodes were connected to their respective wires, that the solder joints did not add extraordinary impedance, and that the $\mathrm{Ag} / \mathrm{AgCl}$ electrodes were capable of measuring the correct resistor and capacitor values. The ELVIS prototyping 
board was arranged according to the description in the Breadboard section. Since the electrode tips were $0.8 \mathrm{~mm}$ in diameter and a solid connection to an electrical element was difficult, an electrical testing hook clip (Figure 17) was utilized. One hook clip was placed on the central electrode and another was placed on an outer electrode. The opposite ends of both hook clip wires attached to either side of an electrical component as shown in Figure 18.

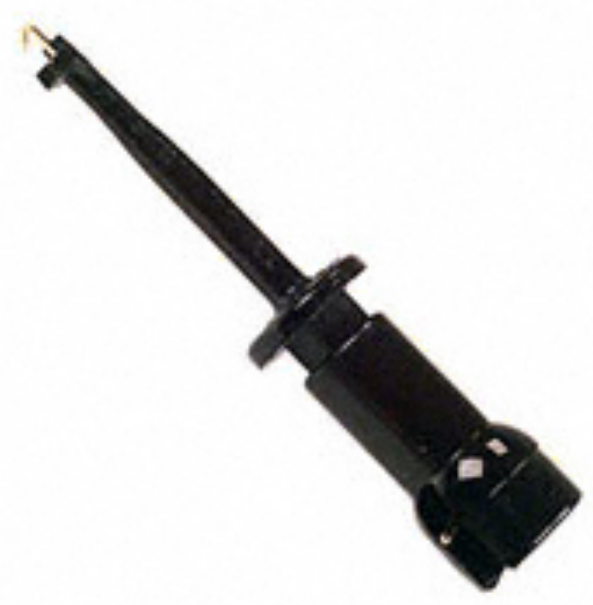

Figure 17: Electrical Testing Hook Clip [45] An example electrical testing hook clip used for grabbing small components.

The same quantity and value of resistors and capacitors used in the previous validations were tested between the same two electrodes at 2 and $10 \mathrm{kHz}$ frequencies. After testing of the electrical components was complete, the free ends of the hook clips were connected together to measure the system impedance. This was conducted 8 times for each of the 8 outer electrodes. The intrinsic system impedance of the two electrodes tested with electrical components was subtracted from the recorded data and compared to the electrical component values provided by the manufacturer for each frequency. The intrinsic system impedances of all outer electrodes were also checked for homogeneity. If 
the system impedances were similar, then we could deduce that the resistor and capacitor values reliably identified by the one tested outer electrode could also be reliably identified by all other outer electrodes.

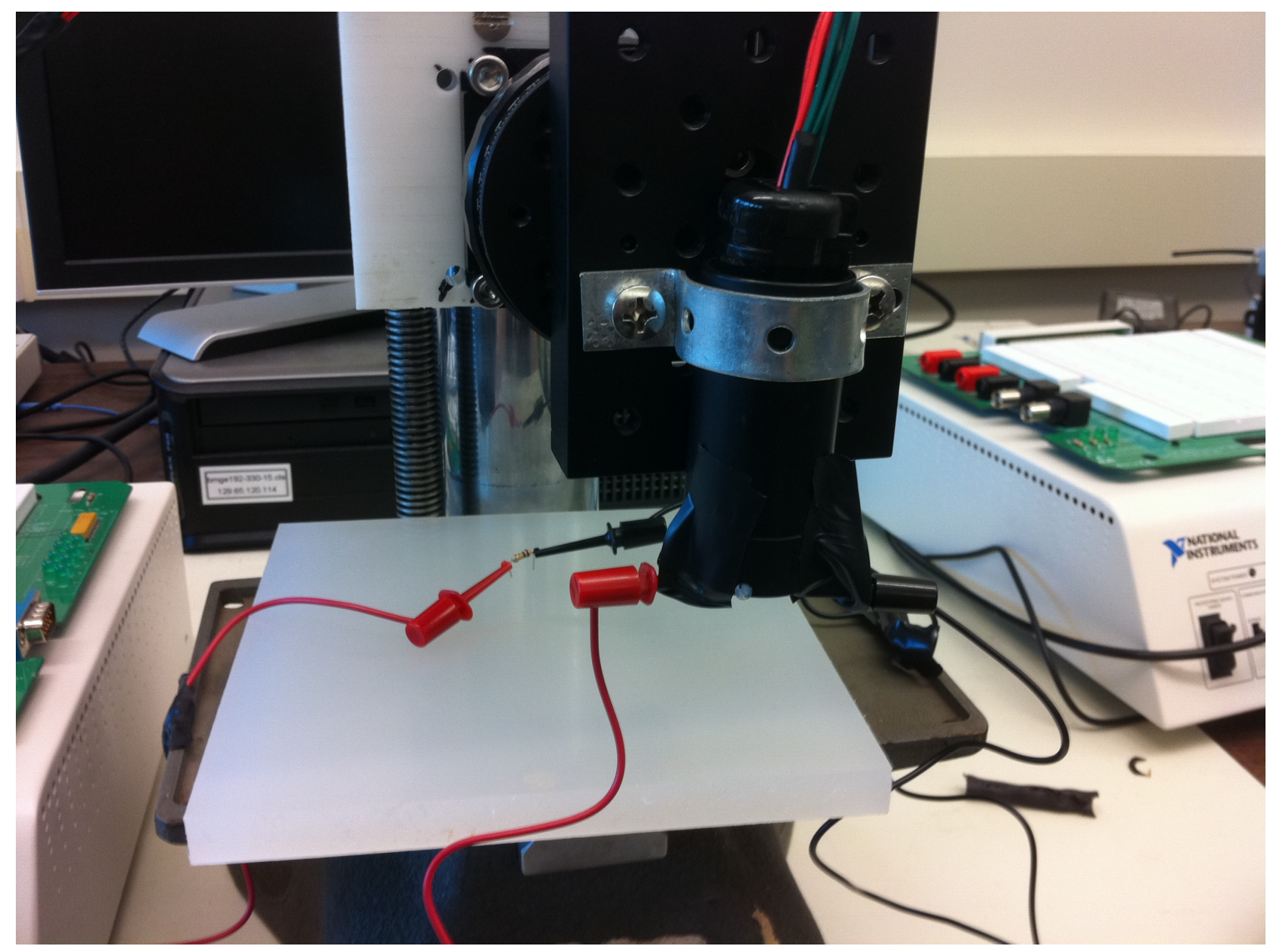

Figure 18: Electrode Device Validation Setup

Electrical testing hook clips connect two electrodes via an electrical component. Experimental Validation

With the entire system validated, any measurements conducted on biological tissues that fell within the capabilities of the system could be considered reliable. The experimental hypothesis that the electrode device could differentiate between melanoma and healthy skin tissue based on impedance measurements must now be validated. Raw 
and cooked chicken thigh skin and meat were used for preliminary verification.

Following that, melanoma and epidermis tissue engineered skin analogues were tested. Both experiments are described in more detail in the following sections.

\section{Raw Chicken Skin and Meat}

Chicken tissue samples from Foster Farms were purchased from local grocery stores and used for experimentation because of their availability, low cost, and continuity with previous work. While chicken meat and skin did not directly correlate to human melanoma and epidermis skin tissue, the principles behind the detection of melanoma would still exist in the chicken. That is, the anatomy, physiology, and moisture content of chicken skin and meat at a cellular level should allow for differentiation by the electrode device. This validation served as a low cost, preliminary test to determine if the electrode device could differentiate from visually distinct tissues. If it could, then more expensive validation efforts using anatomically and physiologically correct tissues may be employed.

Twenty measurements each were performed on two different chicken thighs. Half of the measurements (ten locations) were performed on the skin, while the other half were tested on the meat. Each measurement consisted of impedance values in all 8 directions at 2 and $10 \mathrm{kHz}$ frequencies. Distinct locations were used for each measurement, while attempting to conserve the orientation of chicken thigh for as many measurements as possible. The orientation could possibly produce different impedance values based on the anisotropic nature of biological tissues. Before beginning experimentation, the chicken thigh was allowed to come to thermal equilibrium with the room. All attempts were made to keep the pressure of each electrode similar to one 
another and consistent throughout multiple measurements by rotating the electrode device fixture as needed. Impedance values of chicken thigh meat and skin at each frequency were compared to find statistical differences between the two groups. An example image of the chicken tissue test is shown in Figure 19.

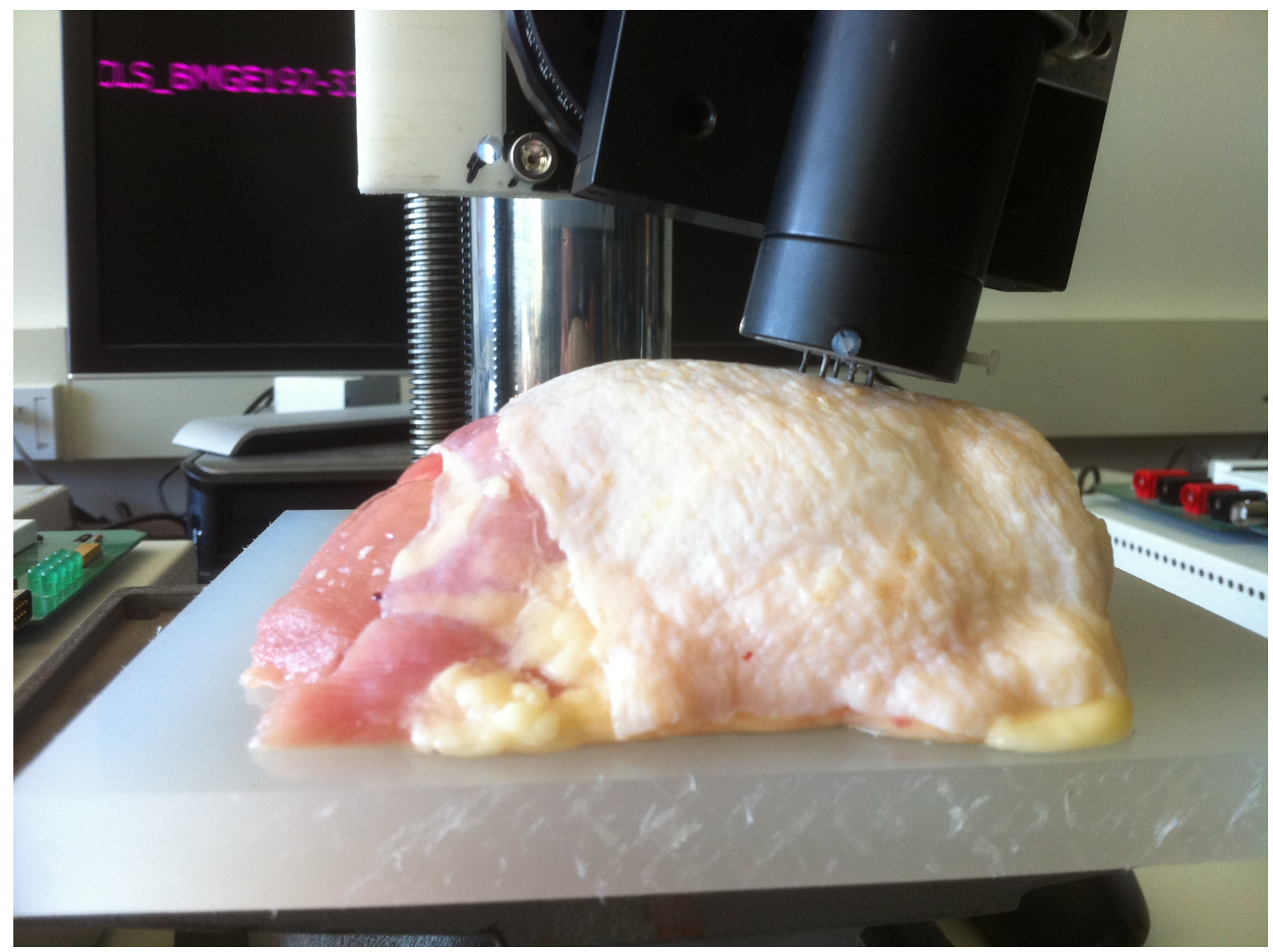

Figure 19: Chicken Tissue Validation Setup

The electrode device is rotated so that all electrodes are flush with the surface of the chicken tissue.

\section{Raw and Cooked Chicken}

The previous validation shows that the electrode device can differentiate two visually distinct tissues. However, the differences between normal epidermis and melanoma are much more subtle. As discussed in Cancerous Electrical Properties, the changes in membrane permeability cause cell swelling. Thus, the moisture content of 
melanoma tissue increases. Using cooked chicken in comparison to raw chicken is an attempt to create a difference in moisture content within the same tissue type. Finding differences in impedance between cooked and raw skin or cooked and raw meat gives a better indication of successful trials with more advanced, better-suited tissue samples.

The same two chicken thighs used in the previous validation were cooked in a convection oven for 35 minutes at 350 degrees Fahrenheit. After reaching thermal equilibrium with the room, the same methods used in the previous validation were employed. Briefly, twenty measurements each were performed on the two chicken thighs - ten on skin, ten on meat. Both 2 and $10 \mathrm{kHz}$ frequencies were used for all test locations. During cooking, the skin became stiffer and lifted away from the meat of the chicken. For experimental purposes, the electrode device was actuated until the skin was in contact with meat again. The impedances of cooked skin and meat were compared to that of raw skin and meat at both frequencies.

\section{Tissue Engineered Skin Analogues}

Tissue engineered skin analogues purchased from MatTek Corporation were used for the final experimental validation. EpiDerm ${ }^{\mathrm{TM}}$, a human 3-D skin-like tissue structure, and Melanoma, a full thickness human melanoma skin model, were obtained because of

their similarities to in-vivo epidermis and melanoma tissues. Epiderm ${ }^{\mathrm{TM}}$ contained normal human epidermal keratinocytes derived from neonatal-foreskin tissue. According to MatTek, Epiderm ${ }^{\mathrm{TM}}$ closely resembled the human skin and consisted of the basal, spinous, granular, and cornified layers. Studies also showed that Epiderm ${ }^{\mathrm{TM}}$ approaches the barrier properties of normal skin [46]; Epiderm's ${ }^{\mathrm{TM}}$ structure is shown at 400x magnification in Figure 20. Melanoma, shown in Figure 21, contained human melanoma 
cells, normal human epidermal keratinocytes, and normal human dermal fibroblasts. According to MatTek, the Melanoma analogues closely resembled the progression of melanoma in vivo. Both Epiderm ${ }^{\mathrm{TM}}$ and Melanoma analogues were highly reproducible, had highly differentiated cells, were metabolically and mitotically active tissues, and were cultured in serum-free medium on specially prepared cell culture inserts [46].

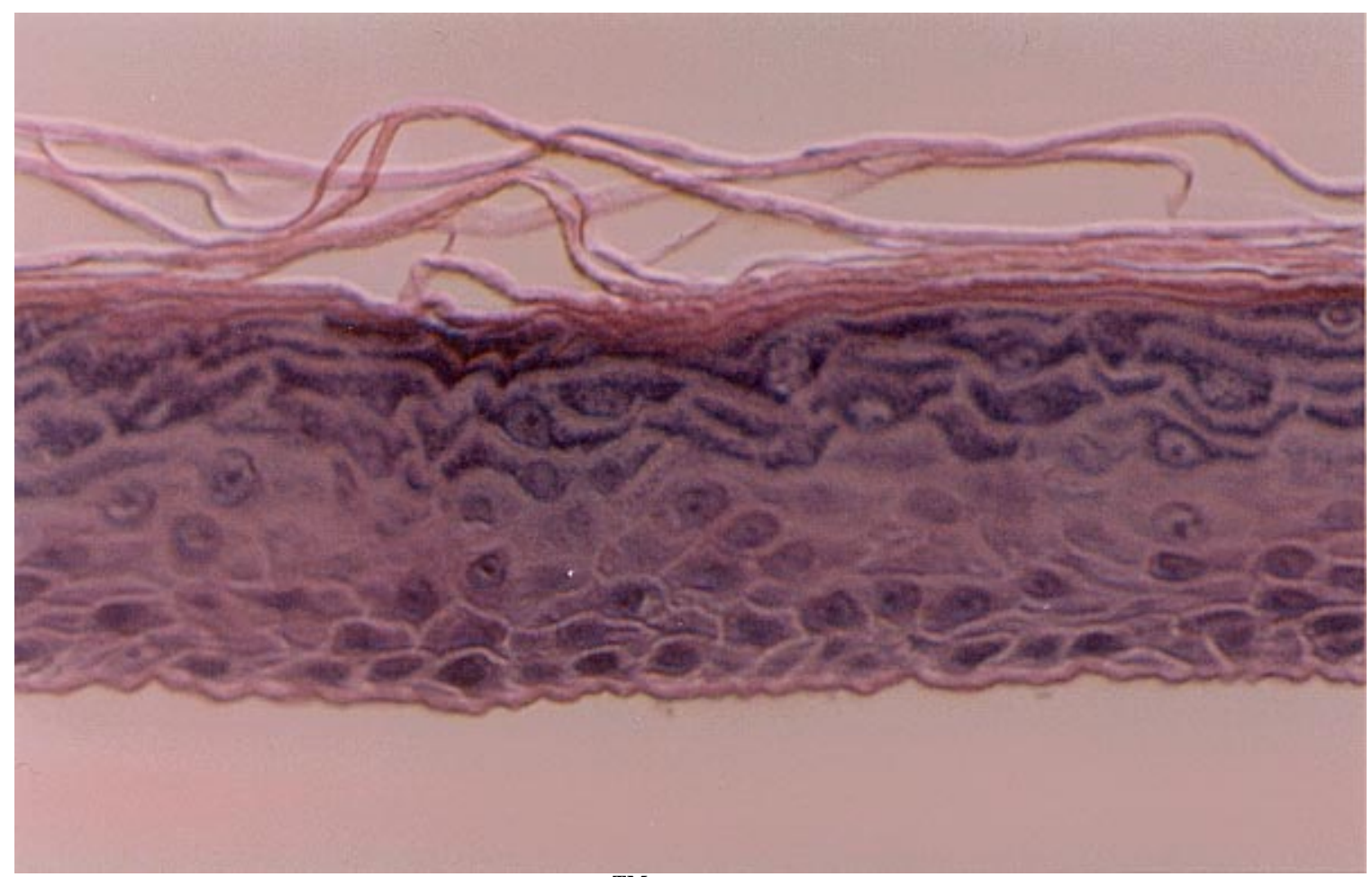

Figure 20: Epiderm ${ }^{\mathrm{TM}}$ Histological Cross-Section A histological section of Epiderm ${ }^{\mathrm{TM}}$ taken at 400x magnification [46].

Epiderm $^{\mathrm{TM}}$ was ideal for impedance measurements because of its structural resemblance and barrier function. In vivo, the lipid barrier of the epidermis creates many problems for impedance measurements due to the high capacitance. Thus, it is beneficial that the barrier function was reproduced in the skin analogue to better mimic actual skin. Melanoma was ideal as a melanoma tissue analogue because it was metabolically active and contained different stages of tumor growth. It also was a full thickness sample that consisted of the epidermis and dermis. 
Three samples each of Epiderm ${ }^{\mathrm{TM}}$ and Melanoma were tested. Since the samples were $1 \mathrm{~cm}$ in diameter, only one measurement was performed per sample. All samples used had been frozen for approximately 2 years and needed rehydration before testing. Twenty uL of deionized water was placed on a petri dish. The tissue sample being measured was removed from a $10 \mathrm{~mL}$ conical tube and deposited atop the water droplet. The electrode device was actuated until all electrodes were contacting the sample and the program was started. All 8 directions were measured at 2 and $10 \mathrm{kHz}$ frequencies. Impedance measurements from Epiderm ${ }^{\mathrm{TM}}$ were compared to that of Melanoma for a statistical difference. Finding a difference would serve as reasonable evidence for accepting the experimental hypothesis that melanoma could be diagnosed by analyzing the impedance values in multiple directions.

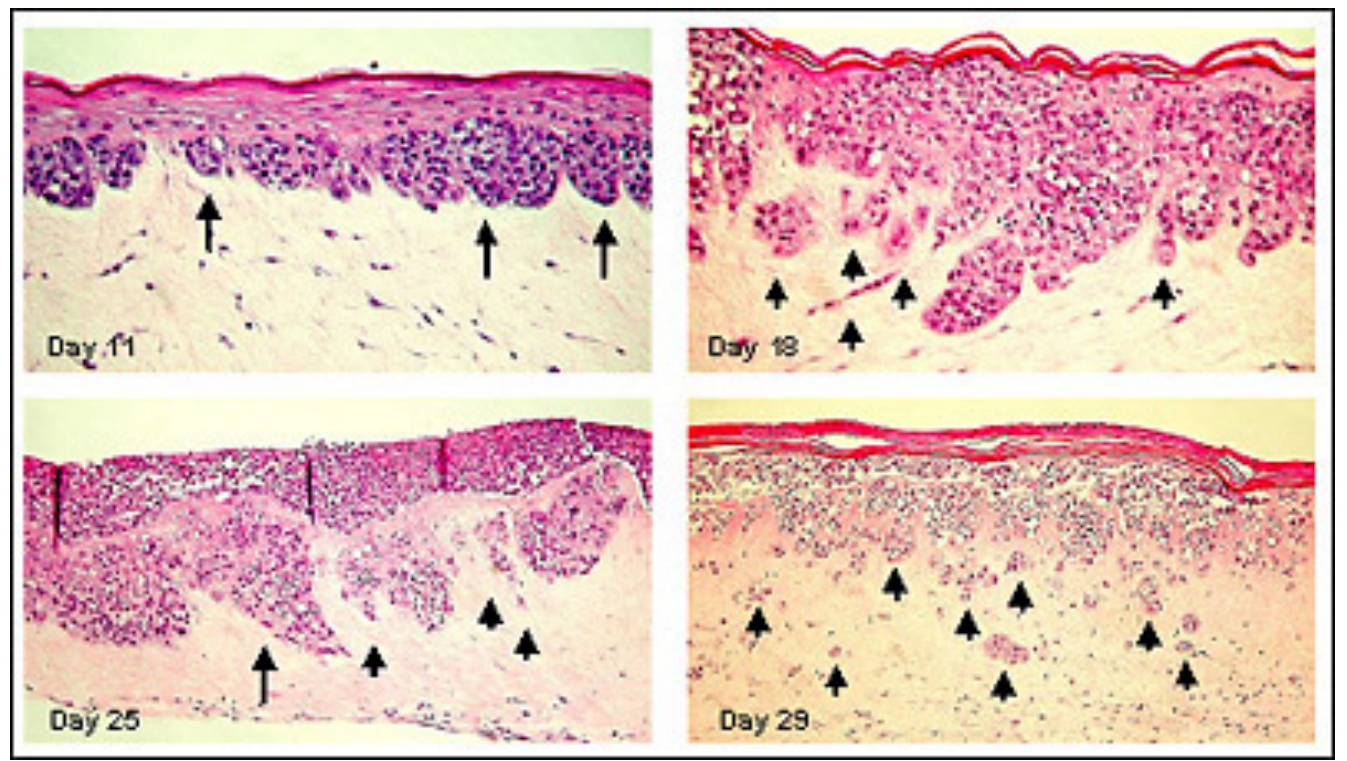

Figure 21: Melanoma Tissue Analogue Histological Cross-Sections

The Melanoma histological cross sections depict melanoma cells at the epidermal/dermal boundary (long arrows) and metastatic melanoma cells (short arrows) [46]. 


\section{Results}

Following the completion of the experiments, all data was organized into tables using Microsoft Excel and transferred to Minitab for statistical analysis. The statistical analysis included Student T-tests, one-way ANOVA analyses, and/or multiple regression

models. The data and statistical results will be presented in the following sections. For a discussion of the results and a conclusion about the validity of the device and experimental hypothesis, see the Discussion section.

\section{ELVIS Validation Results}

The data obtained for the ELVIS validation resistors is presented in Table 3 and Table 4 for the $2 \mathrm{kHz}$ and $10 \mathrm{kHz}$ tests, respectively. The first column labeled "Resistor Value" is the face value of the resistors that is provided by the manufacturer. The "Measured Resistance" column is the resistance component of the measured impedance. The absolute value of the percent error for each measurement is calculated in column three. Since the manufacturer indicates that the tolerance of each resistor is 5\%, the measured resistance value may have a calculated percent error of $5 \%$ and still be reliable. Thus, column four provides information on whether the measured resistance is within the tolerance allowed by the manufacturer. The value of column four is "Y" for yes if the absolute value of the experimental error is less than 5\%. Conversely, a value of "N" for no is shown if the experimental error exceeds 5\%. 
Table 3: ELVIS Validation Resistor Values at $2 \mathrm{kHz}$

\begin{tabular}{|r|r|r|r|}
\hline Resistor Value (ohms) & $\begin{array}{c}\text { Measured Resistance } \\
\text { (ohms) }\end{array}$ & $\begin{array}{c}\text { Experimental Error } \\
(\%)\end{array}$ & $\begin{array}{c}\text { Within 5\% Tolerance } \\
(\mathrm{Y} / \mathrm{N})\end{array}$ \\
\hline 1 & 3.573 & 257.3 & $\mathrm{~N}$ \\
\hline 1 & 3.578 & 257.8 & $\mathrm{~N}$ \\
\hline 1 & 3.55 & 255 & $\mathrm{~N}$ \\
\hline 10 & 12.647 & 26.47 & $\mathrm{~N}$ \\
\hline 10 & 12.442 & 24.42 & $\mathrm{~N}$ \\
\hline 10 & 12.509 & 25.09 & $\mathrm{~N}$ \\
\hline 100 & 101.902 & 1.902 & $\mathrm{Y}$ \\
\hline 100 & 100.747 & 0.747 & $\mathrm{Y}$ \\
\hline 100 & 101.269 & 1.269 & $\mathrm{Y}$ \\
\hline 1,000 & 976.164 & 2.3836 & $\mathrm{Y}$ \\
\hline 1,000 & 991.353 & 0.8647 & $\mathrm{Y}$ \\
\hline 1,000 & 994.461 & 0.5539 & $\mathrm{Y}$ \\
\hline 10,000 & 9939.484 & 0.60516 & $\mathrm{Y}$ \\
\hline 10,000 & 9754.059 & 2.45941 & $\mathrm{Y}$ \\
\hline 10,000 & 9872.324 & 1.27676 & $\mathrm{Y}$ \\
\hline 100,000 & 99273.07 & 0.72693 & $\mathrm{Y}$ \\
\hline 100,000 & 99422.341 & 0.577659 & $\mathrm{Y}$ \\
\hline 100,000 & 100528.066 & 0.528066 & $\mathrm{Y}$ \\
\hline $1,000,000$ & 969616.092 & 3.0383908 & $\mathrm{Y}$ \\
\hline $1,000,000$ & 983668.296 & 1.6331704 & $\mathrm{Y}$ \\
\hline $1,000,000$ & 971611.515 & 2.8388485 & $\mathrm{Y}$ \\
\hline & & & \\
\hline
\end{tabular}

Table 4: ELVIS Validation Resistor Values at $10 \mathrm{kHz}$

\begin{tabular}{|r|r|r|c|}
\hline Resistor Value (ohms) & $\begin{array}{c}\text { Measured Resistance } \\
\text { (ohms) }\end{array}$ & $\begin{array}{c}\text { Experimental Error } \\
(\%)\end{array}$ & $\begin{array}{c}\text { Within 5\% Tolerance } \\
(\mathrm{Y} / \mathrm{N})\end{array}$ \\
\hline 1 & 3.48 & 247.80 & $\mathrm{~N}$ \\
\hline 1 & 3.48 & 248.00 & $\mathrm{~N}$ \\
\hline 1 & 3.48 & 248.00 & $\mathrm{~N}$ \\
\hline 10 & 12.57 & 25.65 & $\mathrm{~N}$ \\
\hline 10 & 12.35 & 23.48 & $\mathrm{~N}$ \\
\hline 10 & 12.45 & 24.49 & $\mathrm{~N}$ \\
\hline 100 & 101.84 & 1.83 & $\mathrm{Y}$ \\
\hline 100 & 100.72 & 0.72 & $\mathrm{Y}$ \\
\hline 100 & 101.18 & 1.18 & $\mathrm{Y}$ \\
\hline 1,000 & 976.01 & 2.40 & $\mathrm{Y}$ \\
\hline 1,000 & 996.30 & 0.37 & $\mathrm{Y}$ \\
\hline 1,000 & 995.70 & 0.43 & $\mathrm{Y}$ \\
\hline 10,000 & 9879.43 & 1.21 & $\mathrm{Y}$ \\
\hline 10,000 & 9951.68 & 0.48 & $\mathrm{Y}$ \\
\hline 10,000 & 9766.04 & 2.34 & $\mathrm{Y}$ \\
\hline 100,000 & 98862.71 & 1.14 & $\mathrm{Y}$ \\
\hline 100,000 & 99336.73 & 0.66 & $\mathrm{Y}$ \\
\hline 100,000 & 100879.94 & 0.88 & $\mathrm{Y}$ \\
\hline $1,000,000$ & 399099.19 & 60.09 & $\mathrm{~N}$ \\
\hline $1,000,000$ & 397399.65 & 60.26 & $\mathrm{~N}$ \\
\hline $1,000,000$ & 397255.33 & 60.27 & $\mathrm{~N}$ \\
\hline & & & \\
\hline
\end{tabular}


The capacitor data obtained from the ELVIS validation at $2 \mathrm{kHz}$ and $10 \mathrm{kHz}$ is provided in Table 5 and Table 6 , respectively. The face value of the capacitor provided by the manufacturer is located in the column labeled "Capacitor Value" and is given in Farads. The reactance component of the measured impedance in ohms is shown in the second column. The measured reactance is used with Equation 2 to calculate the capacitance in Farads and is presented in column three. Column four shows the calculated percent error from the capacitor face value. The "Within Tolerance" column offers a quick reference to whether the measured capacitor value falls within the $10 \%$ tolerance specification provided by the manufacturer.

Table 5: ELVIS Validation Capacitor Values at 2 kHz

\begin{tabular}{|r|r|r|r|c|}
\hline $\begin{array}{c}\text { Capacitor Value } \\
(\mathrm{F})\end{array}$ & $\begin{array}{c}\text { Measured } \\
\text { Reactance } \\
\text { (ohms) }\end{array}$ & $\begin{array}{c}\text { Calculated } \\
\text { Capacitance (F) }\end{array}$ & $\begin{array}{c}\text { Experimental } \\
\text { Error }(\%)\end{array}$ & $\begin{array}{c}\text { Within } \\
\text { Tolerance } \\
\text { (Y/N) }\end{array}$ \\
\hline $1.00 \mathrm{E}-09$ & -78713.11 & $1.064 \mathrm{E}-09$ & 6.42 & $\mathrm{Y}$ \\
\hline $1.00 \mathrm{E}-09$ & -75655.15 & $1.107 \mathrm{E}-09$ & 7.72 & $\mathrm{~N}$ \\
\hline $1.00 \mathrm{E}-09$ & -77777.66 & $1.077 \mathrm{E}-09$ & 1.76 & $\mathrm{Y}$ \\
\hline $1.00 \mathrm{E}-08$ & -8231.78 & $1.018 \mathrm{E}-08$ & 7.61 & $\mathrm{Y}$ \\
\hline $1.00 \mathrm{E}-08$ & -7783.91 & $1.076 \mathrm{E}-08$ & 5.67 & $\mathrm{Y}$ \\
\hline $1.00 \mathrm{E}-08$ & -7926.77 & $1.057 \mathrm{E}-08$ & 3.96 & $\mathrm{Y}$ \\
\hline $1.00 \mathrm{E}-07$ & -805.75 & $1.040 \mathrm{E}-07$ & 3.11 & $\mathrm{Y}$ \\
\hline $1.00 \mathrm{E}-07$ & -812.38 & $1.031 \mathrm{E}-07$ & 5.85 & $\mathrm{Y}$ \\
\hline $1.00 \mathrm{E}-07$ & -791.40 & $1.058 \mathrm{E}-07$ & 6.90 & $\mathrm{Y}$ \\
\hline $1.00 \mathrm{E}-06$ & -81.40 & $1.029 \mathrm{E}-06$ & 3.10 & $\mathrm{Y}$ \\
\hline $1.00 \mathrm{E}-06$ & -78.33 & $1.069 \mathrm{E}-06$ & 8.29 & $\mathrm{Y}$ \\
\hline $1.00 \mathrm{E}-06$ & -81.25 & $1.031 \mathrm{E}-06$ & 10.92 & $\mathrm{~N}$ \\
\hline $1.00 \mathrm{E}-05$ & -7.74 & $1.083 \mathrm{E}-05$ & 12.12 & $\mathrm{~N}$ \\
\hline $1.00 \mathrm{E}-05$ & -7.55 & $1.109 \mathrm{E}-05$ & & \\
\hline $1.00 \mathrm{E}-05$ & -7.47 & $1.121 \mathrm{E}-05$ & & \\
\hline
\end{tabular}


Table 6: ELVIS Validation Capacitor Values at $10 \mathrm{kHz}$

\begin{tabular}{|r|r|r|r|c|}
\hline $\begin{array}{c}\text { Capacitor Value } \\
(\mathrm{F})\end{array}$ & $\begin{array}{c}\text { Measured } \\
\text { Reactance } \\
\text { (ohms) }\end{array}$ & $\begin{array}{c}\text { Calculated } \\
\text { Capacitance (F) }\end{array}$ & $\begin{array}{c}\text { Experimental } \\
\text { Error (\%) }\end{array}$ & $\begin{array}{c}\text { Within } \\
\text { Tolerance } \\
(\mathrm{Y} / \mathrm{N})\end{array}$ \\
\hline $1.00 \mathrm{E}-09$ & -15039.82 & $1.058 \mathrm{E}-09$ & 5.82 & $\mathrm{Y}$ \\
\hline $1.00 \mathrm{E}-09$ & -14530.14 & $1.095 \mathrm{E}-09$ & 9.53 & $\mathrm{Y}$ \\
\hline $1.00 \mathrm{E}-09$ & -14910.07 & $1.067 \mathrm{E}-09$ & 6.74 & $\mathrm{Y}$ \\
\hline $1.00 \mathrm{E}-08$ & -1591.25 & $1.000 \mathrm{E}-08$ & 0.02 & $\mathrm{Y}$ \\
\hline $1.00 \mathrm{E}-08$ & -1528.90 & $1.041 \mathrm{E}-08$ & 4.10 & $\mathrm{Y}$ \\
\hline $1.00 \mathrm{E}-08$ & -1499.42 & $1.061 \mathrm{E}-08$ & 6.14 & $\mathrm{Y}$ \\
\hline $1.00 \mathrm{E}-07$ & -151.01 & $1.054 \mathrm{E}-07$ & 5.40 & $\mathrm{Y}$ \\
\hline $1.00 \mathrm{E}-07$ & -151.84 & $1.048 \mathrm{E}-07$ & 4.82 & $\mathrm{Y}$ \\
\hline $1.00 \mathrm{E}-07$ & -148.49 & $1.072 \mathrm{E}-07$ & 15.66 & $\mathrm{Y}$ \\
\hline $1.00 \mathrm{E}-06$ & -13.76 & $1.157 \mathrm{E}-06$ & 20.75 & $\mathrm{~N}$ \\
\hline $1.00 \mathrm{E}-06$ & -13.18 & $1.208 \mathrm{E}-06$ & 16.02 & $\mathrm{~N}$ \\
\hline $1.00 \mathrm{E}-06$ & -13.72 & $1.160 \mathrm{E}-06$ & 1064.58 & $\mathrm{~N}$ \\
\hline $1.00 \mathrm{E}-05$ & 0.17 & $-9.646 \mathrm{E}-05$ & 916.18 & $\mathrm{~N}$ \\
\hline $1.00 \mathrm{E}-05$ & 0.20 & $-8.162 \mathrm{E}-05$ & 833.43 & $\mathrm{~N}$ \\
\hline $1.00 \mathrm{E}-05$ & 0.22 & $-7.334 \mathrm{E}-05$ & & \\
\hline & & & & \\
\hline
\end{tabular}

\section{Multiplexer Validation Results}

The resistor data obtained from the switch validation experiment at $2 \mathrm{kHz}$ is provided in Table 7. This data is comparable to that obtained from the multiplexer validation experiments with resistors at $10 \mathrm{kHz}$ and capacitors at 2 and $10 \mathrm{kHz}$ in that the majority of measured values fall outside of the allowable tolerance range of $5 \%$.

Therefore, the resistance and reactance values from the three intrinsic multiplexer impedance tests were averaged for each electrode and frequency. Table 8 presents the averaged data for each electrode at 2 and $10 \mathrm{kHz}$. 
Table 7: Multiplexer Validation Resistor Values at $2 \mathrm{kHz}$

\begin{tabular}{|r|r|r|c|}
\hline Resistor Value (ohms) & $\begin{array}{c}\text { Measured Resistance } \\
\text { (ohms) }\end{array}$ & $\begin{array}{c}\text { Experimental Error } \\
(\%)\end{array}$ & $\begin{array}{c}\text { Within 5\% Tolerance } \\
(\mathrm{Y} / \mathrm{N})\end{array}$ \\
\hline 1 & 64.50 & 6350.20 & $\mathrm{~N}$ \\
\hline 1 & 64.32 & 6332.10 & $\mathrm{~N}$ \\
\hline 1 & 64.56 & 6355.60 & $\mathrm{~N}$ \\
\hline 10 & 73.59 & 635.85 & $\mathrm{~N}$ \\
\hline 10 & 73.37 & 633.69 & $\mathrm{~N}$ \\
\hline 10 & 73.57 & 635.72 & $\mathrm{~N}$ \\
\hline 100 & 162.46 & 62.46 & $\mathrm{~N}$ \\
\hline 100 & 162.83 & 62.83 & $\mathrm{~N}$ \\
\hline 100 & 163.24 & 63.24 & $\mathrm{~N}$ \\
\hline 1,000 & 1045.77 & 4.58 & $\mathrm{Y}$ \\
\hline 1,000 & 1036.89 & 3.69 & $\mathrm{Y}$ \\
\hline 1,000 & 1037.26 & 3.73 & $\mathrm{Y}$ \\
\hline 10,000 & 10010.84 & 0.11 & $\mathrm{Y}$ \\
\hline 10,000 & 9921.70 & 0.78 & $\mathrm{Y}$ \\
\hline 10,000 & 10142.49 & 1.42 & $\mathrm{Y}$ \\
\hline 100,000 & 98083.38 & 1.92 & $\mathrm{Y}$ \\
\hline 100,000 & 99057.11 & 0.94 & $\mathrm{Y}$ \\
\hline 100,000 & 99169.93 & 0.83 & $\mathrm{Y}$ \\
\hline $1,000,000$ & 771537.53 & 22.85 & $\mathrm{~N}$ \\
\hline $1,000,000$ & 783858.22 & 21.61 & $\mathrm{~N}$ \\
\hline $1,000,000$ & 779009.45 & 22.10 & $\mathrm{~N}$ \\
\hline & & & \\
\hline
\end{tabular}

Table 8: Averaged Intrinsic Multiplexer Impedance Values

\begin{tabular}{|c|c|c|c|c|c|}
\hline $\begin{array}{l}\text { Frequency } \\
(\mathrm{Hz})\end{array}$ & $\begin{array}{l}\text { Average } \\
\text { Impedance } \\
\text { (ohms) }\end{array}$ & $\begin{array}{l}\text { Average } \\
\text { Phase }\end{array}$ & $\begin{array}{l}\text { Average } \\
\text { Resistance } \\
\text { (ohms) }\end{array}$ & $\begin{array}{l}\text { Average } \\
\text { Reactance } \\
\text { (ohms) }\end{array}$ & Electrodes \\
\hline 2000 & 63.597 & 0.379 & 63.596 & 0.421 & \multirow{2}{*}{0} \\
\hline 10000 & 63.877 & 2.331 & 63.824 & 2.598 & \\
\hline 2000 & 63.695 & 0.409 & 63.693 & 0.455 & \multirow{2}{*}{1} \\
\hline 10000 & 63.716 & 2.338 & 63.663 & 2.599 & \\
\hline 2000 & 63.716 & 0.406 & 63.714 & 0.451 & \multirow{2}{*}{2} \\
\hline 10000 & 63.694 & 2.341 & 63.640 & 2.602 & \\
\hline 2000 & 63.653 & 0.408 & 63.652 & 0.453 & \multirow{2}{*}{3} \\
\hline 10000 & 63.601 & 2.341 & 63.548 & 2.598 & \\
\hline 2000 & 63.470 & 0.411 & 63.468 & 0.456 & \multirow{2}{*}{4} \\
\hline 10000 & 63.408 & 2.344 & 63.355 & 2.594 & \\
\hline 2000 & 63.453 & 0.410 & 63.451 & 0.455 & \multirow{2}{*}{5} \\
\hline 10000 & 63.414 & 2.343 & 63.361 & 2.593 & \\
\hline 2000 & 63.337 & 0.409 & 63.335 & 0.452 & \multirow{2}{*}{6} \\
\hline 10000 & 63.304 & 2.344 & 63.251 & 2.590 & \\
\hline 2000 & 63.440 & 0.409 & 63.438 & 0.454 & \multirow{2}{*}{7} \\
\hline 10000 & 63.373 & 2.347 & 63.320 & 2.595 & \\
\hline
\end{tabular}


The average intrinsic resistances from Table 8 were subtracted from the multiplexer validation resistor data based on the frequency and electrode number in which the data was recorded. The new resistor values for the multiplexer validation at 2 and $10 \mathrm{kHz}$ are presented in Table 9 and 10, respectively. Similar to the ELVIS validation results, the tables show the face value of the resistor provided by the manufacturer, the resistance component of the measured impedance, the calculated percent error based on the face value, and whether the percent error falls within the allowable 5\% tolerance range.

Table 9: Adjusted Multiplexer Validation Resistor Values at $2 \mathrm{kHz}$

\begin{tabular}{|c|c|c|c|}
\hline Resistor Value (ohms) & $\begin{array}{l}\text { Measured Resistance } \\
\text { (ohms) }\end{array}$ & $\begin{array}{l}\text { Experimental Error } \\
(\%)\end{array}$ & $\begin{array}{c}\text { Within } 5 \% \text { Tolerance } \\
(\mathrm{Y} / \mathrm{N})\end{array}$ \\
\hline 1 & 0.906 & 9.367 & $\mathrm{~N}$ \\
\hline 1 & 0.725 & 27.467 & $\mathrm{~N}$ \\
\hline 1 & 0.960 & 3.967 & $\mathrm{Y}$ \\
\hline 10 & 9.892 & 1.083 & $\mathrm{Y}$ \\
\hline 10 & 9.676 & 3.243 & $Y$ \\
\hline 10 & 9.879 & 1.213 & $\mathrm{Y}$ \\
\hline 100 & 98.750 & 1.250 & $\mathrm{Y}$ \\
\hline 100 & 99.111 & 0.889 & $\mathrm{Y}$ \\
\hline 100 & 99.522 & 0.478 & $\mathrm{Y}$ \\
\hline 1,000 & 982.117 & 1.788 & $\mathrm{Y}$ \\
\hline 1,000 & 973.241 & 2.676 & $\mathrm{Y}$ \\
\hline 1,000 & 973.606 & 2.639 & $\mathrm{Y}$ \\
\hline 10,000 & 9947.376 & 0.526 & $\mathrm{Y}$ \\
\hline 10,000 & 9858.233 & 1.418 & $\mathrm{Y}$ \\
\hline 10,000 & 10079.024 & 0.790 & $\mathrm{Y}$ \\
\hline 100,000 & 98019.932 & 1.980 & $\mathrm{Y}$ \\
\hline 100,000 & 98993.662 & 1.006 & $\mathrm{Y}$ \\
\hline 100,000 & 99106.480 & 0.894 & $\mathrm{Y}$ \\
\hline $1,000,000$ & 771474.195 & 22.853 & $\mathrm{~N}$ \\
\hline $1,000,000$ & 783794.783 & 21.621 & $\mathrm{~N}$ \\
\hline $1,000,000$ & 778946.010 & 22.105 & $\mathrm{~N}$ \\
\hline
\end{tabular}


Table 10: Adjusted Multiplexer Validation Resistor Values at $10 \mathrm{kHz}$

\begin{tabular}{|c|c|c|c|}
\hline Resistor Value (ohms) & $\begin{array}{l}\text { Measured Resistance } \\
\text { (ohms) }\end{array}$ & $\begin{array}{l}\text { Experimental Error } \\
\qquad(\%)\end{array}$ & $\begin{array}{c}\text { Within } 5 \% \text { Tolerance } \\
(\mathrm{Y} / \mathrm{N})\end{array}$ \\
\hline 1 & 0.902 & 9.767 & $\mathrm{~N}$ \\
\hline 1 & 0.989 & 1.067 & $\mathrm{Y}$ \\
\hline 1 & 0.993 & 0.667 & $\mathrm{Y}$ \\
\hline 10 & 9.895 & 1.053 & $\mathrm{Y}$ \\
\hline 10 & 9.793 & 2.073 & $\mathrm{Y}$ \\
\hline 10 & 9.875 & 1.253 & $\mathrm{Y}$ \\
\hline 100 & 98.696 & 1.304 & $\mathrm{Y}$ \\
\hline 100 & 99.219 & 0.781 & $\mathrm{Y}$ \\
\hline 100 & 99.674 & 0.326 & $\mathrm{Y}$ \\
\hline 1,000 & 982.190 & 1.781 & $\mathrm{Y}$ \\
\hline 1,000 & 973.126 & 2.687 & $\mathrm{Y}$ \\
\hline 1,000 & 973.421 & 2.658 & $\mathrm{Y}$ \\
\hline 10,000 & 9945.803 & 0.542 & $\mathrm{Y}$ \\
\hline 10,000 & 9852.997 & 1.470 & $\mathrm{Y}$ \\
\hline 10,000 & 10068.064 & 0.681 & $\mathrm{Y}$ \\
\hline 100,000 & 95902.467 & 4.098 & $\mathrm{Y}$ \\
\hline 100,000 & 95597.675 & 4.402 & $\mathrm{Y}$ \\
\hline 100,000 & 95683.207 & 4.317 & $\mathrm{Y}$ \\
\hline $1,000,000$ & 244610.593 & 75.539 & $\mathrm{~N}$ \\
\hline $1,000,000$ & 263550.992 & 73.645 & $\mathrm{~N}$ \\
\hline $1,000,000$ & 264127.630 & 73.587 & $\mathrm{~N}$ \\
\hline
\end{tabular}

The average intrinsic reactance values from Table 8 were subtracted from the multiplexer validation capacitor reactance data based on the frequency and electrode in which the data was recorded. The adjusted capacitor data recorded at 2 and $10 \mathrm{kHz}$ is shown in Table 11 and Table 12, respectively. The tables provide the face value of the capacitor, the adjusted reactance component of the measured impedance, the calculated capacitance and percent error, and whether the percent error falls within the allowable $10 \%$ tolerance range as specified by the manufacturer. 
Table 11: Adjusted Multiplexer Validation Capacitor Values at $2 \mathrm{kHz}$

\begin{tabular}{|r|r|r|r|c|}
\hline $\begin{array}{c}\text { Capacitor Value } \\
(\mathrm{F})\end{array}$ & $\begin{array}{c}\text { Measured } \\
\text { Reactance } \\
\text { (ohms) }\end{array}$ & $\begin{array}{c}\text { Calculated } \\
\text { Capacitance (F) }\end{array}$ & $\begin{array}{c}\text { Experimental } \\
\text { Error (\%) }\end{array}$ & $\begin{array}{c}\text { Within } \\
\text { Tolerance (Y/N) }\end{array}$ \\
\hline $1.00 \mathrm{E}-09$ & -71385.03 & $1.115 \mathrm{E}-09$ & 11.48 & $\mathrm{~N}$ \\
\hline $1.00 \mathrm{E}-09$ & -73654.41 & $1.080 \mathrm{E}-09$ & 8.04 & $\mathrm{Y}$ \\
\hline $1.00 \mathrm{E}-09$ & -71362.71 & $1.115 \mathrm{E}-09$ & 11.51 & $\mathrm{~N}$ \\
\hline $1.00 \mathrm{E}-08$ & -7497.88 & $1.061 \mathrm{E}-08$ & 6.13 & $\mathrm{Y}$ \\
\hline $1.00 \mathrm{E}-08$ & -7640.46 & $1.042 \mathrm{E}-08$ & 4.15 & $\mathrm{Y}$ \\
\hline $1.00 \mathrm{E}-08$ & -7662.36 & $1.039 \mathrm{E}-08$ & 3.86 & $\mathrm{Y}$ \\
\hline $1.00 \mathrm{E}-07$ & -761.33 & $1.045 \mathrm{E}-07$ & 4.52 & $\mathrm{Y}$ \\
\hline $1.00 \mathrm{E}-07$ & -766.57 & $1.038 \mathrm{E}-07$ & 3.81 & $\mathrm{Y}$ \\
\hline $1.00 \mathrm{E}-07$ & -688.00 & $1.157 \mathrm{E}-07$ & 15.66 & N \\
\hline $1.00 \mathrm{E}-06$ & -75.18 & $1.059 \mathrm{E}-06$ & 5.85 & $\mathrm{Y}$ \\
\hline $1.00 \mathrm{E}-06$ & -76.33 & $1.043 \mathrm{E}-06$ & 4.26 & $\mathrm{Y}$ \\
\hline $1.00 \mathrm{E}-06$ & -75.30 & $1.057 \mathrm{E}-06$ & 5.68 & $\mathrm{Y}$ \\
\hline $1.00 \mathrm{E}-05$ & -7.43 & $1.071 \mathrm{E}-05$ & 7.10 & $\mathrm{Y}$ \\
\hline $1.00 \mathrm{E}-05$ & -7.41 & $1.074 \mathrm{E}-05$ & 7.39 & $\mathrm{Y}$ \\
\hline $1.00 \mathrm{E}-05$ & -7.27 & $1.094 \mathrm{E}-05$ & 9.39 & $\mathrm{Y}$ \\
\hline
\end{tabular}

Table 12: Adjusted Multiplexer Validation Capacitor Values at $10 \mathrm{kHz}$

\begin{tabular}{|r|r|r|r|c|}
\hline $\begin{array}{c}\text { Capacitor Value } \\
(\mathrm{F})\end{array}$ & $\begin{array}{c}\text { Measured } \\
\text { Reactance } \\
\text { (ohms) }\end{array}$ & $\begin{array}{c}\text { Calculated } \\
\text { Capacitance (F) }\end{array}$ & $\begin{array}{c}\text { Experimental } \\
\text { Error (\%) }\end{array}$ & $\begin{array}{c}\text { Within } \\
\text { Tolerance (Y/N) }\end{array}$ \\
\hline $1.00 \mathrm{E}-09$ & -14404.20 & $1.105 \mathrm{E}-09$ & 10.49 & $\mathrm{~N}$ \\
\hline $1.00 \mathrm{E}-09$ & -14867.63 & $1.070 \mathrm{E}-09$ & 7.05 & $\mathrm{Y}$ \\
\hline $1.00 \mathrm{E}-09$ & -14417.19 & $1.104 \mathrm{E}-09$ & 10.39 & $\mathrm{~N}$ \\
\hline $1.00 \mathrm{E}-08$ & -1518.25 & $1.048 \mathrm{E}-08$ & 4.83 & $\mathrm{Y}$ \\
\hline $1.00 \mathrm{E}-08$ & -1545.79 & $1.030 \mathrm{E}-08$ & 2.96 & $\mathrm{Y}$ \\
\hline $1.00 \mathrm{E}-08$ & -1553.65 & $1.024 \mathrm{E}-08$ & 2.44 & $\mathrm{Y}$ \\
\hline $1.00 \mathrm{E}-07$ & -151.93 & $1.048 \mathrm{E}-07$ & 4.75 & $\mathrm{Y}$ \\
\hline $1.00 \mathrm{E}-07$ & -153.76 & $1.035 \mathrm{E}-07$ & 3.51 & $\mathrm{Y}$ \\
\hline $1.00 \mathrm{E}-07$ & -137.28 & $1.159 \mathrm{E}-07$ & 15.94 & N \\
\hline $1.00 \mathrm{E}-06$ & -15.01 & $1.061 \mathrm{E}-06$ & 6.07 & $\mathrm{Y}$ \\
\hline $1.00 \mathrm{E}-06$ & -15.21 & $1.046 \mathrm{E}-06$ & 4.64 & $\mathrm{Y}$ \\
\hline $1.00 \mathrm{E}-06$ & -14.98 & $1.062 \mathrm{E}-06$ & 6.23 & $\mathrm{Y}$ \\
\hline $1.00 \mathrm{E}-05$ & -1.49 & $1.070 \mathrm{E}-05$ & 6.96 & $\mathrm{Y}$ \\
\hline $1.00 \mathrm{E}-05$ & -1.48 & $1.072 \mathrm{E}-05$ & 7.22 & $\mathrm{Y}$ \\
\hline $1.00 \mathrm{E}-05$ & -1.46 & $1.090 \mathrm{E}-05$ & 8.96 & $\mathrm{Y}$ \\
\hline
\end{tabular}




\section{Device Validation Results}

Resistor and capacitor measurements from the device validation experiments suffered from the same high intrinsic impedance as the multiplexer validation experiments. This produced many measurements that were not within the allowable 5\% tolerance range. The data, provided in the Appendix for completeness, is removed from this section because of its resemblance to Table 7 . In post processing, the average intrinsic device impedance values were subtracted from the measured data to yield the actual measured impedance of the electrical component. Table 13 provides the average impedance, phase, resistance, and reactance of the device dependent on the electrode and frequency at which the data was recorded.

Table 13: Averaged Intrinsic Device Impedance Data

\begin{tabular}{|c|c|c|c|c|c|}
\hline $\begin{array}{l}\text { Frequency } \\
\qquad(\mathrm{Hz})\end{array}$ & $\begin{array}{c}\text { Average } \\
\text { Impedance } \\
\text { (ohms) }\end{array}$ & $\begin{array}{c}\text { Average } \\
\text { Phase }\end{array}$ & $\begin{array}{c}\text { Average } \\
\text { Resistance } \\
\text { (ohms) }\end{array}$ & $\begin{array}{c}\text { Average } \\
\text { Reactance } \\
\text { (ohms) }\end{array}$ & Electrodes \\
\hline 2000 & 63.913 & 0.397 & 63.912 & 0.443 & \multirow{2}{*}{0} \\
\hline 10000 & 64.207 & 2.458 & 64.148 & 2.754 & \\
\hline 2000 & 64.037 & 0.434 & 64.035 & 0.485 & \multirow{2}{*}{1} \\
\hline 10000 & 64.066 & 2.428 & 64.008 & 2.715 & \\
\hline 2000 & 64.052 & 0.431 & 64.050 & 0.481 & \multirow{2}{*}{2} \\
\hline 10000 & 64.080 & 2.424 & 64.023 & 2.711 & \\
\hline 2000 & 63.843 & 0.438 & 63.841 & 0.488 & \multirow{2}{*}{3} \\
\hline 10000 & 63.936 & 2.431 & 63.878 & 2.712 & \\
\hline 2000 & 63.695 & 0.435 & 63.693 & 0.484 & \multirow{2}{*}{4} \\
\hline 10000 & 63.719 & 2.438 & 63.662 & 2.711 & \\
\hline 2000 & 63.763 & 0.429 & 63.761 & 0.477 & \multirow{2}{*}{5} \\
\hline 10000 & 63.812 & 2.429 & 63.754 & 2.705 & \\
\hline 2000 & 63.624 & 0.441 & 63.622 & 0.489 & \multirow{2}{*}{6} \\
\hline 10000 & 63.707 & 2.436 & 63.649 & 2.707 & \\
\hline 2000 & 62.947 & 0.398 & 62.946 & 0.437 & \multirow{2}{*}{7} \\
\hline 10000 & 63.288 & 2.443 & 63.230 & 2.697 & \\
\hline
\end{tabular}


The average resistance values were subtracted from the measured resistance values based on the electrode and frequency at which the data was recorded. The adjusted resistance values for the device validation at 2 and $10 \mathrm{kHz}$ are shown in Table 14 and Table 15 , respectively. Column 1 provides the face value of the resistor in ohms. Column 2 is the resistance component of the measured impedance in ohms. The experimental error is calculated in column 3 based on the resistor face value. The final column shows whether the measured resistance falls within the allowable 5\% tolerance as specified by the manufacturer.

Table 14: Adjusted Device Validation Resistor Values at $2 \mathrm{kHz}$

\begin{tabular}{|c|c|c|c|}
\hline Resistor Value (ohms) & $\begin{array}{l}\text { Measured Resistance } \\
\text { (ohms) }\end{array}$ & $\begin{array}{c}\text { Experimental Error } \\
(\%)\end{array}$ & $\begin{array}{c}\text { Within } 5 \% \text { Tolerance } \\
(\mathrm{Y} / \mathrm{N})\end{array}$ \\
\hline 1 & 1.092 & 9.200 & $\mathrm{~N}$ \\
\hline 1 & 1.035 & 3.500 & $\mathrm{Y}$ \\
\hline 1 & 1.106 & 10.600 & $\mathrm{~N}$ \\
\hline 10 & 10.003 & 0.030 & $\mathrm{Y}$ \\
\hline 10 & 9.961 & 0.390 & $\mathrm{Y}$ \\
\hline 10 & 10.030 & 0.300 & $\mathrm{Y}$ \\
\hline 100 & 99.056 & 0.944 & $\mathrm{Y}$ \\
\hline 100 & 99.949 & 0.051 & $\mathrm{Y}$ \\
\hline 100 & 99.469 & 0.531 & $\mathrm{Y}$ \\
\hline 1,000 & 974.059 & 2.594 & $\mathrm{Y}$ \\
\hline 1,000 & 982.924 & 1.708 & $\mathrm{Y}$ \\
\hline 1,000 & 973.952 & 2.605 & $\mathrm{Y}$ \\
\hline 10,000 & 9954.849 & 0.452 & $\mathrm{Y}$ \\
\hline 10,000 & 10087.475 & 0.875 & $\mathrm{Y}$ \\
\hline 10,000 & 9870.341 & 1.297 & $\mathrm{Y}$ \\
\hline 100,000 & 99112.306 & 0.888 & $\mathrm{Y}$ \\
\hline 100,000 & 99225.581 & 0.774 & $\mathrm{Y}$ \\
\hline 100,000 & 98264.690 & 1.735 & $\mathrm{Y}$ \\
\hline $1,000,000$ & 801043.472 & 19.896 & $\mathrm{~N}$ \\
\hline $1,000,000$ & 791142.239 & 20.886 & $\mathrm{~N}$ \\
\hline $1,000,000$ & 792843.733 & 20.716 & $\mathrm{~N}$ \\
\hline
\end{tabular}


Table 15: Adjusted Device Validation Resistor Values at $10 \mathrm{kHz}$

\begin{tabular}{|c|c|c|c|}
\hline Resistor Value (ohms) & $\begin{array}{l}\text { Measured Resistance } \\
\text { (ohms) }\end{array}$ & $\begin{array}{l}\text { Experimental Error } \\
\qquad(\%)\end{array}$ & $\begin{array}{c}\text { Within } 5 \% \text { Tolerance } \\
(\mathrm{Y} / \mathrm{N})\end{array}$ \\
\hline 1 & 1.081 & 8.067 & $\mathrm{~N}$ \\
\hline 1 & 1.096 & 9.567 & $\mathrm{~N}$ \\
\hline 1 & 1.106 & 10.567 & $\mathrm{~N}$ \\
\hline 10 & 10.021 & 0.207 & $\mathrm{Y}$ \\
\hline 10 & 9.927 & 0.733 & $\mathrm{Y}$ \\
\hline 10 & 10.010 & 0.097 & $\mathrm{Y}$ \\
\hline 100 & 99.019 & 0.981 & $\mathrm{Y}$ \\
\hline 100 & 99.880 & 0.120 & $\mathrm{Y}$ \\
\hline 100 & 99.439 & 0.561 & $\mathrm{Y}$ \\
\hline 1,000 & 974.451 & 2.555 & $Y$ \\
\hline 1,000 & 983.397 & 1.660 & $\mathrm{Y}$ \\
\hline 1,000 & 974.145 & 2.586 & $\mathrm{Y}$ \\
\hline 10,000 & 9962.718 & 0.373 & $\mathrm{Y}$ \\
\hline 10,000 & 10096.420 & 0.964 & $\mathrm{Y}$ \\
\hline 10,000 & 9877.401 & 1.226 & $\mathrm{Y}$ \\
\hline 100,000 & 96582.834 & 3.417 & $\mathrm{Y}$ \\
\hline 100,000 & 96701.997 & 3.298 & $\mathrm{Y}$ \\
\hline 100,000 & 95849.491 & 4.151 & $\mathrm{Y}$ \\
\hline $1,000,000$ & 205745.569 & 79.425 & $\mathrm{~N}$ \\
\hline $1,000,000$ & 198722.483 & 80.128 & $\mathrm{~N}$ \\
\hline $1,000,000$ & 197578.106 & 80.242 & $\mathrm{~N}$ \\
\hline
\end{tabular}

The average intrinsic reactance values were subtracted from the measured capacitance data based on the electrode and frequency in which they were recorded. The adjusted capacitance values for the device validation at 2 and $10 \mathrm{kHz}$ are shown in Table 16 and Table 17, respectively. Column 1 provides the face value of the capacitor in Farads. Column 2 is the reactance component of the measured impedance in ohms. The capacitance in Farads is calculated in column 3 according to Equation 2. Column 4 is the calculated percent error and column 5 shows whether the measured capacitance falls within the allowable $10 \%$ tolerance as specified by the manufacturer. 
Table 16: Adjusted Device Validation Capacitor Values at $2 \mathrm{kHz}$

\begin{tabular}{|r|r|r|r|c|}
\hline $\begin{array}{c}\text { Capacitor Value } \\
(\mathrm{F})\end{array}$ & $\begin{array}{c}\text { Measured } \\
\text { Reactance (ohms) }\end{array}$ & $\begin{array}{c}\text { Calculated } \\
\text { Capacitance (F) }\end{array}$ & $\begin{array}{c}\text { Experimental } \\
\text { Error (\%) }\end{array}$ & $\begin{array}{c}\text { Within } \\
\text { Tolerance (Y/N) }\end{array}$ \\
\hline $1.00 \mathrm{E}-09$ & -73109.80567 & $1.08847 \mathrm{E}-09$ & 8.85 & $\mathrm{Y}$ \\
\hline $1.00 \mathrm{E}-09$ & -71493.74667 & $1.11307 \mathrm{E}-09$ & 11.31 & $\mathrm{~N}$ \\
\hline $1.00 \mathrm{E}-09$ & -70655.26267 & $1.12628 \mathrm{E}-09$ & 12.63 & $\mathrm{~N}$ \\
\hline $1.00 \mathrm{E}-08$ & -7492.967667 & $1.06203 \mathrm{E}-08$ & 6.20 & $\mathrm{Y}$ \\
\hline $1.00 \mathrm{E}-08$ & -7652.075667 & $1.03995 \mathrm{E}-08$ & 3.99 & $\mathrm{Y}$ \\
\hline $1.00 \mathrm{E}-08$ & -7645.348667 & $1.04086 \mathrm{E}-08$ & 4.09 & $\mathrm{Y}$ \\
\hline $1.00 \mathrm{E}-07$ & -761.7386667 & $1.04468 \mathrm{E}-07$ & 4.47 & $\mathrm{Y}$ \\
\hline $1.00 \mathrm{E}-07$ & -688.1126667 & $1.15646 \mathrm{E}-07$ & 15.65 & N \\
\hline $1.00 \mathrm{E}-07$ & -767.0526667 & $1.03744 \mathrm{E}-07$ & 3.74 & $\mathrm{Y}$ \\
\hline $1.00 \mathrm{E}-06$ & -76.44666667 & $1.04095 \mathrm{E}-06$ & 4.10 & $\mathrm{Y}$ \\
\hline $1.00 \mathrm{E}-06$ & -75.33566667 & $1.05631 \mathrm{E}-06$ & 5.63 & $\mathrm{Y}$ \\
\hline $1.00 \mathrm{E}-06$ & -75.30366667 & $1.05675 \mathrm{E}-06$ & 5.68 & $\mathrm{Y}$ \\
\hline $1.00 \mathrm{E}-05$ & -7.384666667 & $1.0776 \mathrm{E}-05$ & 7.76 & $\mathrm{Y}$ \\
\hline $1.00 \mathrm{E}-05$ & -7.409666667 & $1.07397 \mathrm{E}-05$ & 7.40 & $\mathrm{Y}$ \\
\hline $1.00 \mathrm{E}-05$ & -7.239666667 & $1.09919 \mathrm{E}-05$ & 9.92 & $\mathrm{Y}$ \\
\hline
\end{tabular}

Table 17: Adjusted Device Validation Capacitor Values at $10 \mathrm{kHz}$

\begin{tabular}{|r|r|r|r|c|}
\hline $\begin{array}{c}\text { Capacitor Value } \\
\text { (F) }\end{array}$ & $\begin{array}{c}\text { Measured } \\
\text { Reactance (ohms) }\end{array}$ & $\begin{array}{c}\text { Calculated } \\
\text { Capacitance (F) }\end{array}$ & $\begin{array}{c}\text { Experimental } \\
\text { Error }(\%)\end{array}$ & $\begin{array}{c}\text { Within } \\
\text { Tolerance (Y/N) }\end{array}$ \\
\hline $1.00 \mathrm{E}-09$ & -14847.90833 & $1.0719 \mathrm{E}-09$ & 7.19 & $\mathrm{Y}$ \\
\hline $1.00 \mathrm{E}-09$ & -14448.63633 & $1.10152 \mathrm{E}-09$ & 10.15 & N \\
\hline $1.00 \mathrm{E}-09$ & -14356.25333 & $1.10861 \mathrm{E}-09$ & 10.86 & N \\
\hline $1.00 \mathrm{E}-08$ & -1521.620333 & $1.04596 \mathrm{E}-08$ & 4.60 & $\mathrm{Y}$ \\
\hline $1.00 \mathrm{E}-08$ & -1556.505333 & $1.02251 \mathrm{E}-08$ & 2.25 & $\mathrm{Y}$ \\
\hline $1.00 \mathrm{E}-08$ & -1552.953333 & $1.02485 \mathrm{E}-08$ & 2.49 & $\mathrm{Y}$ \\
\hline $1.00 \mathrm{E}-07$ & -152.2203333 & $1.04556 \mathrm{E}-07$ & 4.56 & $\mathrm{Y}$ \\
\hline $1.00 \mathrm{E}-07$ & -137.6023333 & $1.15663 \mathrm{E}-07$ & 15.66 & N \\
\hline $1.00 \mathrm{E}-07$ & -154.4563333 & $1.03042 \mathrm{E}-07$ & 3.04 & $\mathrm{Y}$ \\
\hline $1.00 \mathrm{E}-06$ & -15.26433333 & $1.04266 \mathrm{E}-06$ & 4.27 & $\mathrm{Y}$ \\
\hline $1.00 \mathrm{E}-06$ & -15.02433333 & $1.05931 \mathrm{E}-06$ & 5.93 & $\mathrm{Y}$ \\
\hline $1.00 \mathrm{E}-06$ & -15.04733333 & $1.0577 \mathrm{E}-06$ & 5.77 & $\mathrm{Y}$ \\
\hline $1.00 \mathrm{E}-05$ & -1.494333333 & $1.06506 \mathrm{E}-05$ & 6.51 & $\mathrm{Y}$ \\
\hline $1.00 \mathrm{E}-05$ & -1.489333333 & $1.06863 \mathrm{E}-05$ & 6.86 & $\mathrm{Y}$ \\
\hline $1.00 \mathrm{E}-05$ & -1.464333333 & $1.08688 \mathrm{E}-05$ & 8.69 & $\mathrm{Y}$ \\
\hline
\end{tabular}




\section{Raw Chicken Results}

The program used for the chicken experiments output data labeled with the frequency, impedance, phase, resistance, reactance, and electrode number. The data obtained from the experiments on raw chicken meat and skin was transferred to Microsoft Excel where the location number, sample number, and tissue type/condition were added to the spreadsheet. This data was loaded in Minitab and all columns were separated according to frequency. Student's T-tests were performed comparing the impedance of raw chicken meat and raw chicken skin at 2 and $10 \mathrm{kHz}$. The test hypotheses were established as follows:

$$
\begin{aligned}
& H_{o}: \mu_{1}=\mu_{2} \\
& H_{A}: \mu_{1} \neq \mu_{2}
\end{aligned}
$$

where $\mu_{1}$ was the population mean impedance of raw meat and $\mu_{2}$ was the population mean impedance of raw skin. The p-values of 0.001 and 0.001 for the 2 and $10 \mathrm{kHz} t-$ tests, respectively, were less than the $\alpha$-value of 0.05 and the null hypothesis $\left(\mathrm{H}_{\mathrm{o}}\right)$ was rejected. This meant that the impedance values for raw chicken meat and raw chicken skin were statistically different. The Minitab t-test outputs for the 2 and $10 \mathrm{kHz}$ cases are located in Appendix D.

Since there were over 600 data points collected for raw chicken meat and skin, the data was depicted with a scatterplot. The scatterplots shown in Figure 22 and 23 graphed the raw chicken meat and skin data based on their resistance (x-axis) and reactance (yaxis) values. Both figures showed two separate linear trends for each group, although the separation between the groups was more prominent in the $10 \mathrm{kHz}$ plot. Also notice that the raw meat had a greater spread of data, which was shown by the standard deviation (StDev) in the t-test outputs in Appendix D. 


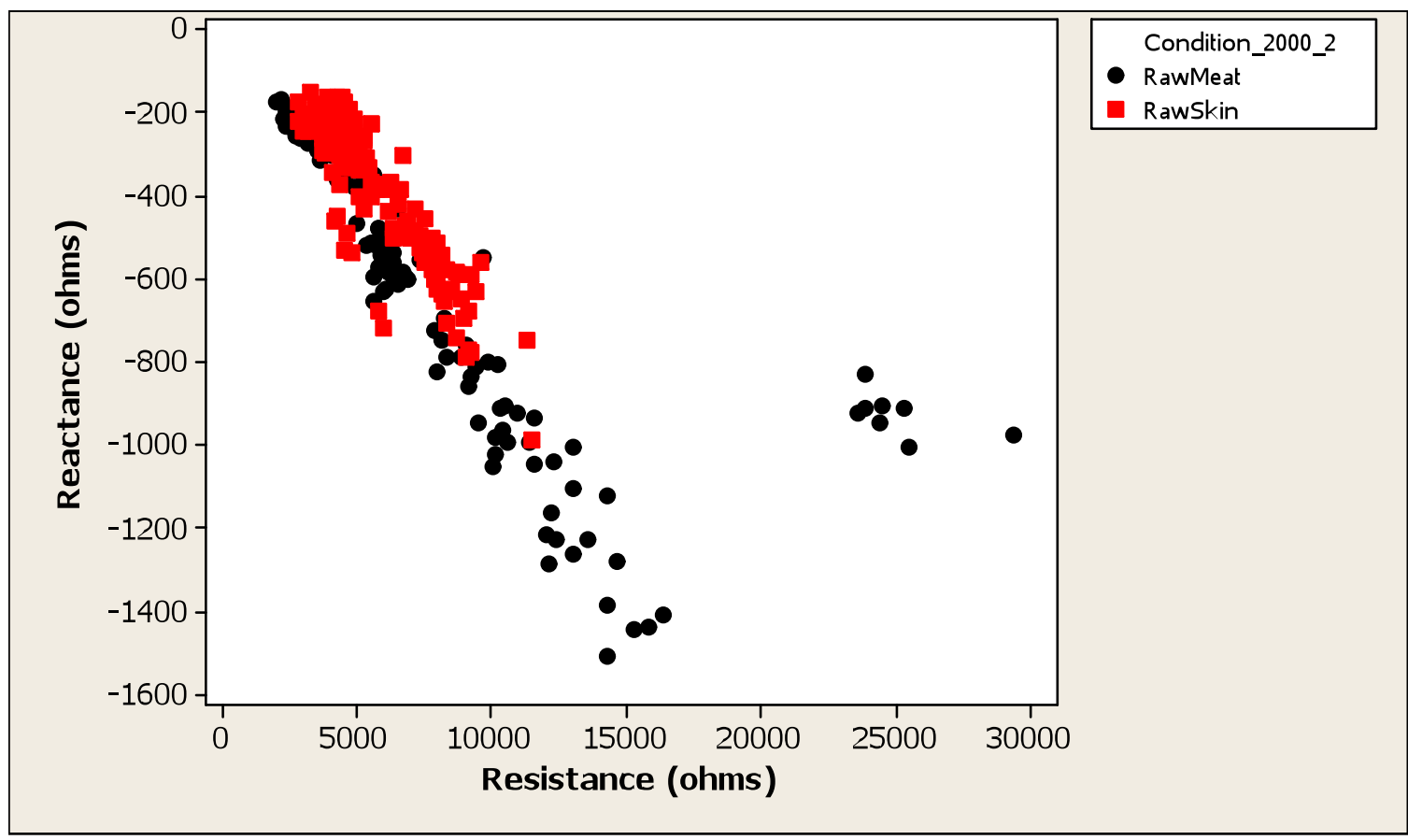

Figure 22: Scatterplot of Raw Chicken Skin and Meat at $2 \mathrm{kHz}$

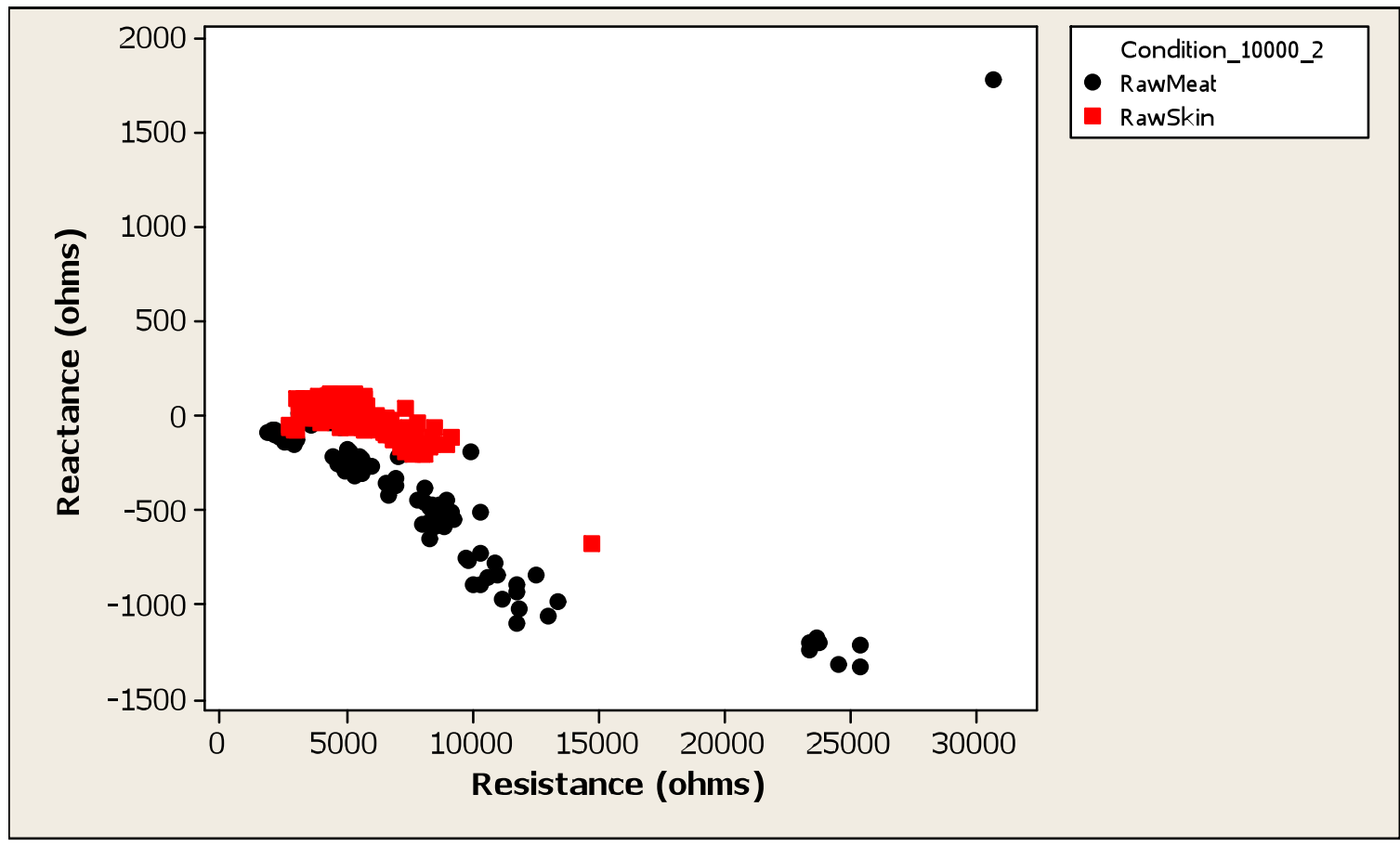

Figure 23: Scatterplot of Raw Chicken Skin and Meat at $10 \mathrm{kHz}$ 


\section{Cooked Chicken Results}

Impedance data obtained during experimentation on cooked chicken skin and meat were compared using a Student's t-test. The statistical hypotheses were as follows:

$$
\begin{aligned}
& H_{o}: \mu_{1}=\mu_{2} \\
& H_{A}: \mu_{1} \neq \mu_{2}
\end{aligned}
$$

where $\mu_{1}$ was the population mean impedance of cooked meat and $\mu_{2}$ was the population mean impedance of cooked skin. The p-values of 0.000 and 0.000 for the 2 and $10 \mathrm{kHz}$ tests, respectively, were less than the $\alpha$-value of 0.05 and the null hypothesis was rejected. We concluded that the population mean impedance of cooked meat was statistically different than that of cooked skin. The Minitab t-test outputs are provided in Appendix D.

Notice that the mean of the cooked skin at $2 \mathrm{kHz}$ was 1.8 Mega-ohms. As seen in the ELVIS, multiplexer, and device validation results, the 1 Mega-ohm resistor could not be correctly identified. The implications of this will be considered in the Discussion section. Figures 24 and 25 provide a visual representation of the cooked chicken meat and skin data by graphing their resistances and reactances. Since the cooked skin data was so large and scattered, it made the cooked meat data appear to be a single point. In actuality, all points more negative than a reactance of $-100,000$ ohms and larger than a resistance of 1 Mega-ohm could probably be considered an outlier because of the measurement limitations of the ELVIS system. However, even with those points removed, there was still a large enough separation between the cooked meat and cooked skin data to produce statistical significance. 


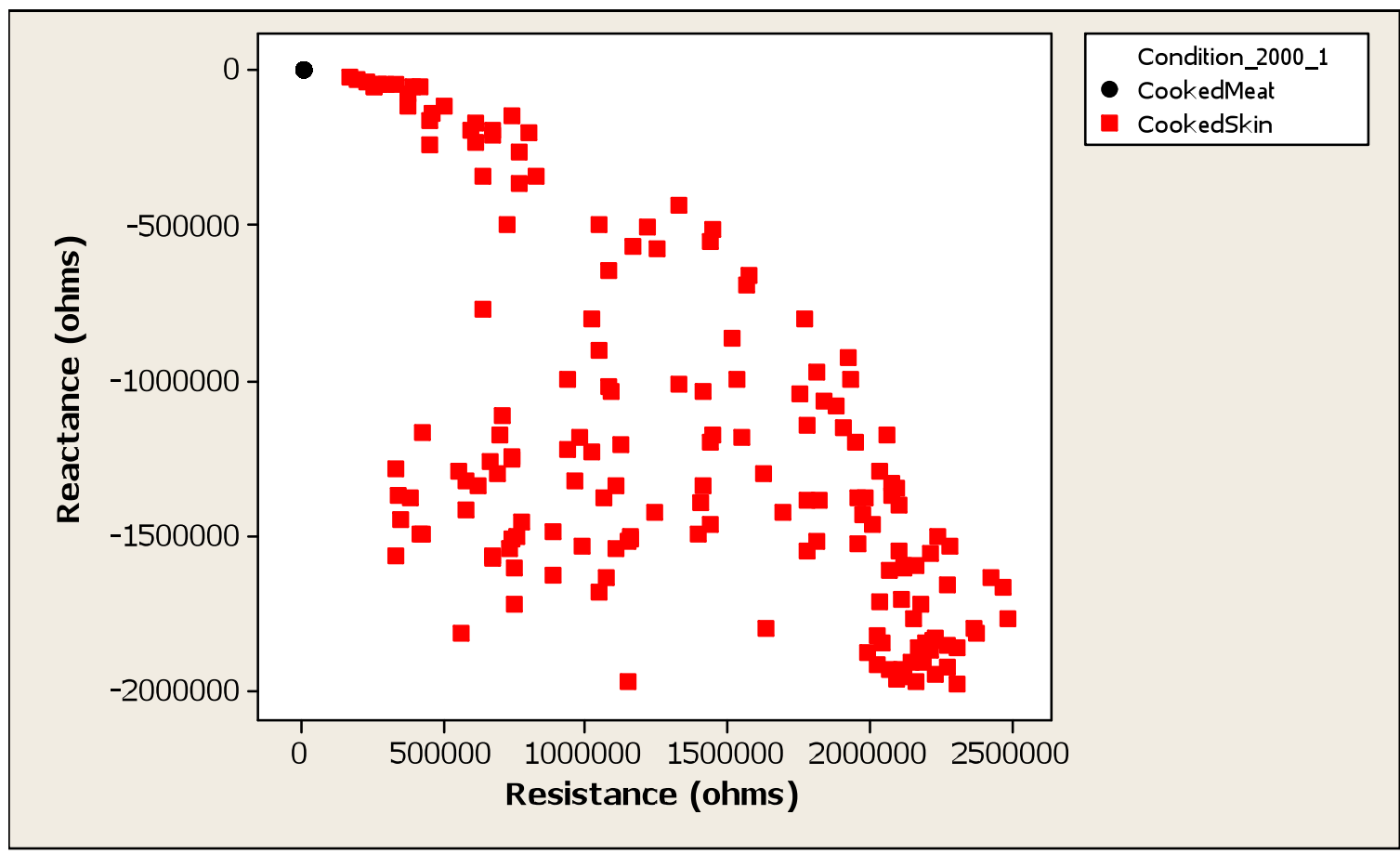

Figure 24: Scatterplot of Cooked Chicken Meat and Skin at $2 \mathrm{kHz}$

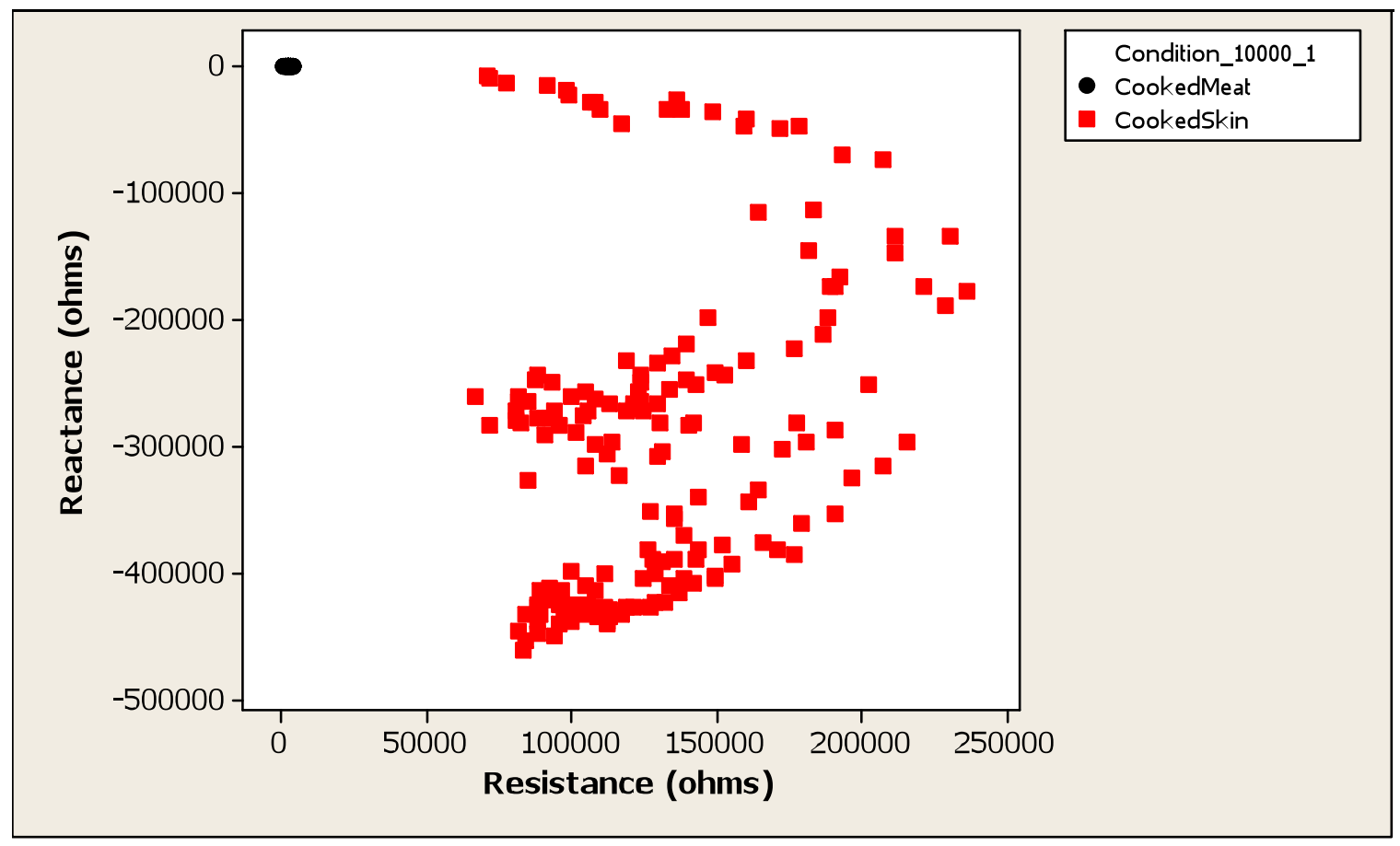

Figure 25: Scatterplot of Cooked Chicken Meat and Skin at $10 \mathrm{kHz}$ 


\section{Cooked Vs. Raw Chicken Results}

Cooked and raw chicken tissue data were compared to each other to see if the device could differentiate between the same tissues under different conditions (i.e. cooked meat vs. raw meat and cooked skin vs. raw skin). With multiple groups, two statistical approaches could be used, either one-way ANOVA or multiple regression models. One-way ANOVA analyses do not adjust the statistics based on the contributions from other parameters. For instance, the impedance data could be separated by frequency, but electrode number, location number, and other similar parameters could not be accounted for in the analysis. For this reason, a multiple regression model was employed.

For the multiple regression model, the frequency, electrode number, and tissue type/condition were used to predict the impedance of the tissue. The tissue type/condition was assigned as an adjusted categorical predictor, meaning that the $\beta$-values produced for the categorical predictor represented the estimated average change when moving from one group - the reference group - to another group. A $\beta$-value and a p-value were produced in the Minitab multiple regression output. The p-value was the statistical value that determines which of the following hypotheses is true:

$$
\begin{aligned}
& H_{o}: \beta_{x}=0 \\
& H_{A}: \beta_{x} \neq 0
\end{aligned}
$$

where the subscript $\mathrm{x}$ denoted a positive integer corresponding to the parameter number in the model. The Minitab multiple regression output for all chicken tissue types is shown in Appendix D.

With the reference group automatically assigned to the cooked meat, the p-values tested for a statistical difference of the cooked skin, raw meat, and raw skin groups against the cooked meat group. The corresponding p-values for the cooked skin, raw 
meat, and raw skin groups were $0.000,0.360$, and 0.533 , respectively. The only p-value less than the $\alpha$-value of 0.05 was the cooked skin group. This means that the population mean impedance of cooked skin was significantly different from the population mean impedance of cooked meat adjusting for all other variables. However, looking at the "Analysis of Variance" section in the Minitab output above, the p-value for the Lack-ofFit test was 0.000 . The Lack-of-Fit test used a null hypothesis $\left(\mathrm{H}_{\mathrm{o}}\right)$ that a linear model was the best choice and an alternative hypothesis $\left(\mathrm{H}_{\mathrm{A}}\right)$ that a non-linear model was the best choice. Since the Lack-of-Fit p-value was less than the $\alpha$-value of 0.05 , the null hypothesis was rejected and a non-linear model was determined to be better.

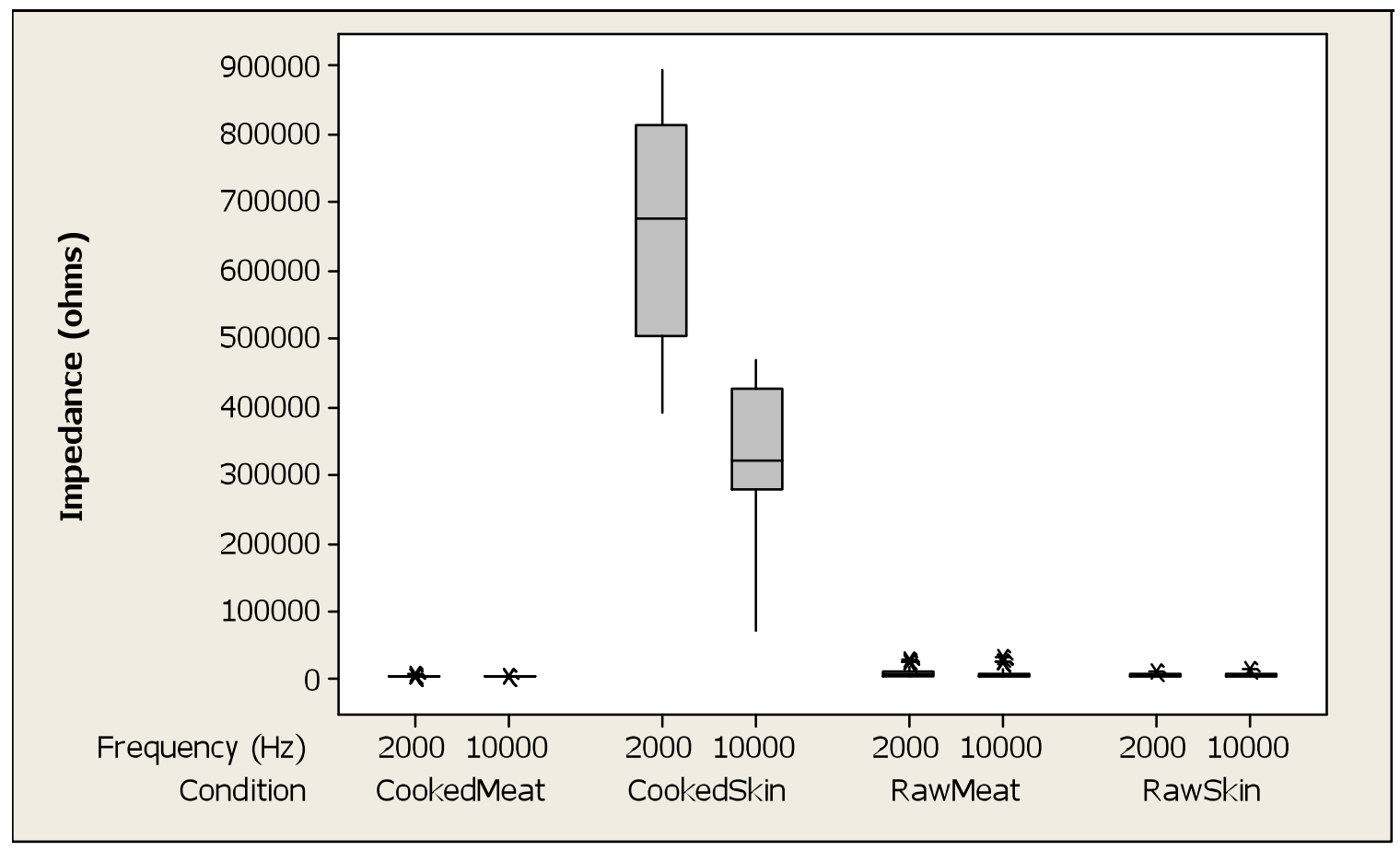

Figure 26: Boxplot of Chicken Tissue Impedance

The lack of significance of the data and the conclusion that a non-linear model was better could result from the high leverage that the cooked skin data had on the rest of the data. Leverage refers to the characteristic of the cooked skin impedance to obscure 
the statistical significance of the other data because of its large values. Figure 26 shows a boxplot of the impedance for each tissue type/condition and frequency. A boxplot shows the minimum value, the end of the bottom line; the lower quartile, the bottom horizontal line; the median, the middle horizontal line; the upper quartile, the upper horizontal line; and the maximum value, the end of the top line, for each group. This figure depicts the leverage of the cooked skin data and the issue with the current multiple regression model. For this reason, the cooked skin data was removed from the analysis and the multiple regression model was conducted again.

The new multiple regression model used frequency, electrode number, and the cooked meat, raw meat, and raw skin to predict the impedance. The Minitab output of this model is located in Appendix $D$. With a cooked meat reference group, the p-values for the raw meat and raw skin groups were 0.000 and 0.000 . Both of the p-values were less than the $\alpha$-value of 0.05 . Thus, the null hypothesis was rejected and it was concluded that the population mean impedance of the raw meat and raw skin were significantly different than the population mean impedance of the cooked meat group adjusting for all other variables. The frequency and electrode number $\mathrm{p}$-values were 0.027 and 0.582 , respectively. From this data, we concluded that the average impedance from data acquired at $2 \mathrm{kHz}$ was significantly different from that acquired at $10 \mathrm{kHz}$ and that the electrode in which the measurements were recorded had no significant effect on the impedance measured. Furthermore, the Lack-of-Fit p-value was 1.000 indicating that a linear model was a good choice for the data. A boxplot of the impedance values for cooked meat, raw meat, and raw skin and both frequencies is shown in Figure 27. 
Differences in the median value and scatter of data for each group was more easily identified when the large cooked chicken skin values were eliminated.

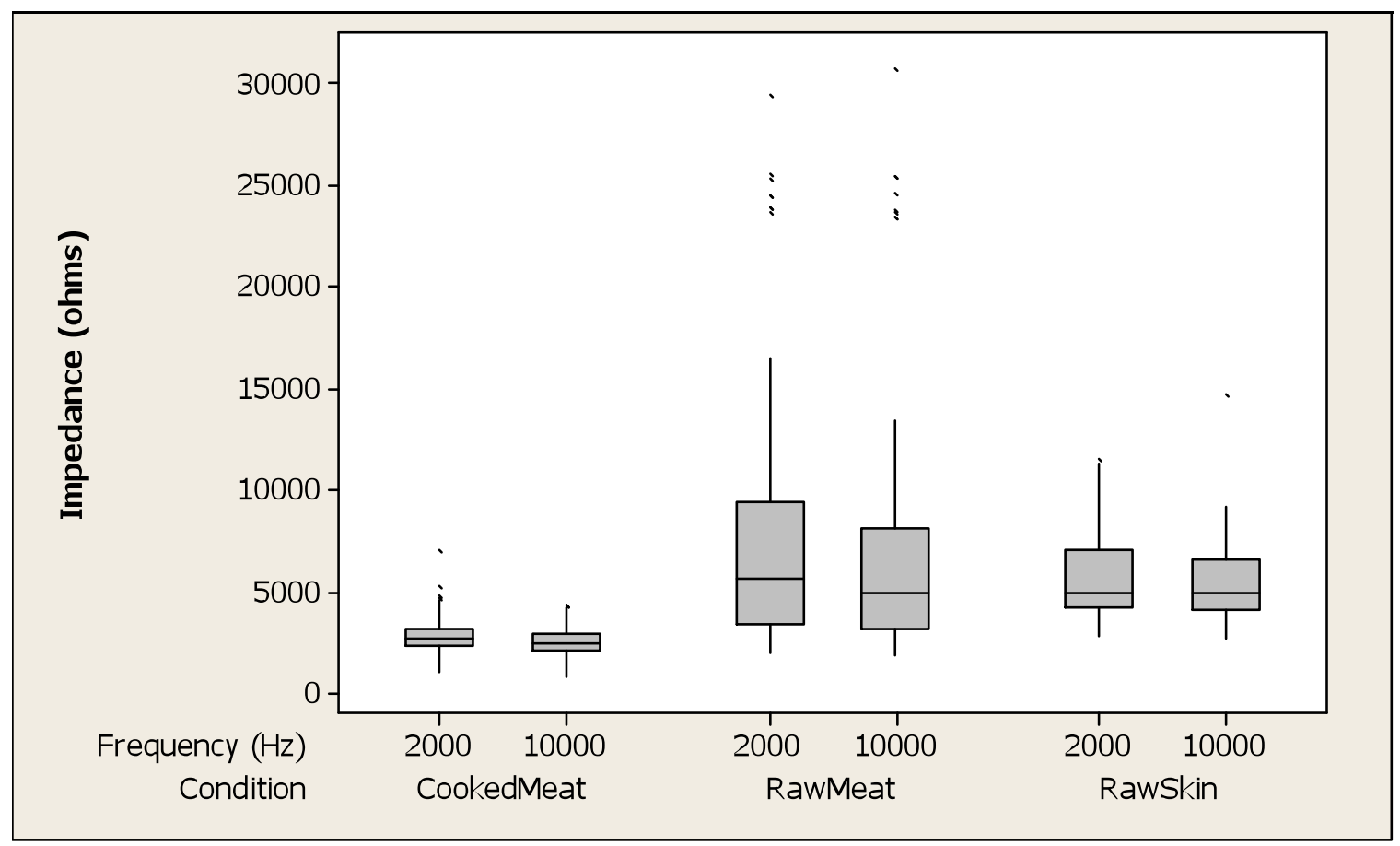

Figure 27: Boxplot of Chicken Tissue Impedances - Excluding Cooked Skin

The mean impedance values for cooked meat, cooked skin, raw meat, and raw skin at $2 \mathrm{kHz}$ were 2788.6,657110, 7130, and 5583, ohms respectively. The mean impedance values at $10 \mathrm{kHz}$ were 2596.5, 330041, 6347, and $5278 \mathrm{ohms}$, respectively. From the mean impedance results, chicken skin increased in impedance when cooked, while chicken meat decreased in impedance. In the raw state, chicken meat had higher impedance than the chicken skin. In addition, testing at $10 \mathrm{kHz}$ yielded smaller impedance values than testing at $2 \mathrm{kHz}$.

\section{Tissue Engineered Skin Analogue Results}

When compiling the data for the tissue engineered skin analogues, all impedance values greater than 1 Mega-ohm were deleted because of the measurement limitations of 
ELVIS at such high values. Like the chicken tissue data, the skin analogue data was labeled with frequency, impedance, phase, resistance, reactance, and electrode number by the program. After transferring the data to Minitab, the sample number and sample type parameters were added. A multiple regression model using frequency, electrode number, and tissue type (i.e. Epiderm ${ }^{\mathrm{TM}}$ or Melanoma) to predict the impedance was employed for the statistical analysis. The Minitab multiple regression model is shown in Appendix D.

With an Epiderm ${ }^{\mathrm{TM}}$ reference group, the p-value for Melanoma was 0.058. While close, the p-value was not less than the $\alpha$-value of 0.05 . Thus, the null hypothesis - that the Epiderm ${ }^{\mathrm{TM}}$ and Melanoma population mean impedances were equal - was retained. Furthermore, the Lack-of-Fit p-value was 0.998, which was greater than the $\alpha$-value of 0.05. Therefore, a linear model was the best choice for this data. Two alternatives, namely compiling the data independent of frequency and removing outliers, were conducted.

Reviewing the Minitab multiple regression output above, the p-values for the frequency and electrode number were greater than the $\alpha$-value of 0.05 . This means that the impedance values did not statistically differ from each other based on the frequency and electrode number. Since the frequency did not produce statistical differences, data from both frequencies were combined into one group. A Student's t-test was performed on the integrated frequency data comparing the population mean impedance of Epiderm $^{\mathrm{TM}}$ and Melanoma. The Minitab t-test output is shown in Appendix D.

The t-test p-value was 0.048 , which was less than the $\alpha$-value of 0.05 . Thus, the null hypothesis that the population mean impedance of Epiderm ${ }^{\mathrm{TM}}$ equaled the population mean impedance of Melanoma was rejected; there was a statistical difference between 
impedance values from Melanoma and Epiderm ${ }^{\mathrm{TM}}$. A boxplot depicting the impedance values of Epiderm ${ }^{\mathrm{TM}}$ and Melanoma is shown in Figure 28. Notice that the Epiderm ${ }^{\mathrm{TM}}$ data had a small deviation from the median compared to the wide scatter of the Melanoma data.

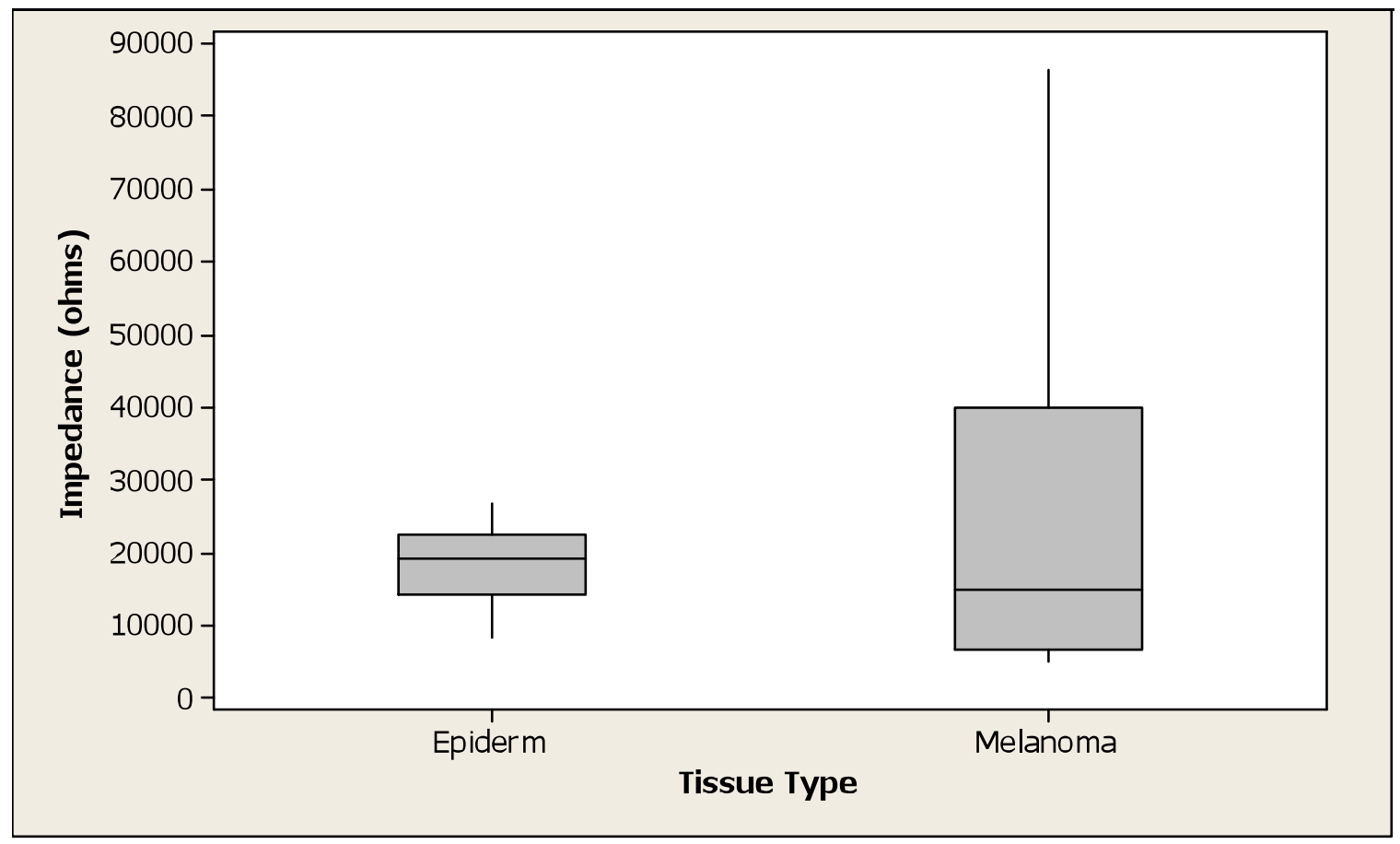

Figure 28: Boxplot of Tissue Engineered Skin Analogues

The second alternative that involved removing outliers was valid due to the condition of the tissue. The tissue samples were previously used by other members for other experiments and then frozen for two years until their use in this thesis. Furthermore, the stage of melanoma, as far as growth time, was unknown for the samples because of improper labeling by previous students. The different stages of melanoma, mainly horizontal or vertical growth phases, could have either increased or decreased the number of cancerous cells linearly between two electrodes, respectively. These various environmental unknowns may have lead to variations and errors in the data. For these reasons, 13 outliers, as predicted by Minitab, were removed from the data. A multiple 
regression model using frequency, electrode number and tissue type to predict the impedance was employed. The Minitab multiple regression output is provided in Appendix D.

With an Epiderm ${ }^{\mathrm{TM}}$ reference group, the p-value for Melanoma was 0.022, which was less than the $\alpha$-value of 0.05 . The null hypothesis that the population mean impedance of Epiderm ${ }^{\mathrm{TM}}$ was equal to the population mean impedance of Melanoma was rejected. Therefore, there was a statistical difference between the impedance values of the two groups. Furthermore, the Lack-of-Fit p-value was 0.8989 , which was larger than the $\alpha$-value of 0.05 . The null hypothesis that a linear model was sufficient was retained. The average impedance for Epiderm ${ }^{\mathrm{TM}}$ and Melanoma tissue samples at $2 \mathrm{kHz}$ were 19,469 and 24,276 ohms, respectively. The average impedance for Epiderm ${ }^{\mathrm{TM}}$ and Melanoma tissue samples at $10 \mathrm{kHz}$ were 16,628 and $23,407 \mathrm{ohms}$, respectively. The average impedance of the Melanoma tissue samples was larger than that of the Epiderm ${ }^{\mathrm{TM}}$ samples. 


\section{Discussion}

A discussion of the results and conclusions made in the previous section will be presented here. Where appropriate, the discussion will reference the overall hypothesis of this thesis - that melanoma skin cancer can be differentiated from normal epidermis tissue through impedance measurements by a multi-electrode device.

\section{Device Design Discussion}

The device design was described in the Methods section under the Electrode Device subtitle. Overall, the design worked well for the 9-electrode arrangement in that the majority of electrodes were fixed in place, breaking of the electrodes rarely occurred, and the assembly was uncomplicated. However, a few issues occurred during the duration of experiments. Firstly, the tolerances of the $\mathrm{Ag} / \mathrm{AgCl}$ electrodes from Warner Instruments were very loose. All electrodes had approximately the same length, but varying diameters of $\mathrm{AgCl}$ due to varying manufacturing and quality control. This created some issues when placing the electrodes through the electrode holder openings. Larger diameter electrodes were difficult to fit through the electrode holder and would stop short of the electrode ridge developed into the design; this created electrodes that protruded further from the device face than other electrodes and could have created differences in impedance measurements due to dissimilar pressures on the electrode tips. To correct the issue, some of the $\mathrm{AgCl}$ was gently trimmed by Kelly forceps. Smaller diameter electrodes reached the electrode ridge, but were too small to feel the effects of the vice mechanism. This resulted in free motion into and out of the electrode holder face and could have created varying pressure on the electrode tips. While only occurring to 
one electrode, the free movement was corrected by applying a small amount of epoxy to the electrode and electrode holder.

Other issues with the $\mathrm{Ag} / \mathrm{AgCl}$ electrodes were related to their cost and fragility. Each electrode was approximately $\$ 25.00$, which if mass-produced would be an exceptional expense. Furthermore, the fragility of the electrodes created difficulties in placing them within the electrode holder, soldering them to wires without inflicting damage, and testing various tissues and electrical components without bending or breaking the tips. These specific electrodes were chosen for this thesis mainly for continuity with a previous student's thesis. However, if this project was continued, the $\mathrm{Ag} / \mathrm{AgCl}$ electrodes could be cheaply manufactured by purchasing silver wire and either soaking it in household bleach or applying a current to it while in $\mathrm{NaCl}$ or $\mathrm{KCl}$ solution [38]. In addition, gold or $\mathrm{Ag} / \mathrm{AgCl}$ microelectrodes could be produced through wafer fabrication methods. This will be discussed in more detail in the Future Work section.

\section{ELVIS Validation Discussion}

The data presented in Tables 3 through 6 comprise the ELVIS validation results. The resistor and capacitor values that could be identified by the ELVIS system to within the $5 \%$ tolerance range provided by the manufacturer comprised the reliable range of the ELVIS system. Any resistance and reactance value from the chicken tissues or skin analogues that fell within this reliable range could be considered reliable as well. From the data, values of resistors from 100 ohms to $100 \mathrm{k}$-ohms could be successfully identified to within the $5 \%$ tolerance range provided by the manufacturer at both frequencies. The $1 \mathrm{M}$-ohm resistor could be successfully measured by the ELVIS system at $2 \mathrm{kHz}$ only. With such a high resistor value, it was possible that the injection of 
surrounding electrical noise from nearby lights and other electronics disturbed the impedance analyzer algorithm. At $10 \mathrm{kHz}$ the algorithm could have a more difficult time filtering the noise and establishing the amplitude and phase of the signal, resulting in an incorrect resistance reading.

For the ELVIS capacitor results, values from $1 \mathrm{nF}$ to $1 \mathrm{uF}$ could be reliably measured with the ELVIS system at $2 \mathrm{kHz}$ to within the $10 \%$ tolerance range provided by the manufacturer. The $1 \mathrm{nF}$ value was included, because the reactance value was reliably recorded $66.7 \%$ of the time, with the wrongfully identified value at the cusp of the $10 \%$ boundary. At $10 \mathrm{kHz}$, the ELVIS system reliably identified the capacitance of values from $1 \mathrm{nF}$ to $0.1 \mathrm{uF}$ to within the $10 \%$ tolerance range provided by the manufacturer. These capacitor values correlated to reactance measurements from approximately $-80,000$ to $-80 \mathrm{ohms}$ and $-15,000$ to $-150 \mathrm{ohms}$ for the 2 and $10 \mathrm{kHz}$ cases, respectively.

In regards to Glenn Stante's thesis, his recorded resistance values for chicken tissues and tissue engineered skin analogues at $10 \mathrm{kHz}$ ranged from 1 to $50 \mathrm{k}$-ohms and 1 to $40 \mathrm{k}$-ohms, respectively. These values all fell within the reliable resistor range of 100 ohms to $100 \mathrm{k}$-ohms from this thesis project. Thus, it is likely that future chicken tissue and skin analogue resistance measurements will fall within the reliable resistor range as well. Stante's recorded reactance values for chicken tissues and tissue engineered skin analogues at $10 \mathrm{kHz}$ ranged from $-12 \mathrm{ohms}$ to $-5.5 \mathrm{k}$-ohms and $-100 \mathrm{ohms}$ to $-14 \mathrm{k}$-ohms, respectively [18]. Although all of the values did not fall between the $-15,000$ to $-150 \mathrm{ohm}$ range as determined by this thesis' ELVIS validation, several things could occur that warrant continuation of the experiment. Firstly, the addition of the multiplexer and device may alter the measurement capabilities of the ELVIS system, bringing the predicted 
chicken tissue and skin analogue reactances within the correct range. Secondly, the ELVIS system could be inherently different from the ELVIS system used during Glenn Stante's thesis. That is, the DC offset or hardware calibration could differ between ELVIS systems. Thus, the reactances measured from chicken tissues and skin analogues may still be within the tolerable range of the ELVIS system used for this thesis.

This validation established a range of resistance and capacitance values that could be reliably identified by the ELVIS system. While data from Stante's thesis did not completely coincide with this range, additional validations may prove otherwise.

\section{Multiplexer Validation Discussion}

As discussed briefly in the Methods section under the Multiplexer Validation subtitle, multiplexers inherently add impedance to the circuit. The effects of the added impedance in an application in which the accuracy of the impedance is crucial can be seen in Table 7, which shows a reduced ability to identify the resistors and capacitors correctly. Without any post-processing, the measurement capabilities of the ELVIS system are reduced so that only 1 to $100 \mathrm{k}$-ohm resistors can be reliably measured at 2 $\mathrm{kHz}$. Similar reductions in measurement capabilities are also shown with resistors at 10 $\mathrm{kHz}$ and capacitors at 2 and $10 \mathrm{kHz}$.

Since impedances in series are added together to get the total impedance, and the impedances of the entire measurement system and specimen are in series, the average intrinsic impedance can be subtracted from the raw measurement data based on Equation 10 to produce the impedance of the specimen (i.e. resistor, capacitor, chicken, etc) itself.

Equation 10: Impedance Components in Series

$$
Z_{\text {Total }}=Z_{1}+Z_{2}+\ldots Z_{n}
$$


where $\mathrm{n}$ is a positive integer. Interestingly enough, the measurement capabilities of the ELVIS system improved. Tables 9 through 12 summarize the multiplexer validation data after adjusting for the intrinsic impedance. At 2 and $10 \mathrm{kHz}$, resistors valued from 10 ohms to $100 \mathrm{k}$-ohms were identified correctly to within the $5 \%$ tolerance range provided by the manufacturer. Even though three 1-ohm resistors were correctly identified between the 2 and $10 \mathrm{kHz}$ tests, the other experimental errors of the 1-ohm resistors were beyond the acceptable range. Thus, the 1-ohm value was not included in the range of resistors that can be reliably measured by the ELVIS system.

After analyzing the adjusted capacitor data, it was concluded that capacitor values from $10 \mathrm{nF}$ to $10 \mathrm{uF}$ could be identified to within the $10 \%$ tolerance range for the 2 and $10 \mathrm{kHz}$ tests. Looking at the data in detail, one gross outlier could be seen - the third 0.1 $\mathrm{uF}$ capacitor. This value was so much greater than surrounding data, and given the other two correctly identified $0.1 \mathrm{uF}$ capacitors, it was likely that a manufacturing or packaging error occurred. The correctly identified capacitor values correspond to reactance values of $-7,500$ to -7 ohms and $-1,500$ to -1.5 ohms for the 2 and $10 \mathrm{kHz}$ cases, respectively. Also take note that the experimental errors of the 1-nF capacitors were on the cusp of the $10 \%$ tolerance boundary. Since the reactance values corresponding to the $1 \mathrm{nF}$ and $10 \mathrm{nF}$ capacitors were $-15,000$ and $-1,500$ ohms, respectively, it is likely that many reactance values in-between were within the $10 \%$ tolerance range.

Adding the multiplexer changes the range of resistance and capacitance values that can be reliably identified by the ELVIS system to within the tolerance provided by the manufacturer. The device validation must be examined to determine the range of resistance and capacitance values for the entire system. 


\section{Device Validation Discussion}

The addition of the device to the ELVIS and multiplexer system can create further impedance errors with poor solder connections, extra wires, and/or electrode-tissue interfaces. After running the validation experiments with the device, it was discovered that high intrinsic impedances reduced the measurement capabilities of the ELVIS system. However, after filtering out the average intrinsic impedance, the measurement capabilities of the ELVIS system were enhanced. This effect, similar to what occurred in the multiplexer validation, derives from the high accuracy, but narrow range of the ELVIS system. For instance, the 10-ohm resistor could not be properly identified by the ELVIS system alone. However, adding the multiplexer and device raised the impedance to approximately $74 \mathrm{ohms}$ ( $10 \mathrm{ohms}+$ intrinsic resistance of approximately $64 \mathrm{ohms}$ ).

The intrinsic resistance raised the value of the 10 -ohm resistor to within the measurement range of the ELVIS system. The intrinsic impedance alone was also high enough to be within the measurement range of the ELVIS system. With the high accuracy of the ELVIS system within an acceptable measurement range, it reliably recorded the values of the intrinsic resistance and combined resistance. These values, once subtracted from one another, reliably identified the 10-ohm resistor. The characteristics of the ELVIS system, multiplexer, and device allowed for measurement of values outside of the ELVIS system range.

The data gathered during the device validation is summarized in Tables 13 through 17. At 2 and $10 \mathrm{kHz}$, resistor values from $10 \mathrm{ohms}$ to $100 \mathrm{k}$-ohms were reliably identified by the ELVIS system to within the 5\% acceptable tolerance range provided by the manufacturer. This range encompassed all of the values recorded by Glenn Stante 
during his investigations with chicken tissue and tissue engineered skin analogues. Again, these values were 1 to $50 \mathrm{k}$-ohms and 1 to $40 \mathrm{k}$-ohms for the chicken tissues and skin analogues, respectively.

The results from the capacitor data indicated that values from $10 \mathrm{nF}$ to $10 \mathrm{uF}$ could be reliably identified to within the $10 \%$ tolerance range provided by the manufacturer. With the same set of resistors and capacitors used in the multiplexer and device validations, the same outlier was present (second $0.1 \mathrm{uF}$ capacitor). Similar to the multiplexer validation, the experimental errors for the 1-nF capacitors were on the cusp of the $10 \%$ tolerance boundary. With a wide margin of reactance values between the 1 $\mathrm{nF}$ and $10 \mathrm{nF}$ capacitors, it was likely that many values in-between fell within the $10 \%$ acceptable tolerance range. The reactance value ranges of correctly identified capacitors were $-7,500$ to $-7 \mathrm{ohms}$ and $-1,500$ to $-1.5 \mathrm{ohms}$ for the 2 and $10 \mathrm{kHz}$ cases, respectively. Considering Glenn Stante's recorded reactance values at $10 \mathrm{kHz}$ that ranged from -12 ohms to $-14 \mathrm{k}$-ohms, there was a region from -1.5 to $-14 \mathrm{k}$-ohms that would be measured incorrectly. However, the values of chicken tissues and skin analogues depended on the specific ELVIS system and measurement electrodes used. Thus, further investigation into the impedances of the chicken tissues and skin analogues must be conducted.

Adding the electrode device did not change the intrinsic impedance greatly. The range of resistance and capacitance values that can be reliably identified by the ELVIS system are identical to that of the multiplexer validation. While Stante's results do not directly coincide with this range, the results from this thesis may. 


\section{Raw Chicken Discussion}

The results from experimentation on raw chicken tissues are shown in Figures 22 and 23. By looking at the scatterplots, one can see a separation of the black and red dots more prominently in the $10 \mathrm{kHz}$ plot. The visual separations of data between the raw chicken meat and raw chicken skin serve as a preliminary test for a statistical difference. To ensure that a statistical difference is actually present, the t-test results were analyzed. With p-values for both the 2 and $10 \mathrm{kHz}$ tests less than the $\alpha$-value of 0.05 , the null hypothesis was rejected. Therefore, the population mean impedance of the raw chicken meat and raw chicken skin groups were statistically different.

The average raw chicken meat and raw chicken skin impedances at $2 \mathrm{kHz}$ were 7,130 and 5,583 ohms, respectively. The average raw chicken meat and raw chicken skin impedances at $10 \mathrm{kHz}$ were 6,347 and 5,278 ohms, respectively. At both frequencies, the average raw chicken meat impedance was larger than that of raw chicken skin. Given that skin and meat cells were both structurally and physiologically different, differences in impedance were expected.

The ranges of resistance values for raw chicken meat and raw chicken skin at 2 $\mathrm{kHz}$ were 1,962 to 29,396 and 2,793 to 11,464 ohms, respectively. The ranges of resistance values for raw chicken meat and raw chicken skin at $10 \mathrm{kHz}$ were 1,855 to 30,671 and 2,696 to 14,705 ohms, respectively. All ranges of measured resistance values fell between the 10 -ohm to $100 \mathrm{k}-\mathrm{ohm}$ range from the device validation. Thus, all resistances values for raw chicken meat and skin could be considered reliable.

The ranges of reactance values for raw chicken meat and raw chicken skin at 2 $\mathrm{kHz}$ were $-1,509$ to -167 and -989 to -149 ohms, respectively. The ranges of reactance 
values for raw chicken meat and raw chicken skin at $10 \mathrm{kHz}$ were $-1,338$ to 1,786 and -681 to $117 \mathrm{ohms}$, respectively. All of the $2 \mathrm{kHz}$ reactance values fell between the $-7,500$ to $-7 \mathrm{ohm}$ range determined during the device validation. At $10 \mathrm{kHz}$, some values were found outside of the device validation range of $-1,500$ to -1.5 ohms. For raw meat at 10 $\mathrm{kHz}$, there were approximately 15 of 320 measurements that were outside the reactance range. Since only a few measurements were outside this range, the reactance data for raw meat at $10 \mathrm{kHz}$ was determined to be reliable. For raw skin at $10 \mathrm{kHz}$, approximately one quarter of the reactance values were outside the device validation range. These values tended to be close to zero and mainly recorded on one of the two chicken samples. Since these values, while positive, were close to zero, relatively close to the other reactance data for raw skin, and were not adjusted for the intrinsic impedance of the system, they were taken to be reliable.

With all of the resistance measurements and the majority of the reactance measurements falling in the reliable range of the ELVIS system as determined by the device validation results, the impedance values for raw chicken tissues were considered reliable. Therefore, the electrode device and measurement system are capable of discerning differences in tissues in multiple directions based on impedance.

\section{Cooked Chicken Discussion}

The data obtained from the cooked chicken experimentation is depicted in Figures 24 and 25. Visually, one can see a clear separation between the cooked chicken meat and cooked chicken skin data. Statistically, the t-test p-values comparing cooked meat and cooked skin at 2 and $10 \mathrm{kHz}$ were less than the $\alpha$-value of 0.05 . The null hypothesis was rejected and the two groups were determined to be statistically different from each other. 
However, a few issues arose during the experimentation on cooked skin. Firstly, after cooking the chicken, the skin became stiff and detached from the chicken meat in many locations. If the skin was not touching the meat during experimentation, the measured impedance would resemble that of an open circuit - approximately 2 M-ohms or greater. To correct the issue, the device was actuated until the electrodes pressed the skin against the meat. Secondly, even with the skin against the meat, the majority of measured impedance values exceeded the allowable range as determined by the device validation. Thus, the impedance values for cooked chicken skin could not be reliably measured with the device and measurement system used in this thesis. However, regardless of the actual impedance values of cooked chicken skin, they were extremely large compared to other groups and could most likely by differentiated from the cooked chicken meat.

The ranges of resistance for the cooked meat and cooked skin at $2 \mathrm{kHz}$ were 985 to 6,959 and 170,921 to $2,494,270$ ohms, respectively. The ranges of resistance for the cooked chicken meat and cooked chicken skin at $10 \mathrm{kHz}$ were 791 to 4,325 and 66,735 to 236,744 ohms, respectively. As discussed above, the majority of the cooked skin could not be considered reliable because it exceeded the measurement limitations of the ELVIS system. The cooked meat values all fell within the resistance measurement range of 10 ohms to $100 \mathrm{k}$-ohms as determined by the device validation.

The ranges of reactance for the cooked meat and cooked skin at $2 \mathrm{kHz}$ were -710 to -126 and $-1,978,834$ to $-22,953 \mathrm{ohms}$, respectively. The ranges of reactance for the cooked chicken meat and cooked chicken skin at $10 \mathrm{kHz}$ were -176 to 42 and $-461,852$ to $-8,512 \mathrm{ohms}$, respectively. Again, the reactance values of cooked chicken skin exceeded the measurement capabilities of the ELVIS system and were not considered reliable. At 2 
$\mathrm{kHz}$, all of the cooked chicken meat reactance values fell within the acceptable range of $-7,500$ to -7 ohms. At $10 \mathrm{kHz}$, the majority of the cooked chicken meat reactance values fell within the acceptable range of $-1,500$ to -1.5 ohms, with an exception of 15 out of a total 320. Since the majority of the values were acceptable, the values outside of the acceptable range were close to zero, and all values were relatively close to one another, all cooked chicken meat reactance values were considered reliable.

With the resistance and reactance measurements of cooked chicken meat determined to be reliable, the impedance values were reliable as well; impedance consists of both resistance and reactance as per Equation 4. Therefore, the electrode device and measurement system were capable of discerning differences in tissues in multiple directions based on impedance.

\section{Cooked Vs. Raw Chicken Discussion}

As was briefly discussed in the Results section, and more intimately above, the cooked chicken skin measurements were not considered reliable because they exceeded the measurement capabilities of the ELVIS system as determined by the device validation. However, it was not unreasonable to conclude that cooked chicken skin could be differentiated from all other tissue types by its exceedingly large impedance values. The cooked chicken skin data was eliminated from the multiple regression model, because the data was unreliable. Consequentially, the measurements from the other groups were not overshadowed by the large cooked skin impedance values. Excluding cooked chicken skin, the p-values of raw meat and raw skin when compared to cooked meat were less than the $\alpha$-value of 0.05 . Thus, both raw skin and raw meat impedances were statistically different from that of the cooked meat group. As already established by 
a t-test in the Raw Chicken Discussion section, raw meat and raw skin impedances were statistically different from each other. Furthermore, as discussed above, the majority of impedance values from the raw meat, raw skin, and cooked meat groups could be considered reliable. Therefore, the electrode device and measurement system could successfully differentiate between different tissue types and tissue moisture contents, the latter of which was expected to be the major difference between melanoma and healthy skin tissue.

The average impedance of cooked meat at 2 and $10 \mathrm{kHz}$ was 2,788 and 2,596 ohms, respectively. These values are smaller than the average impedance of raw meat. While we would expect the raw meat impedance to be lower than the cooked meat impedance because of the reduction in moisture content during cooking, other events on the cellular level, like anatomical and physiological alterations, could have occurred to change the measured impedance. Comparing Glenn Stante's chicken tissue impedances to the ones measured in this thesis, there were a few differences as seen in Table 18. The cooked meat impedances at $10 \mathrm{kHz}$ was nearly identical to that found by Glenn Stante. However, there was a substantial difference between the raw meat and raw skin impedances and their relative order. For example, in this thesis, the raw meat impedance was higher than the raw skin, whereas Stante found the opposite effect. These issues could potentially be explained by the different ELVIS systems, measurement acquisition methods (automatic as compared to Stante's manual approach), number of electrodes used, and/or pressure on electrode tips during experimentation. 
Table 18: Comparing Measured Impedances to Previous Work

\begin{tabular}{|l|r|r|r|}
\hline & \multicolumn{2}{|c|}{ Impedance (ohms) at 10 kHz } & \\
\hline \multicolumn{1}{|c|}{ Tissue } & This Thesis & Glenn's Thesis & \% Difference \\
\hline Cooked Meat & 2596 & 2784 & 6.75 \\
\hline Raw Meat & 6347 & 1801 & 252.42 \\
\hline Raw Skin & 5278 & 3897 & 35.44 \\
\hline
\end{tabular}

\section{Tissue Engineered Skin Analogue Discussion}

With the conclusion that the electrode device and measurement system used in this thesis could successfully differentiate between different tissue types and tissue moisture contents based on impedance measurements in multiple directions, it must be shown that the same thing could be accomplished on tissue engineered constructs of melanoma and healthy epidermis. If so, then the objective of this thesis would be satisfied and the ability to differentiate between melanoma and healthy epidermis constructs in multiple directions based on impedance measurements would be successful.

As described in the Results section, running a multiple regression model on the Epiderm $^{\mathrm{TM}}$ and Melanoma data resulted in a p-value higher than the $\alpha$-value of 0.05 . However, the data was found to not depend on frequency based on its p-value. Thus, the frequency data was combined and the two groups were analyzed with a t-test. In addition, outliers were removed from the multiple regression model and tested again. Both alternatives (i.e. t-test or removal of outliers) resulted in p-values less than the $\alpha$-value of 0.05 . Thus, the null hypothesis was rejected and the population mean impedance of Epiderm $^{\mathrm{TM}}$ and Melanoma tissue constructs were determined to be statistically different.

Now, the data must be checked to ensure that the values were reliable. At $2 \mathrm{kHz}$, the resistance ranges for Epiderm ${ }^{\mathrm{TM}}$ and Melanoma constructs were 8,843 to 26,470 and 5,235 to 77,059 ohms, respectively. At $10 \mathrm{kHz}$, the resistance ranges for Epiderm ${ }^{\mathrm{TM}}$ and 
Melanoma constructs were 8,201 to 22,228 and 4,904 to 77,072 ohms, respectively. All of these values were within the acceptable range of $10 \mathrm{ohms}$ to $100 \mathrm{k}$-ohms as determined by the device validation. Therefore, the resistance measurements were reliable for both constructs at both frequencies.

Reviewing the capacitor data at $2 \mathrm{kHz}$, the reactance ranges for Epiderm ${ }^{\mathrm{TM}}$ and Melanoma constructs were $-3,934$ to -765 and $-27,041$ to -319 ohms, respectively. Only 3 out of 122 reactance values were beyond the acceptable $-7,500$ to $-7 \mathrm{ohm}$ reactance range as determined by the device validation. As discussed in the Device Validation Discussion section, since the experimental errors for the $1 \mathrm{nF}$ capacitors were close to $10 \%$, and because there were a wide margin of reactances from $10 \mathrm{nF}$ to $1 \mathrm{nF}$ - namely $-7,500$ to $-75,000 \mathrm{ohms}-$ it was likely that a reactance of $-27,041$ was still within the reliable range of the ELVIS system. For these reasons, the reactance data at $2 \mathrm{kHz}$ for both constructs were determined to be reliable. At $10 \mathrm{kHz}$ the reactance ranges for Epiderm ${ }^{\mathrm{TM}}$ and Melanoma constructs were $-4,984$ to -239 and $-38,659$ to -133 ohms, respectively. For this frequency, there were 33 out of 122 reactance values that were beyond the acceptable reactance range of $-1,500$ to -1.5 as determined by the device validation. Again, with the experimental errors of the $1 \mathrm{nF}$ capacitors so close to $10 \%$, and with the wide range of reactances from $10 \mathrm{nF}$ to $1 \mathrm{nF}$ - namely $-1,500$ to $-15,000 \mathrm{ohms}$ - it was likely that many of the reactances closer to $-1,500 \mathrm{ohms}$ were reliable. Overall, there were 6 reactance values that exceeded $-15,000$ ohms and were ultimately removed during the outlier analysis. Thus, the reactance values included in the statistical analysis for both constructs at $10 \mathrm{kHz}$ were reliable. 
With all resistances and the majority of reactances determined to be in an acceptable range for the ELVIS system, the impedance data was concluded to be reliable. Impedance consists of both resistance and reactance as per Equation 4.

The average impedance of Epiderm ${ }^{\mathrm{TM}}$ constructs was less than that of Melanoma constructs. This relationship was in opposition to the data found in the literature, but consistent with Glenn Stante's findings [18, 33, 34]. Possible reasons for the disagreement with the literature most likely stemmed from the tissue samples themselves. Firstly, other student's in unrelated projects used the tissue samples previously. The handling, care, and storage of the samples were not known during those projects. Secondly, the tissue constructs were frozen for 2 years between thesis projects, possibly causing the samples to dry and increase in impedance. Thirdly, the melanoma impedance measurements should be standardized to healthy skin impedance. Since the samples were not derived from the same person/specimen, a standardization protocol could not be established. Fourthly, the samples were tissue engineered constructs and not actual human specimens. Furthermore, the measurements conducted in this thesis were in vitro, compared to in situ measurements by the authors in previous literature. Conducting the experiments with tissue engineered constructs in a petri dish was drastically different from in situ measurements of melanoma and healthy skin. All of these combined factors made it difficult to compare to previous work. In particular, being unable to normalize the melanoma tissue impedances to the healthy tissue impedances made it impossible to compare the recorded data to the normalized conductance value of 6.2 to 6.4 found in previous work. 
Even with the differences from the literature, the objective of the thesis was satisfied and the manufactured electrode device and measurement system were able to differentiate between melanoma and healthy epidermis tissue in multiple directions based on impedance measurements. These experiments increase the possibility that the same device and measurement system could differentiate between in situ melanoma and healthy skin tissues. 


\section{Conclusion}

Analyzing the data obtained from the validation experiments on the ELVIS system, multiplexer, and electrode device, resistor values from $10 \mathrm{ohms}$ to $100 \mathrm{k}$-ohms and capacitor values from $10 \mathrm{nF}$ to $10 \mathrm{uF}$ could be reliably measured to within the tolerance range provided by the manufacturer. The measured resistance and reactance values for all chicken tissues, excluding cooked chicken skin, were within the acceptable resistance and reactance ranges as determined by the validation experiments. The measured resistance and reactance values for both tissue engineered skin analogues were within the acceptable resistance and reactance ranges as determined by the validation experiments. Thus, all impedance data, excluding cooked chicken skin was reliable.

Raw chicken skin and raw chicken meat were determined to be statistically different by a t-test. Cooked chicken skin, having extremely large values, was eliminated. However, the large values in themselves, allow for statistical distinction from cooked chicken meat. A multiple regression model showed that the raw chicken and raw meat impedances were statistically different from that of cooked meat. Therefore, the device and measurement system could distinguish between different tissue types and tissue moisture content, the latter of which simulates the melanoma disease state.

Epiderm $^{\mathrm{TM}}$ and Melanoma skin construct impedances were found to be statistically different after removal of outliers. The electrode device and measurement system could distinguish between tissue engineered skin constructs of Epiderm ${ }^{\mathrm{TM}}$ and Melanoma in multiple directions based on impedance alone. Accordingly, the objective of this thesis was satisfied and the prospect of differentiating in situ melanoma from healthy skin tissue is substantial. 


\section{Future Work}

This thesis project serves as a preliminary study into the feasibility of multidirectional impedance analysis to differentiate between melanoma and healthy skin tissue. Currently, work is being performed on the next generation of the electrode device, which is a multi-electrode chip created by clean room wafer fabrication. Other devices in the future may also have coupling abilities to a radiofrequency tissue ablation tool. The following sections will discuss additional tests with the current electrode device and speculate about the possible design, fabrication method, imaging capabilities, and radiofrequency tissue ablation interplay of the next-gen device(s).

\section{Next Steps}

Next steps with the current electrode device would include more in vitro tests, animal testing on grey horses, and clinical testing with human subjects. The additional in vitro tests should examine more samples for better statistical results and samples with varying melanoma stages to investigate the sensitivity of the device. Using in situ tissues will allow for the full complexity of the skin to be studied, including the effects from hair, nerve endings, a full dermis, sweat glands, and sweat. Thus, grey horses, an animal with a high occurrence of melanoma, should be examined. After animal testing, human subjects should be tested with the device, followed by a biopsy of the lesion and histological analysis of the tissue for diagnosis. All melanoma measurements should be standardized to an ipsilateral healthy epidermis measurement and a database should be created. With a database of values, statistical analysis can be conducted to establish the specificity and sensitivity of a chosen threshold value. The threshold value is then used as a boundary to differentiate between melanoma and healthy skin tissue. 


\section{Next-Gen Device}

The goal of the next-gen device is to identify the exact boundaries of the melanoma tumor. Issues with the current electrode device design are that 8 electrodes at 5 mm distances from one another do not have sufficient resolution to discern accurate boundaries. The more electrodes present and the closer the electrodes are to one another, the higher the resolution possible. However, bringing electrodes closer together creates issues with measurement depth. The depth of measurement is dependent on the distance between electrodes and the source signal frequency. The current is estimated to reach depths that are approximately $1 / 2$ the separation of electrodes [25]. Furthermore, high frequency signals tend to reach deeper locations, while low frequency signals remain superficial [24]. Since melanoma lesions can be approximately $4 \mathrm{~mm}$ thick, it is important that measurement signals reach $4 \mathrm{~mm}$ into the tissue [13]. For these reasons, electrodes should be placed in a linear fashion so that switching the active electrode to the next one on the line (i.e. switching from adjacent electrodes to one inactive electrode in-between) could alter measurement depth. Thus, a matrix pattern or offset parallel lines may be optimal.

The construction of the microelectrode is completed in a clean room with wafer fabrication techniques. First, a 4" silicon wafer is cleaned with ethanol, acetone, and isopropyl alcohol (IPA) while spinning [47]. The wafer is removed and dried with pressurized air. Then, a positive photoresist, such as SPR 955-2.1, is spun onto the wafer to produce a sacrificial layer [47]. The photoresist is baked on a hotplate, exposed with light to a glass mask patterned with the electrode layout, and ammonia baked to reverse

the image of the mask [47]. Another exposure to light is followed by development in MF 
701 [47]. After drying, 100 Angstroms of titanium and 1000 Angstroms of gold are deposited onto the wafer through e-beam metal evaporation or sputtering [47]. Lift-off of the unwanted metal (everywhere put the electrodes and interconnects) is performed by breakdown of the sacrificial layer in acetone [47]. After drying, the interconnects can be electrically passivated with SU-8. SU-8 is a negative resist that is spun on the wafer, baked, exposed with light to a glass slide patterned with the passivation layer, baked again, and developed in SU-8 Developer [47].

The above recipe creates a microelectrode pattern, with interconnecting wires, out of gold. The electrodes themselves are exposed, while the interconnects are passivated with SU-8. A few alterations may be made to the recipe: 1) a 2 mil polyimide sticker can be placed on the silicon wafer prior to coating with SPR, 2) silver may be deposited onto the wafer instead of gold and titanium, and/or 3) additional gold can be electrodeposited after the passivation layer. The polyimide sticker may be used when a flexible surface is needed. After fabrication, it can be peeled from the silicon wafer and used more effectively on curved skin surfaces. Silver may be an alternative choice to gold for the same reasons that it is used in this thesis; namely, no overpotential and no motion artifacts [35]. Once deposited, the silver can be electrodeposited with silver chloride to create $\mathrm{Ag} / \mathrm{AgCl}$ measurement electrodes. If silver is not used, gold can be further electrodeposited to form a balled surface that protrudes past the passivation layer. The added gold allows for a better contact surface to the skin and increases the electrode surface area, which leads to lower electrode-tissue interface impedances. Other complications that must be fixed include interfacing measurement equipment to the electrodes, having enough input/output ports for controlling the many multiplexers 
involved in the circuit, and creating an algorithm to measure all areas and depths of the skin quickly and accurately.

A possible control algorithm should consider the electrode matrix design as an image. Each measurement between electrodes forms a voxel - a 3-dimensional pixel that identifies the likelihood of melanoma. The microelectrode device would first be placed on an ipsilateral healthy skin location. Each electrode and depth available would be quickly measured and stored in memory. Then, the device would be placed on the suspicious nevus. The algorithm starts recording from the corner and measures all depths possible. The values measured are referenced to the stored values for the ipsilateral location and determined to be cancerous or benign. If benign areas are found, the measurements continue row by row from left to right until a cancerous area is discovered. After measuring all depths possible in the cancerous area, the measurement moves down one row while in the same column (turns right). All depths are checked for cancerous areas. If a cancerous area is discovered, the measurement turns left - in this case, to the right one column while in the same row. If a benign area is discovered, the measurement turns right - to the left one column while in the same row. Continuing this left or right method, the boundaries of a tumor can be found accurately without having to measure the impedance between all electrodes. With this algorithm, a traced 3-dimensional boundary of the tumor is detected and the information can be sent to animation software or therapeutic tools, one of which could be a radiofrequency tissue ablation instrument.

\section{Radiofrequency Tissue Ablation}

Radiofrequency tissue ablation is the use of radio waves between frequencies of 375 to $500 \mathrm{kHz}$ to heat tissue [18]. The movement of the electromagnetic waves through 
the body creates friction that heats the areas where the electromagnetic waves meet [18]. If multiple waves are directed at the right angle, they can intersect at a tumor and constructively interfere with each other. At 41 degrees Celsius, injury of the tissue occurs and reaches necrosis at 46 degrees Celsius [18]. Since melanoma tumors are found on the surface of the body, radiofrequency tissue ablation is ideal. $\mathrm{Ag} / \mathrm{AgCl}$ electrodes can be used to source and sink the radio waves and administer the therapy [18]. Thus, the microelectrode device could double as a melanoma therapy when attached to the proper signal generator. Also, the detected boundaries of the tumor could be transferred to a separate radiofrequency ablation device that uses the information to control its own therapeutic regimen. 


\section{Bibliography}

1. Saladin, K., Anatomy \& Physiology: The Unity of Form and Function. 6th ed, ed. K.A. Queck. 2007, New York, NY: McGraw-Hill.

2. Dugdale, D.C., Zieve, David. Cancer. PubMed Health 2010 [cited 2011 March 3].

3. Reed, J.C., Mechanisms of apoptosis. American Journal of Pathology, 2000. 157(5): p. 1415-1430.

4. Learn About Cancer. American Cancer Society 2010 [cited 2011 March 3].

5. Basal Cell Carcinoma, Ulcerating. 2011, Dermatology Information System.

6. Melanoma. National Cancer Institute 2011 [cited 2011 March 10].

7. Kantor, J., Zieve, David. Skin Cancer. PubMed Health 2009 [cited 2011 March 3].

8. Altekruse SF, K.C., Krapcho M, Neyman N et al. . SEER Cancer Statistics Review, 1975-2007. National Cancer Institute 2010 [cited 2011 March 10].

9. Ulcerated Nodule Hand. 2011, Hove Skin Clinic.

10. Understanding Melanoma. Skin Cancer Foundation [cited 2011 March 3].

11. Meyskens, F.L., P.J. Farmer, and H. Anton-Culver, Etiologic pathogenesis of melanoma: A unifying hypothesis for the missing attributable risk. Clinical Cancer Research, 2004. 10(8): p. 2581-2583.

12. Rigel, D.S., J. Russak, and R. Friedman, The Evolution of Melanoma Diagnosis: 25 Years Beyond the ABCDs. Ca-a Cancer Journal for Clinicians, 2010. 60(5): p. 301-316.

13. What Is Cancer Staging? American Joint Committee on Cancer 2010 [cited 2011 March 10].

14. Needle Lymph Biopsy. 2011, Nucleus Medical Media.

15. Mohs Surgery. 2005, Black Salve Info.

16. Curettage-electrodessication. Skin Cancer Foundation 2011 [cited November 17].

17. Romito, K. Cryosurgery for Nonmelanoma Skin Cancer. WebMD 2010 [cited.

18. Stante, G.C., The Electrical Properties of Human Tissue for the Diagnosis and Treatment of Melanoma Skin Cancer, in Derpartment of Biomedical

Engineeringn. 2009, California Polytechnic State University: San Luis Obispo. p. 118.

19. Webster, J.G., ed. Bioinstrumentation. 2004, John Wiley \& Sons, Inc.

20. Birgersson, U., et al., Non-invasive bioimpedance of intact skin: mathematical modeling and experiments. Physiological Measurement. 32(1): p. 1-18.

21. Okazaki, K., et al. Basic study of a new diagnostic modality by non-invasive measurement of the electrical impedance tomography (EIT) on localized tissues. in 2009 International Conference on Biomedical and Pharmaceutical Engineering (ICBPE 2009). 2009. Singapore, Singapore: Ieee.

22. Matthews, G.G., Cellular Physiology of Nerve and Muscle. Fourth ed. 2003: Blackwell Science Ltd.

23. Yamamoto, T. and Y. Yamamoto, Electrical Properties of the Epidermal Stratum Corneum. Medical and Biological Engineering, 1976. 14(2): p. 151-158. 
24. Hartinger, A.E., et al., A 3-D Hybrid Finite Element Model to Characterize the Electrical Behavior of Cutaneous Tissues. Ieee Transactions on Biomedical Engineering. 57(4): p. 780-789.

25. Aberg, P., et al., Skin cancer identification using multifrequency electrical impedance-a potential screening tool. Biomedical Engineering, IEEE Transactions on, 2004. 51(12): p. 2097-2102.

26. Edelberg, R., Relation of Electrical Properties of Skin to Structure and Physiologic State. Journal of Investigative Dermatology, 1977. 69(3): p. 324-327.

27. Nicander, I. and S. Ollmar, Electrical impedance measurements at different skin sites related to seasonal variations. Skin Research and Technology, 2000. 6(2): p. 81-86.

28. Dinh, S.M., C.W. Luo, and B. Berner, Upper and Lower Limits of Human Skin Electrical-Resistance in Iontophoresis. Aiche Journal, 1993. 39(12): p. 20112018.

29. Aberg, P., et al., Non-invasive and microinvasive electrical impedance spectra of skin cancer - a comparison between two techniques. Skin Research and Technology, 2005. 11(4): p. 281-286.

30. Blad, B. and B. Baldetorp, Impedance spectra of tumour tissue in comparison with normal tissue; A possible clinical application for electrical impedance tomography. Physiological Measurement, 1996. 17: p. A105-A115.

31. Alqabandi, J.A., U.M. Abdel-Motal, and K. Youcef-Toumi, Extracting cancer cell line electrochemical parameters at the single cell level using a microfabricated device. Biotechnology Journal, 2009. 4(2): p. 216-223.

32. Pethig, R. and D.B. Kell, The Passive Electrical-Properties of Biological Systems - Their Significance in Physiology, Biophysics and Biotechnology. Physics in Medicine and Biology, 1987. 32(8): p. 933-970.

33. Har-Shai, Y., et al., Electrical impedance scanning for melanoma diagnosis: A validation study. Plastic and Reconstructive Surgery, 2005. 116(3): p. 782-790.

34. Glickman, Y.A., et al., Electrical impedance scanning: a new approach to skin cancer diagnosis. Skin Research and Technology, 2003. 9(3): p. 262-268.

35. Webster, J.G., ed. Medical Instrumentation. Fourth ed. 2010, John Wiley \& Sons, Inc.

36. Gabriel C, G.S., The Dielectric Properties of Biological Tissues: I. Literature Survey. Physics in Medicine and Biology, 1996. 41: p. 2231-2249.

37. Hemingway A, M.J.F., The High Frequency Resistance of Human Tissue. American Journal of Physiology, 1932. 102: p. 56 - 59.

38. Warner Instruments. Ag/AgCl Pellet, Disc and Wire Electrodes; Silver Wire [cited 2011].

39. NI Educational Laboratory Virtual Instrumentation Suite (NI ELVIS) Hardware User Manual. 2011, National Instruments.

40. NI Educational Laboratory Virtual Instrumentation Suite (NI ELVIS). 2011, NI Developer Zone.

41. NI USB-6251 Mass Term. 2011, National Instruments.

42. Scherz, P., Practical Electronics For Inventors. Second ed. 2007, New York, NY: McGraw-Hill Companies.

43. HEF4051B Product Data Sheet. 2011, NXP. 
44. LabVIEW Accelerates Productivity. 2011, National Instruments.

45. Hook Clips. 2011, Digikey.

46. MatTek Product Information. October 2011 [cited; Available from].

47. McKnight, T.E.e.a., Microarrays of Vertically-Aligned Carbon Nanofiber Electrodes in an Open Fluidic Channel. Journal of Physical Chemistry, 2004. 108: p. 7115-7125. 
Appendix A: Solidworks Drawings

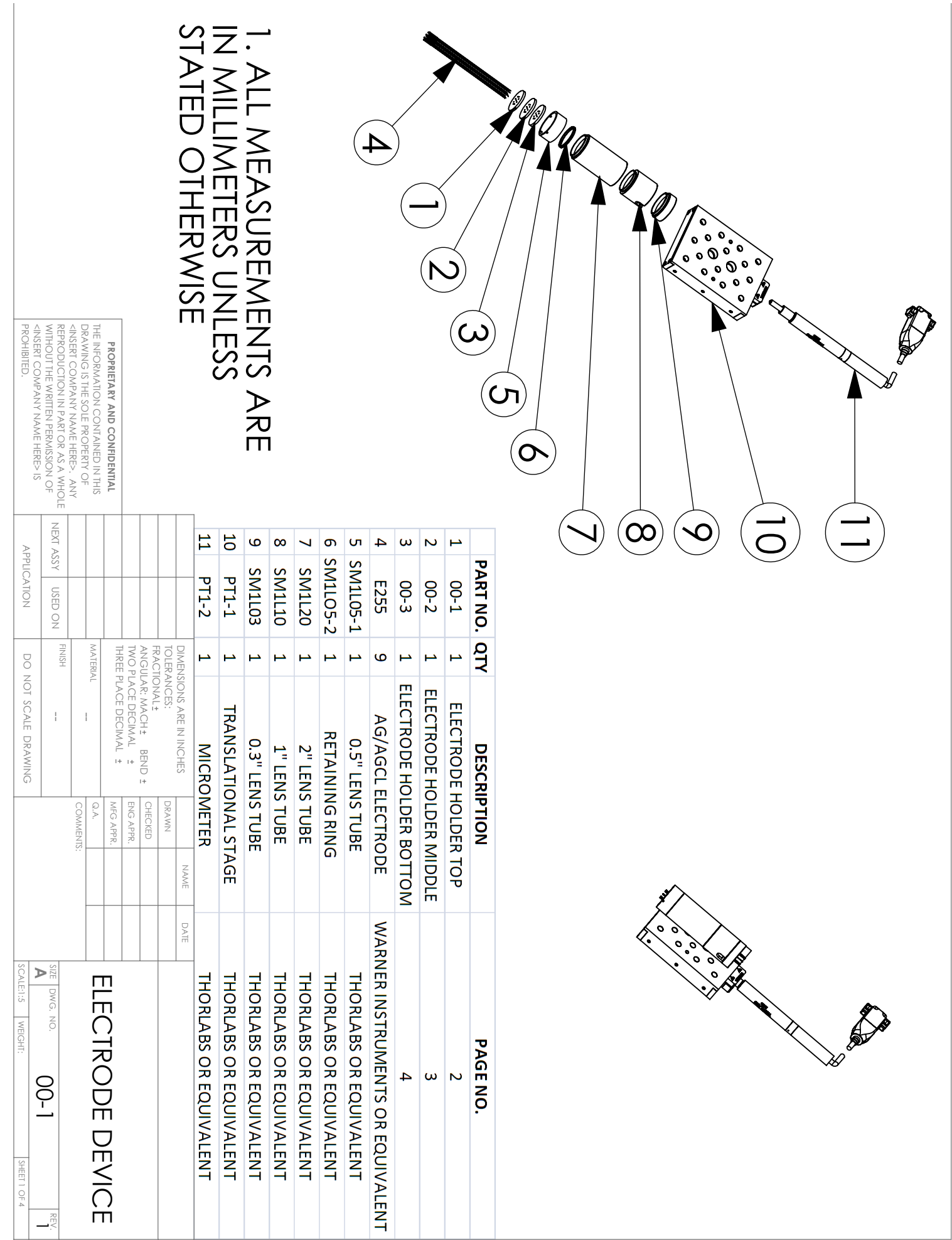

Figure 29: Electrode Device Bill Of Materials 


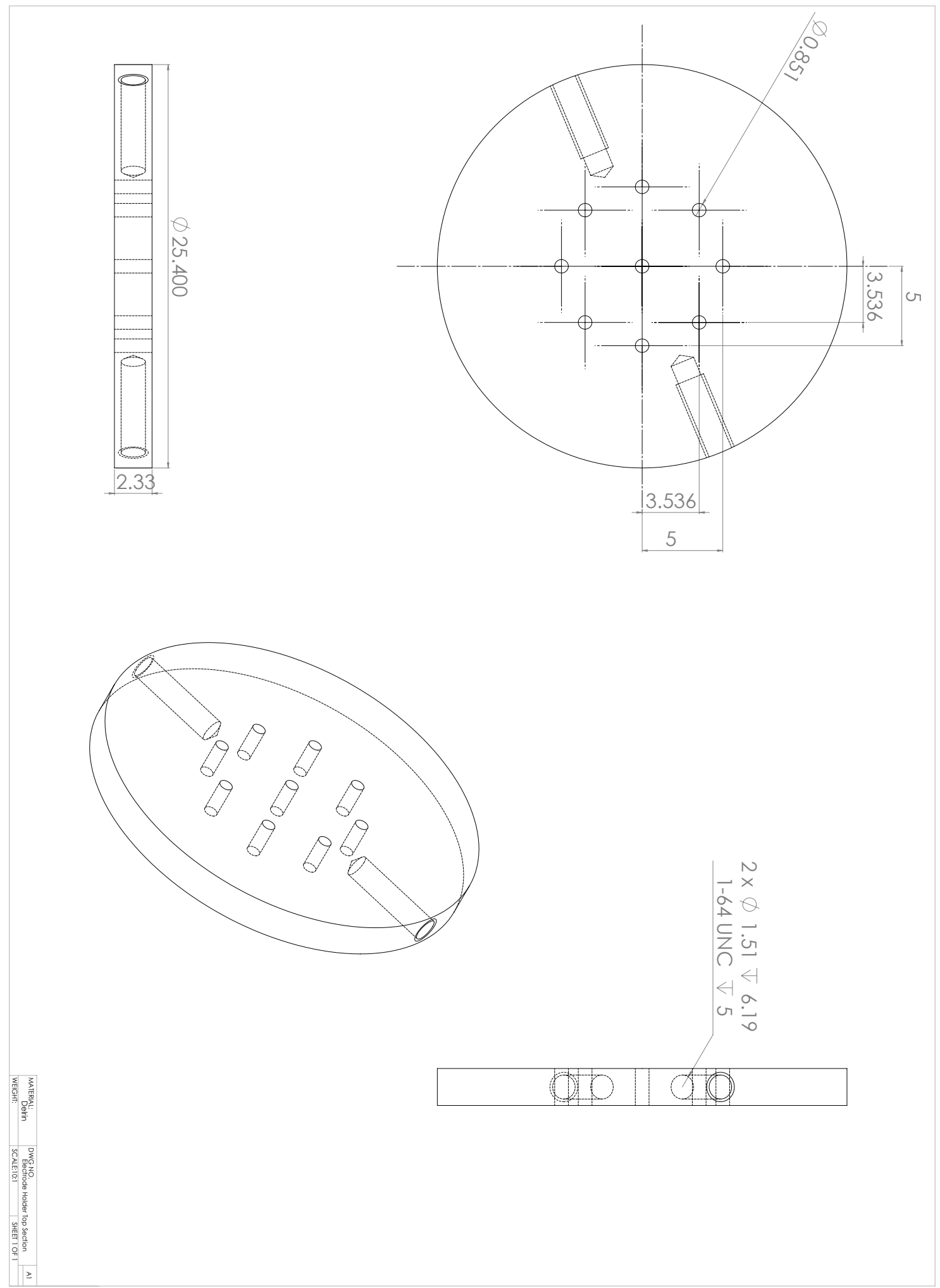

Figure 30: Electrode Holder Top Section Drawing 

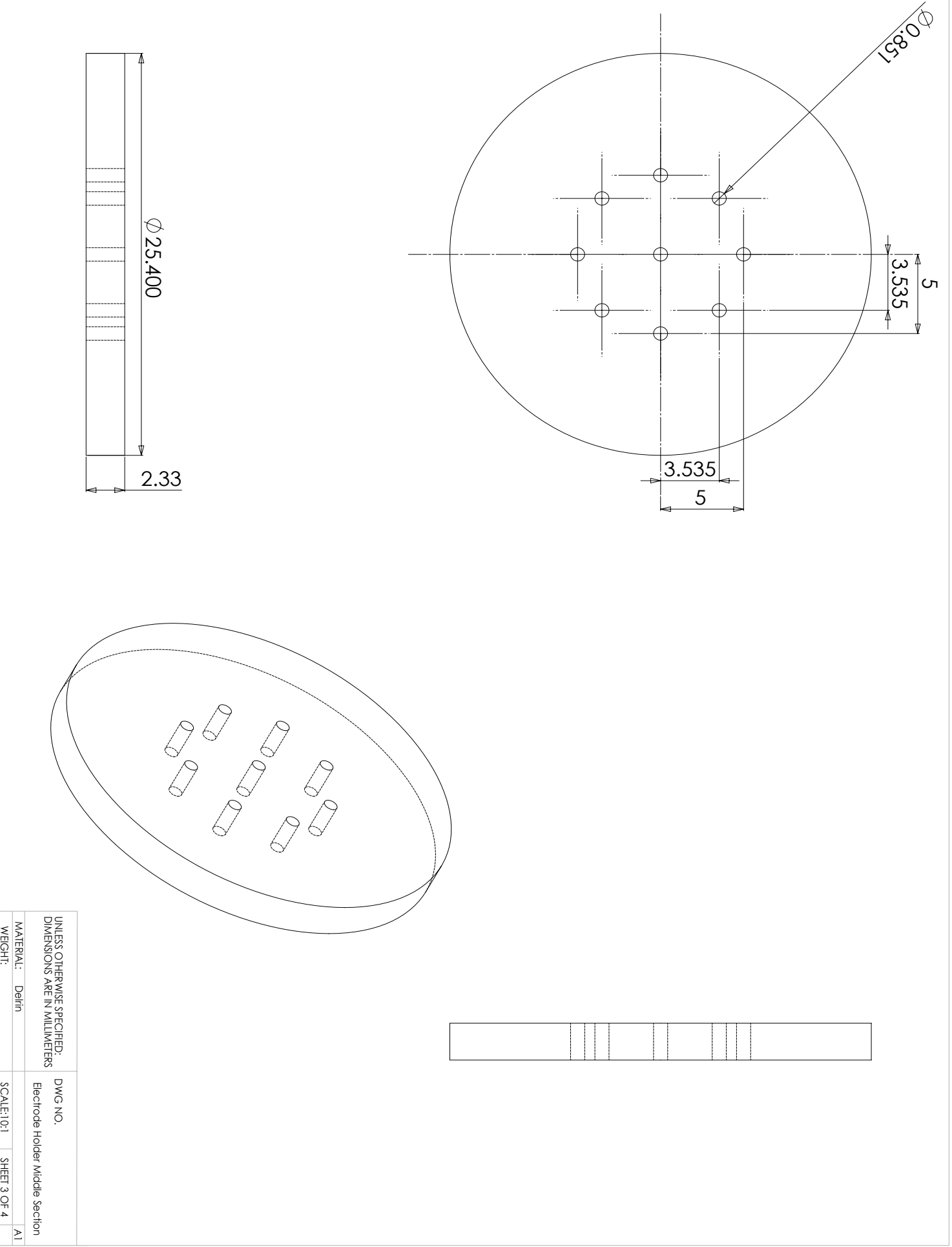

Figure 31: Electrode Holder Middle Section Drawing 


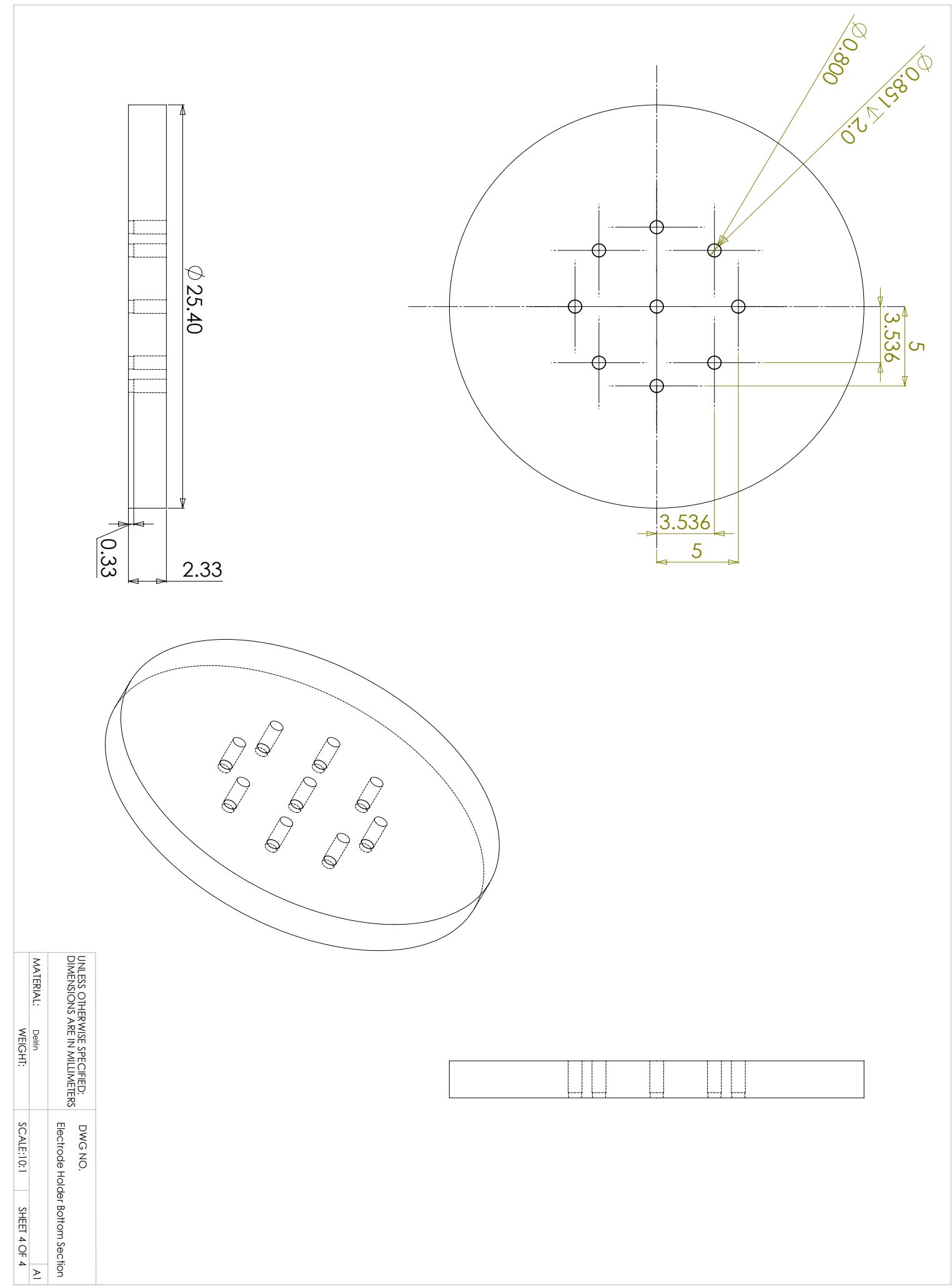

Figure 32: Electrode Holder Bottom Section Drawing 


\section{Appendix B: LabVIEW Program}

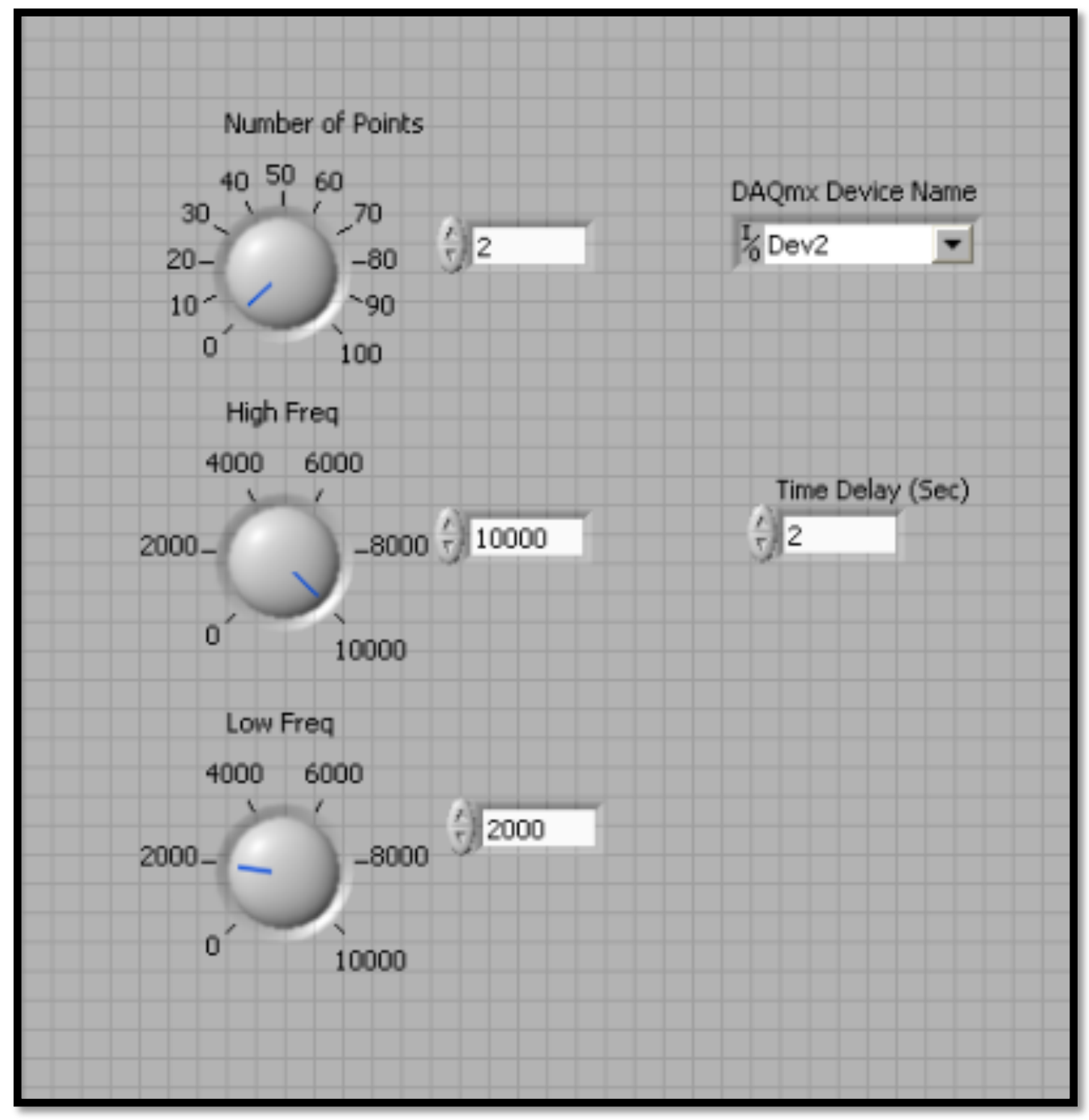

Figure 33: LabVIEW Program Front Panel

The front panel takes the user inputs, in this case number of points, highest frequency, lowest frequency, data acquisition device name, and time delay, and directs them to the program. 


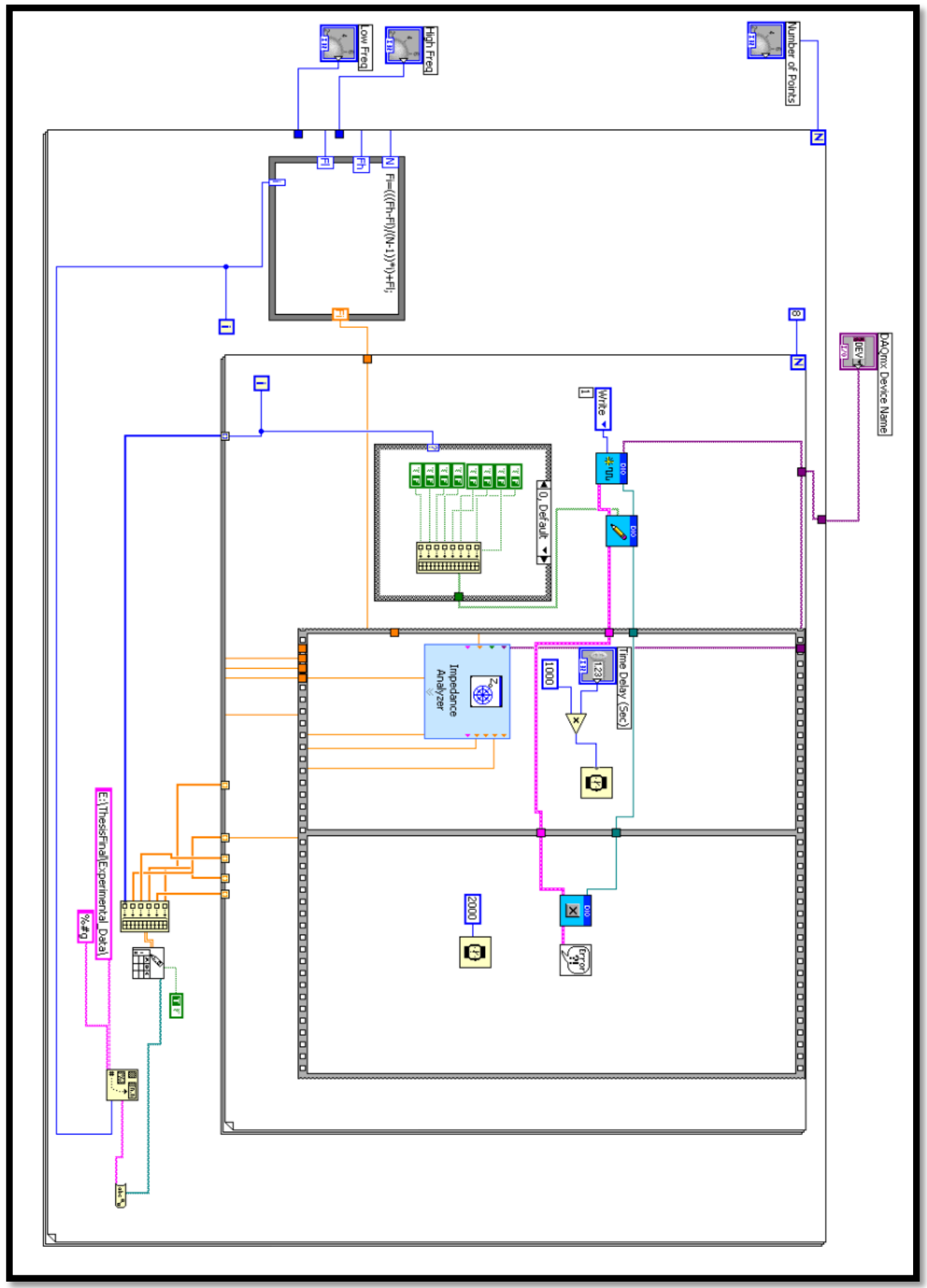

Figure 34: LabVIEW Block Diagram

The block diagram details the background execution of the program 


\section{Appendix C: Validation Data}

The following tables were unused in the main report because of their similarity to other graphs and insignificance to the conclusion of the thesis, but are provided here for completeness.

Table 19: Unadjusted Multiplexer Validation Resistor Values at $10 \mathrm{kHz}$

\begin{tabular}{|r|r|r|c|}
\hline Resistor Value (ohms) & $\begin{array}{c}\text { Measured Resistance } \\
\text { (ohms) }\end{array}$ & $\begin{array}{c}\text { Experimental Error } \\
(\%)\end{array}$ & $\begin{array}{c}\text { Within 5\% Tolerance } \\
(\mathrm{Y} / \mathrm{N})\end{array}$ \\
\hline 1 & 64.73 & 6372.60 & $\mathrm{~N}$ \\
\hline 1 & 64.81 & 6381.30 & $\mathrm{~N}$ \\
\hline 1 & 64.82 & 6381.70 & $\mathrm{~N}$ \\
\hline 10 & 73.56 & 635.58 & $\mathrm{~N}$ \\
\hline 10 & 73.46 & 634.56 & $\mathrm{~N}$ \\
\hline 10 & 73.54 & 635.38 & $\mathrm{~N}$ \\
\hline 100 & 162.34 & 62.34 & $\mathrm{~N}$ \\
\hline 100 & 162.86 & 62.86 & $\mathrm{~N}$ \\
\hline 100 & 163.31 & 63.31 & $\mathrm{~N}$ \\
\hline 1,000 & 1045.74 & 4.57 & $\mathrm{Y}$ \\
\hline 1,000 & 1036.67 & 3.67 & $\mathrm{Y}$ \\
\hline 1,000 & 1036.97 & 3.70 & $\mathrm{Y}$ \\
\hline 10,000 & 10009.16 & 0.09 & $\mathrm{Y}$ \\
\hline 10,000 & 9916.35 & 0.84 & $\mathrm{Y}$ \\
\hline 10,000 & 10131.42 & 1.31 & $\mathrm{Y}$ \\
\hline 100,000 & 95965.83 & 4.03 & $\mathrm{Y}$ \\
\hline 100,000 & 95661.04 & 4.34 & $\mathrm{Y}$ \\
\hline 100,000 & 95746.57 & 4.25 & $\mathrm{Y}$ \\
\hline $1,000,000$ & 244673.84 & 75.53 & $\mathrm{~N}$ \\
\hline $1,000,000$ & 263614.31 & 73.64 & $\mathrm{~N}$ \\
\hline $1,000,000$ & 264190.95 & 73.58 & $\mathrm{~N}$ \\
\hline & & & \\
\hline & & & \\
\hline
\end{tabular}

Table 20: Unadjusted Multiplexer Validation Capacitor Values at $2 \mathrm{kHz}$

\begin{tabular}{|c|c|c|c|c|}
\hline $\begin{array}{c}\text { Capacitor Value } \\
\text { (F) }\end{array}$ & $\begin{array}{l}\text { Measured } \\
\text { Reactance } \\
\text { (ohms) }\end{array}$ & $\begin{array}{c}\text { Calculated } \\
\text { Capacitance }(F)\end{array}$ & $\begin{array}{l}\text { Experimental } \\
\text { Error }(\%)\end{array}$ & $\begin{array}{c}\text { Within } \\
\text { Tolerance }(\mathrm{Y} / \mathrm{N})\end{array}$ \\
\hline $1.00 \mathrm{E}-09$ & -71384.575 & $1.11477 \mathrm{E}-09$ & 11.48 & $\mathrm{~N}$ \\
\hline $1.00 \mathrm{E}-09$ & -73653.959 & $1.08042 \mathrm{E}-09$ & 8.04 & $\mathrm{Y}$ \\
\hline $1.00 \mathrm{E}-09$ & -71362.253 & $1.11512 \mathrm{E}-09$ & 11.51 & $\mathrm{~N}$ \\
\hline $1.00 \mathrm{E}-08$ & -7497.43 & $1.0614 \mathrm{E}-08$ & 6.14 & $\mathrm{Y}$ \\
\hline $1.00 \mathrm{E}-08$ & -7640.002 & $1.04159 \mathrm{E}-08$ & 4.16 & $\mathrm{Y}$ \\
\hline $1.00 \mathrm{E}-08$ & -7661.907 & $1.03861 \mathrm{E}-08$ & 3.86 & $\mathrm{Y}$ \\
\hline $1.00 \mathrm{E}-07$ & -760.875 & $1.04587 \mathrm{E}-07$ & 4.59 & $\mathrm{Y}$ \\
\hline $1.00 \mathrm{E}-07$ & -766.121 & $1.03871 \mathrm{E}-07$ & 3.87 & $\mathrm{Y}$ \\
\hline $1.00 \mathrm{E}-07$ & -687.58 & $1.15736 \mathrm{E}-07$ & 15.74 & $\mathrm{~N}$ \\
\hline $1.00 \mathrm{E}-06$ & -74.728 & $1.06489 \mathrm{E}-06$ & 6.49 & $\mathrm{Y}$ \\
\hline $1.00 \mathrm{E}-06$ & -75.872 & $1.04884 \mathrm{E}-06$ & 4.88 & $\mathrm{Y}$ \\
\hline $1.00 \mathrm{E}-06$ & -74.847 & $1.0632 \mathrm{E}-06$ & 6.32 & $\mathrm{Y}$ \\
\hline $1.00 \mathrm{E}-05$ & -6.977 & $1.14057 \mathrm{E}-05$ & 14.06 & $\mathrm{~N}$ \\
\hline $1.00 \mathrm{E}-05$ & -6.959 & $1.14352 \mathrm{E}-05$ & 14.35 & $\mathrm{~N}$ \\
\hline $1.00 \mathrm{E}-05$ & -6.82 & $1.16683 \mathrm{E}-05$ & 16.68 & $\mathrm{~N}$ \\
\hline
\end{tabular}


Table 21: Unadjusted Multiplexer Validation Capacitor Values at $10 \mathrm{kHz}$

\begin{tabular}{|r|r|r|r|c|}
\hline $\begin{array}{c}\text { Capacitor Value } \\
(\text { F) }\end{array}$ & $\begin{array}{c}\text { Measured } \\
\text { Reactance } \\
\text { (ohms) }\end{array}$ & $\begin{array}{c}\text { Calculated } \\
\text { Capacitance (F) }\end{array}$ & $\begin{array}{c}\text { Experimental } \\
\text { Error }(\%)\end{array}$ & $\begin{array}{c}\text { Within } \\
\text { Tolerance (Y/N) }\end{array}$ \\
\hline $1.00 \mathrm{E}-09$ & -14401.608 & $1.10512 \mathrm{E}-09$ & 10.51 & $\mathrm{~N}$ \\
\hline $1.00 \mathrm{E}-09$ & -14865.036 & $1.07067 \mathrm{E}-09$ & 1.07 & $\mathrm{Y}$ \\
\hline $1.00 \mathrm{E}-09$ & -14414.598 & $1.10412 \mathrm{E}-09$ & 5.01 & $\mathrm{~N}$ \\
\hline $1.00 \mathrm{E}-08$ & -1515.657 & $1.05007 \mathrm{E}-08$ & 3.13 & $\mathrm{Y}$ \\
\hline $1.00 \mathrm{E}-08$ & -1543.196 & $1.03133 \mathrm{E}-08$ & 2.61 & $\mathrm{Y}$ \\
\hline $1.00 \mathrm{E}-08$ & -1551.053 & $1.02611 \mathrm{E}-08$ & 6.58 & $\mathrm{Y}$ \\
\hline $1.00 \mathrm{E}-07$ & -149.334 & $1.06576 \mathrm{E}-07$ & 5.28 & $\mathrm{Y}$ \\
\hline $1.00 \mathrm{E}-07$ & -151.168 & $1.05283 \mathrm{E}-07$ & 18.18 & N \\
\hline $1.00 \mathrm{E}-07$ & -134.677 & $1.18175 \mathrm{E}-07$ & 28.32 & N \\
\hline $1.00 \mathrm{E}-06$ & -12.403 & $1.2832 \mathrm{E}-06$ & 26.16 & $\mathrm{~N}$ \\
\hline $1.00 \mathrm{E}-06$ & -12.615 & $1.26163 \mathrm{E}-06$ & 28.52 & N \\
\hline $1.00 \mathrm{E}-06$ & -12.384 & $1.28517 \mathrm{E}-06$ & 243.38 & N \\
\hline $1.00 \mathrm{E}-05$ & 1.11 & $-1.43383 \mathrm{E}-05$ & 242.36 & N \\
\hline $1.00 \mathrm{E}-05$ & 1.118 & $-1.42357 \mathrm{E}-05$ & 240.60 & $\mathrm{~N}$ \\
\hline $1.00 \mathrm{E}-05$ & 1.132 & $-1.40596 \mathrm{E}-05$ & & \\
\hline
\end{tabular}

Table 22: Unadjusted Device Validation Resistor Values at $2 \mathrm{kHz}$

\begin{tabular}{|r|r|r|c|}
\hline Resistor Value (ohms) & $\begin{array}{c}\text { Measured Resistance } \\
\text { (ohms) }\end{array}$ & $\begin{array}{c}\text { Experimental Error } \\
(\%)\end{array}$ & $\begin{array}{c}\text { Within 5\% Tolerance } \\
(\text { Y/N })\end{array}$ \\
\hline 1 & 64.038 & 6303.80 & $\mathrm{~N}$ \\
\hline 1 & 63.981 & 6298.10 & $\mathrm{~N}$ \\
\hline 1 & 64.052 & 6305.20 & $\mathrm{~N}$ \\
\hline 10 & 72.949 & 629.49 & $\mathrm{~N}$ \\
\hline 10 & 72.907 & 629.07 & $\mathrm{~N}$ \\
\hline 10 & 72.976 & 629.76 & $\mathrm{~N}$ \\
\hline 100 & 162.002 & 62.00 & $\mathrm{~N}$ \\
\hline 100 & 162.895 & 62.90 & $\mathrm{~N}$ \\
\hline 100 & 162.415 & 62.42 & $\mathrm{~N}$ \\
\hline 1,000 & 1037.005 & 3.70 & $\mathrm{Y}$ \\
\hline 1,000 & 1045.87 & 4.59 & $\mathrm{Y}$ \\
\hline 1,000 & 1036.898 & 3.69 & $\mathrm{Y}$ \\
\hline 10,000 & 10017.795 & 0.18 & $\mathrm{Y}$ \\
\hline 10,000 & 10150.421 & 1.50 & $\mathrm{Y}$ \\
\hline 10,000 & 9933.287 & 0.67 & $\mathrm{Y}$ \\
\hline 100,000 & 99175.252 & 0.82 & $\mathrm{Y}$ \\
\hline 100,000 & 99288.527 & 0.71 & $\mathrm{Y}$ \\
\hline 100,000 & 98327.636 & 1.67 & $\mathrm{Y}$ \\
\hline $1,000,000$ & 801106.418 & 19.89 & $\mathrm{~N}$ \\
\hline $1,000,000$ & 791205.185 & 20.88 & $\mathrm{~N}$ \\
\hline $1,000,000$ & 792906.679 & 20.71 & $\mathrm{~N}$ \\
\hline & & & \\
\hline & & & \\
\hline
\end{tabular}


Table 23: Unadjusted Device Validation Resistor Values at $10 \mathrm{kHz}$

\begin{tabular}{|r|r|r|c|}
\hline Resistor Value (ohms) & $\begin{array}{c}\text { Measured Resistance } \\
\text { (ohms) }\end{array}$ & $\begin{array}{c}\text { Experimental Error } \\
(\%)\end{array}$ & $\begin{array}{c}\text { Within 5\% Tolerance } \\
(\mathrm{Y} / \mathrm{N})\end{array}$ \\
\hline 1 & 64.311 & 6331.10 & $\mathrm{~N}$ \\
\hline 1 & 64.326 & 6332.60 & $\mathrm{~N}$ \\
\hline 1 & 64.336 & 6333.60 & $\mathrm{~N}$ \\
\hline 10 & 73.251 & 632.51 & $\mathrm{~N}$ \\
\hline 10 & 73.157 & 631.57 & $\mathrm{~N}$ \\
\hline 10 & 73.24 & 632.40 & $\mathrm{~N}$ \\
\hline 100 & 162.249 & 62.25 & $\mathrm{~N}$ \\
\hline 100 & 163.11 & 63.11 & $\mathrm{~N}$ \\
\hline 100 & 162.669 & 62.67 & $\mathrm{~N}$ \\
\hline 1,000 & 1037.681 & 3.77 & $\mathrm{Y}$ \\
\hline 1,000 & 1046.627 & 4.66 & $\mathrm{Y}$ \\
\hline 1,000 & 1037.375 & 3.74 & $\mathrm{Y}$ \\
\hline 10,000 & 10025.948 & 0.26 & $\mathrm{Y}$ \\
\hline 10,000 & 10159.65 & 1.60 & $\mathrm{Y}$ \\
\hline 10,000 & 9940.631 & 0.59 & $\mathrm{Y}$ \\
\hline 100,000 & 96646.064 & 3.35 & $\mathrm{Y}$ \\
\hline 100,000 & 96765.227 & 3.23 & $\mathrm{Y}$ \\
\hline 100,000 & 95912.721 & 4.09 & $\mathrm{Y}$ \\
\hline $1,000,000$ & 205808.799 & 79.42 & $\mathrm{~N}$ \\
\hline $1,000,000$ & 198785.713 & 80.12 & $\mathrm{~N}$ \\
\hline $1,000,000$ & 197641.336 & 80.24 & $\mathrm{~N}$ \\
\hline & & & \\
\hline
\end{tabular}

Table 24: Unadjusted Device Validation Capacitor Values at $2 \mathrm{kHz}$

\begin{tabular}{|r|r|r|r|c|}
\hline $\begin{array}{c}\text { Capacitor Value } \\
(\mathrm{F})\end{array}$ & $\begin{array}{c}\text { Measured } \\
\text { Reactance } \\
\text { (ohms) }\end{array}$ & $\begin{array}{c}\text { Calculated } \\
\text { Capacitance (F) }\end{array}$ & $\begin{array}{c}\text { Experimental } \\
\text { Error (\%) }\end{array}$ & $\begin{array}{c}\text { Within } \\
\text { Tolerance (Y/N) }\end{array}$ \\
\hline $1.00 \mathrm{E}-09$ & -73109.369 & $1.08847 \mathrm{E}-09$ & 8.85 & $\mathrm{Y}$ \\
\hline $1.00 \mathrm{E}-09$ & -71493.31 & $1.11308 \mathrm{E}-09$ & 11.31 & $\mathrm{~N}$ \\
\hline $1.00 \mathrm{E}-09$ & -70654.826 & $1.12629 \mathrm{E}-09$ & 12.63 & $\mathrm{~N}$ \\
\hline $1.00 \mathrm{E}-08$ & -7492.531 & $1.06209 \mathrm{E}-08$ & 6.21 & $\mathrm{Y}$ \\
\hline $1.00 \mathrm{E}-08$ & -7651.639 & $1.04001 \mathrm{E}-08$ & 4.00 & $\mathrm{Y}$ \\
\hline $1.00 \mathrm{E}-08$ & -7644.912 & $1.04092 \mathrm{E}-08$ & 4.09 & $\mathrm{Y}$ \\
\hline $1.00 \mathrm{E}-07$ & -761.302 & $1.04528 \mathrm{E}-07$ & 4.53 & $\mathrm{Y}$ \\
\hline $1.00 \mathrm{E}-07$ & -687.676 & $1.15719 \mathrm{E}-07$ & 15.72 & $\mathrm{~N}$ \\
\hline $1.00 \mathrm{E}-07$ & -766.616 & $1.03804 \mathrm{E}-07$ & 3.80 & $\mathrm{Y}$ \\
\hline $1.00 \mathrm{E}-06$ & -76.01 & $1.04693 \mathrm{E}-06$ & 4.69 & $\mathrm{Y}$ \\
\hline $1.00 \mathrm{E}-06$ & -74.899 & $1.06246 \mathrm{E}-06$ & 6.25 & $\mathrm{Y}$ \\
\hline $1.00 \mathrm{E}-06$ & -74.867 & $1.06292 \mathrm{E}-06$ & 6.29 & $\mathrm{Y}$ \\
\hline $1.00 \mathrm{E}-05$ & -6.948 & $1.14533 \mathrm{E}-05$ & 14.53 & $\mathrm{~N}$ \\
\hline $1.00 \mathrm{E}-05$ & -6.973 & $1.14122 \mathrm{E}-05$ & 14.12 & $\mathrm{~N}$ \\
\hline $1.00 \mathrm{E}-05$ & -6.803 & $1.16974 \mathrm{E}-05$ & 16.97 & $\mathrm{~N}$ \\
\hline & & & & \\
\hline
\end{tabular}


Table 25: Unadjusted Device Validation Capacitor Values at $10 \mathrm{kHz}$

\begin{tabular}{|c|c|c|c|c|}
\hline $\begin{array}{l}\text { Capacitor Value } \\
\text { (F) }\end{array}$ & $\begin{array}{c}\text { Measured } \\
\text { Reactance } \\
\text { (ohms) }\end{array}$ & $\begin{array}{c}\text { Calculated } \\
\text { Capacitance }(F)\end{array}$ & $\begin{array}{c}\text { Experimental } \\
\text { Error }(\%)\end{array}$ & $\begin{array}{c}\text { Within } \\
\text { Tolerance }(\mathrm{Y} / \mathrm{N})\end{array}$ \\
\hline $1.00 \mathrm{E}-09$ & -14845.211 & $1.0721 \mathrm{E}-09$ & 7.21 & $\mathrm{Y}$ \\
\hline $1.00 \mathrm{E}-09$ & -14445.939 & $1.10173 \mathrm{E}-09$ & 10.17 & $\mathrm{~N}$ \\
\hline $1.00 \mathrm{E}-09$ & -14353.556 & $1.10882 \mathrm{E}-09$ & 10.88 & $\mathrm{~N}$ \\
\hline $1.00 \mathrm{E}-08$ & -1518.923 & $1.04781 \mathrm{E}-08$ & 4.78 & $\mathrm{Y}$ \\
\hline $1.00 \mathrm{E}-08$ & -1553.808 & $1.02429 \mathrm{E}-08$ & 2.43 & $\mathrm{Y}$ \\
\hline $1.00 \mathrm{E}-08$ & -1550.256 & $1.02664 \mathrm{E}-08$ & 2.66 & $\mathrm{Y}$ \\
\hline $1.00 \mathrm{E}-07$ & -149.523 & $1.06442 \mathrm{E}-07$ & 6.44 & Y \\
\hline $1.00 \mathrm{E}-07$ & -134.905 & $1.17976 \mathrm{E}-07$ & 17.98 & $\mathrm{~N}$ \\
\hline $1.00 \mathrm{E}-07$ & -151.759 & $1.04873 \mathrm{E}-07$ & 4.87 & $\mathrm{Y}$ \\
\hline $1.00 \mathrm{E}-06$ & -12.567 & $1.26645 \mathrm{E}-06$ & 26.65 & $\mathrm{~N}$ \\
\hline $1.00 \mathrm{E}-06$ & -12.327 & $1.29111 \mathrm{E}-06$ & 29.11 & $\mathrm{~N}$ \\
\hline $1.00 \mathrm{E}-06$ & -12.35 & $1.2887 \mathrm{E}-06$ & 28.87 & $\mathrm{~N}$ \\
\hline $1.00 \mathrm{E}-05$ & 1.203 & $-1.32298 \mathrm{E}-05$ & 232.30 & $\mathrm{~N}$ \\
\hline $1.00 \mathrm{E}-05$ & 1.208 & $-1.31751 \mathrm{E}-05$ & 231.75 & $\mathrm{~N}$ \\
\hline $1.00 \mathrm{E}-05$ & 1.233 & $-1.29079 \mathrm{E}-05$ & 229.08 & $\mathrm{~N}$ \\
\hline
\end{tabular}




\section{Appendix D: Minitab Outputs}

\section{Raw Chicken Results}

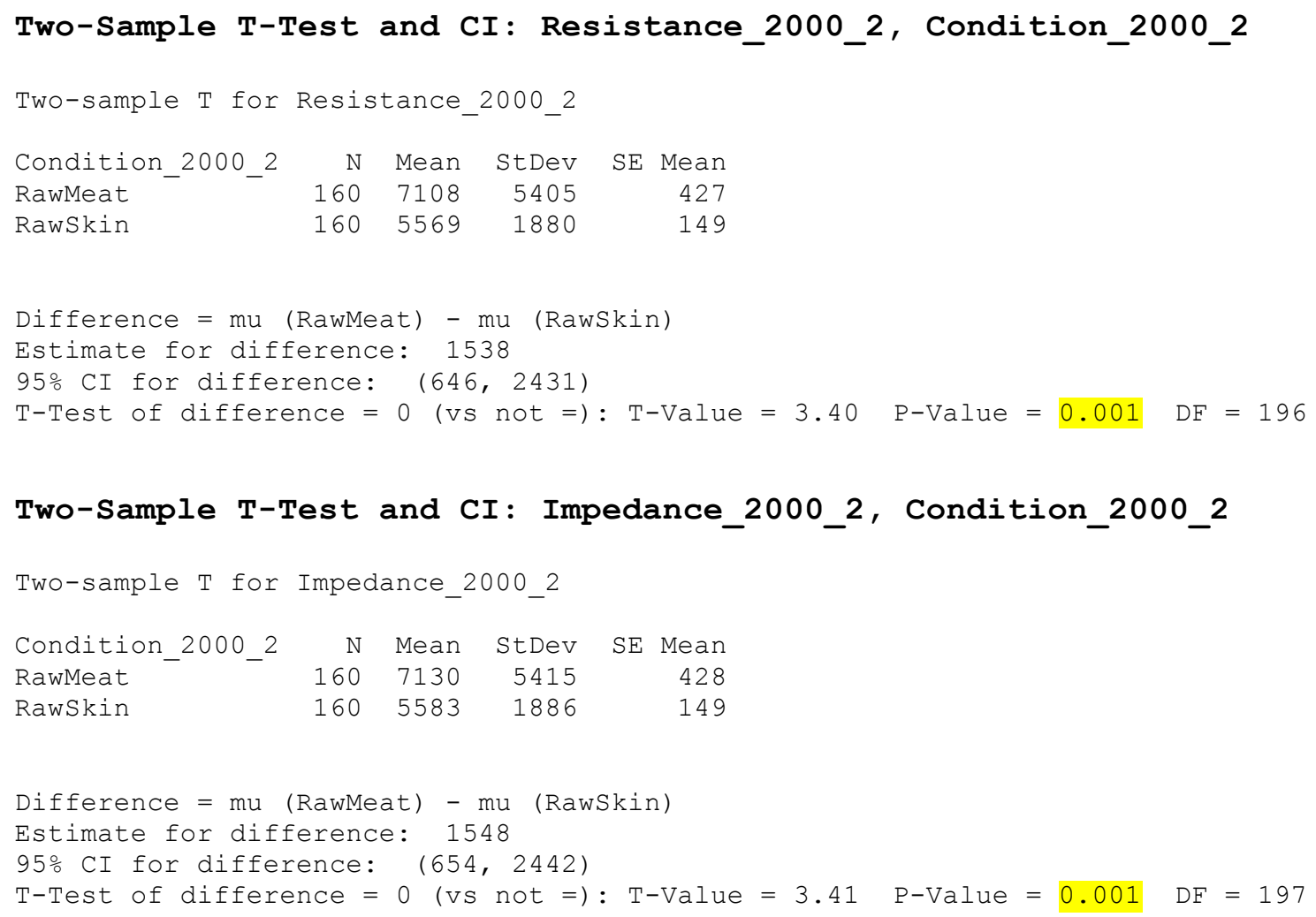

\section{Cooked Chicken Results}

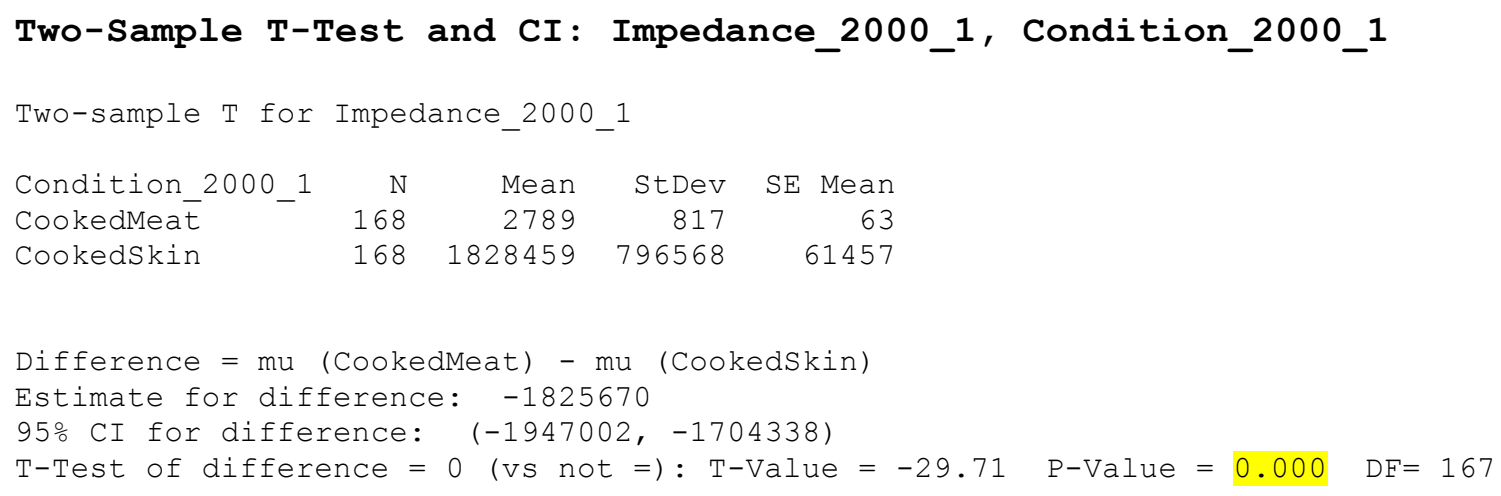




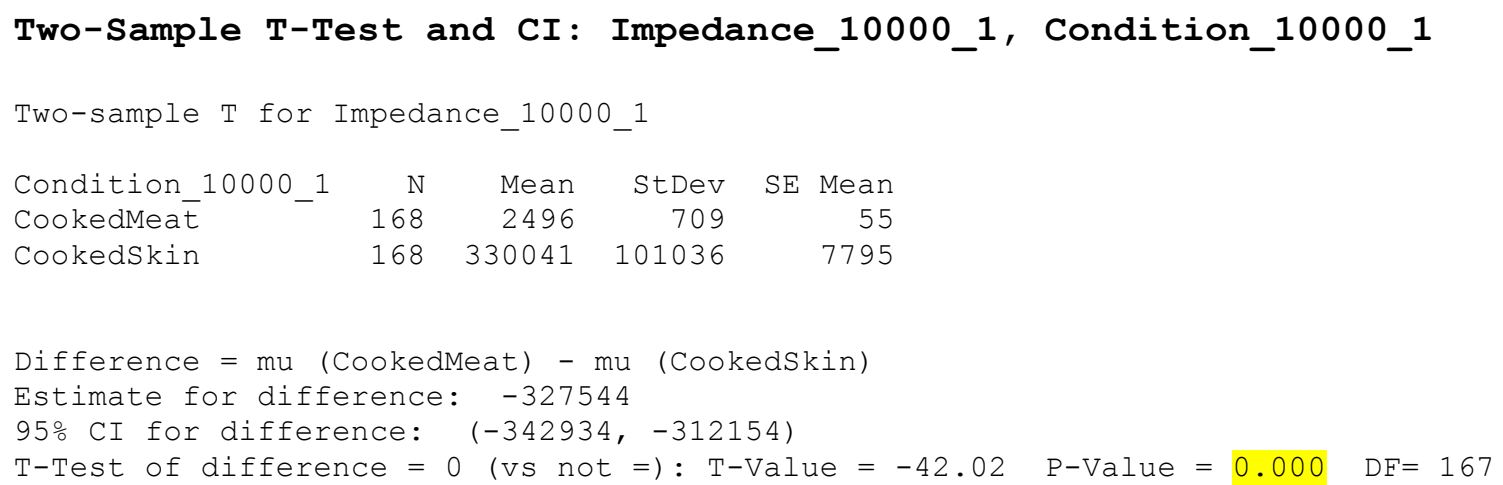

\section{Cooked Vs. Raw Chicken Results}

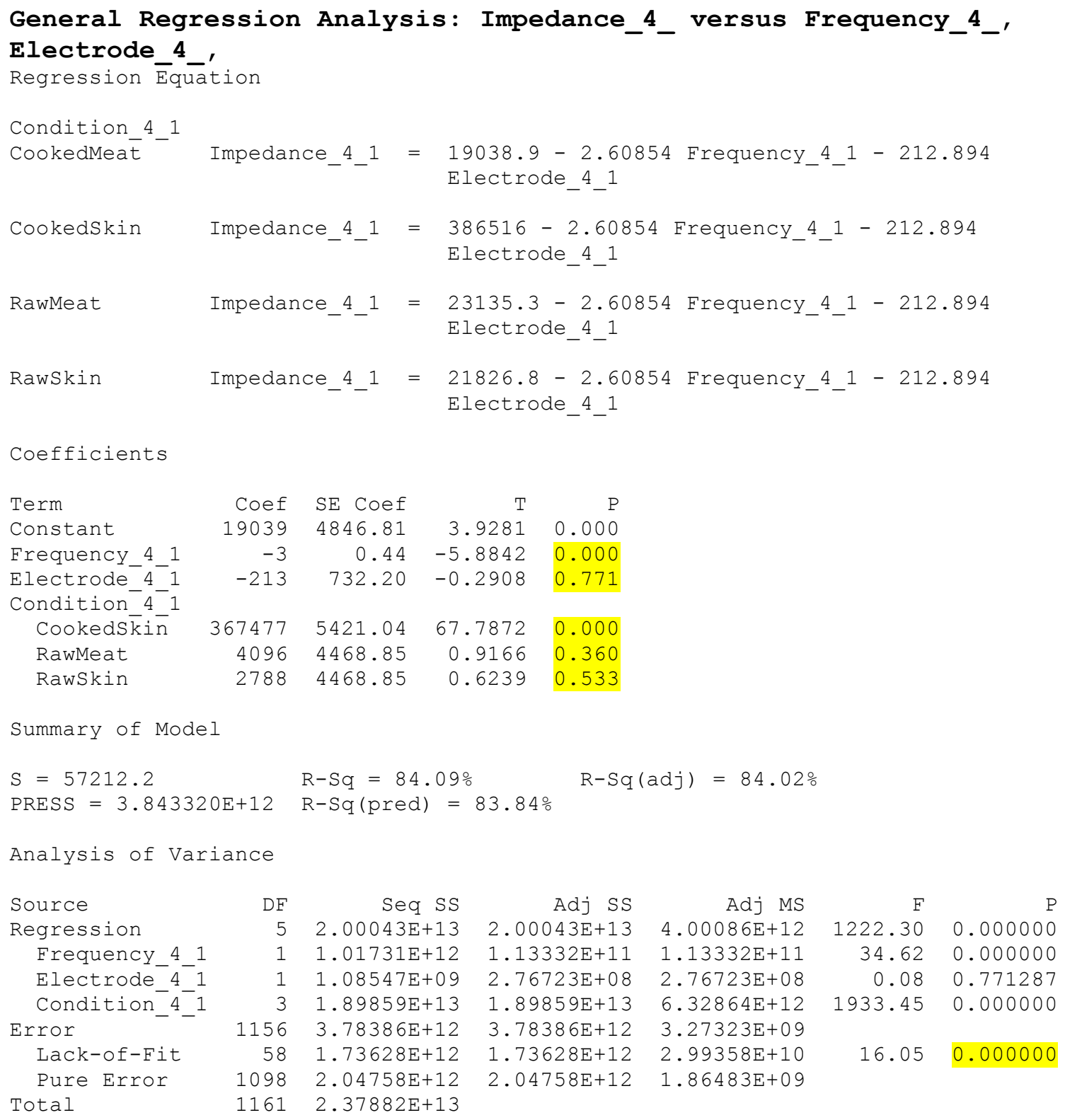

$\begin{array}{rrrrrr}\text { DF } & \text { Seq SS } & \text { Adj SS } & \text { Adj MS } & F & P \\ 5 & 2.00043 \mathrm{E}+13 & 2.00043 \mathrm{E}+13 & 4.00086 \mathrm{E}+12 & 1222.30 & 0.000000 \\ 1 & 1.01731 \mathrm{E}+12 & 1.13332 \mathrm{E}+11 & 1.13332 \mathrm{E}+11 & 34.62 & 0.000000 \\ 1 & 1.08547 \mathrm{E}+09 & 2.76723 \mathrm{E}+08 & 2.76723 \mathrm{E}+08 & 0.08 & 0.771287 \\ 3 & 1.89859 \mathrm{E}+13 & 1.89859 \mathrm{E}+13 & 6.32864 \mathrm{E}+12 & 1933.45 & 0.000000 \\ 1156 & 3.78386 \mathrm{E}+12 & 3.78386 \mathrm{E}+12 & 3.27323 \mathrm{E}+09 & & \\ 58 & 1.73628 \mathrm{E}+12 & 1.73628 \mathrm{E}+12 & 2.99358 \mathrm{E}+10 & 16.05 & 0.000000 \\ 1098 & 2.04758 \mathrm{E}+12 & 2.04758 \mathrm{E}+12 & 1.86483 \mathrm{E}+09 & & \\ 1161 & 2.37882 \mathrm{E}+13 & & & & \end{array}$




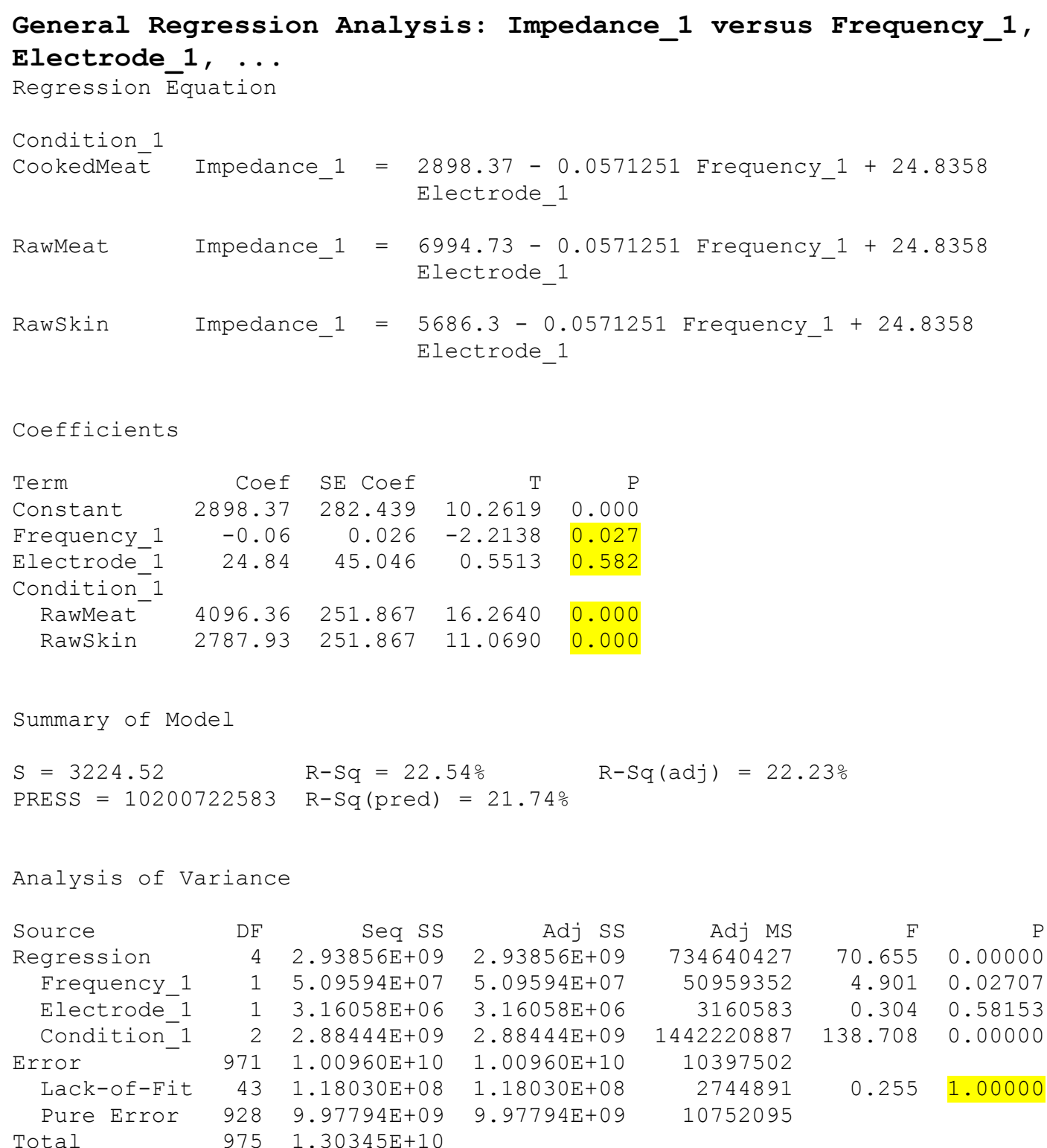




\section{Tissue-Engineered Skin Analogue Results}

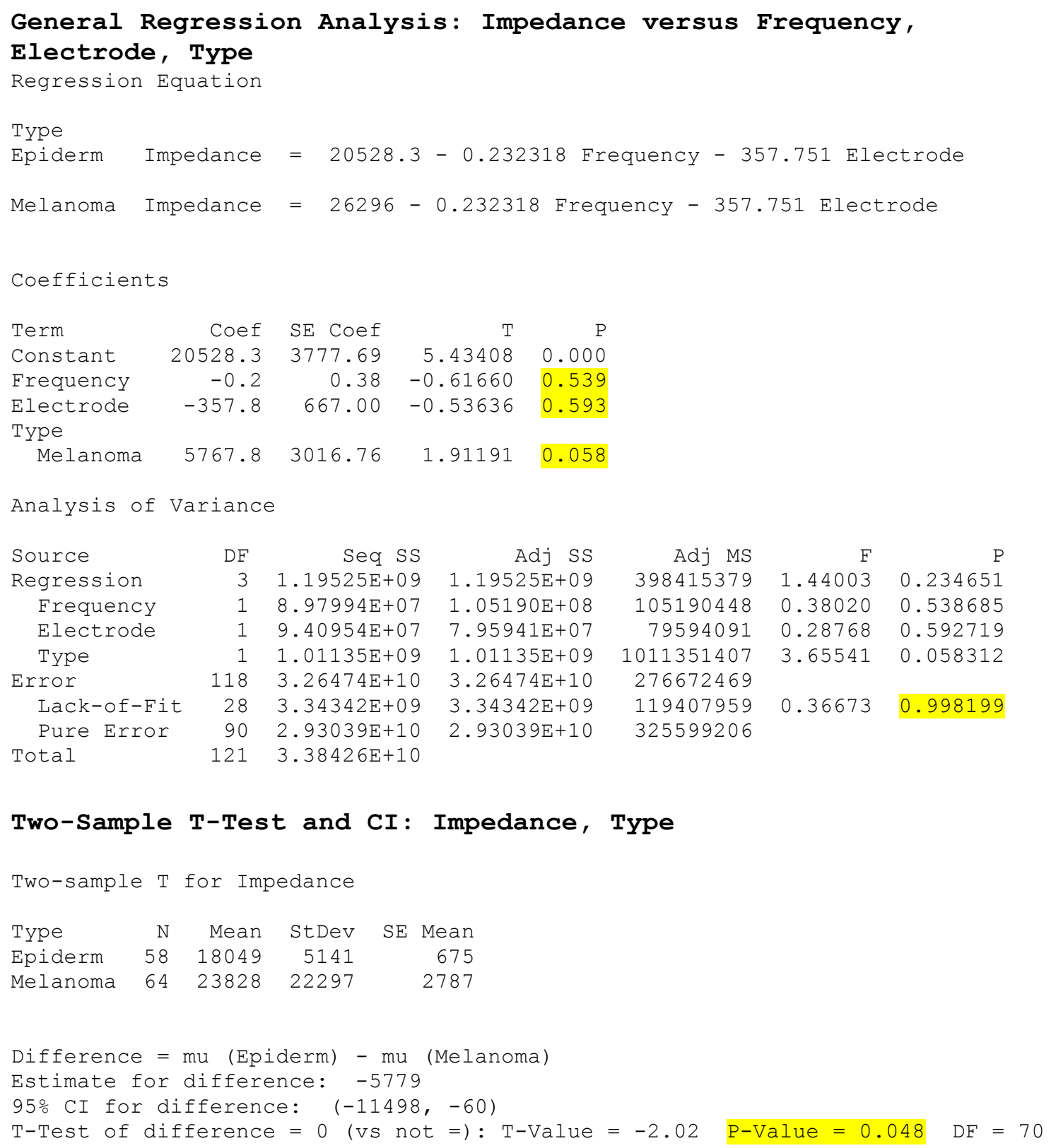




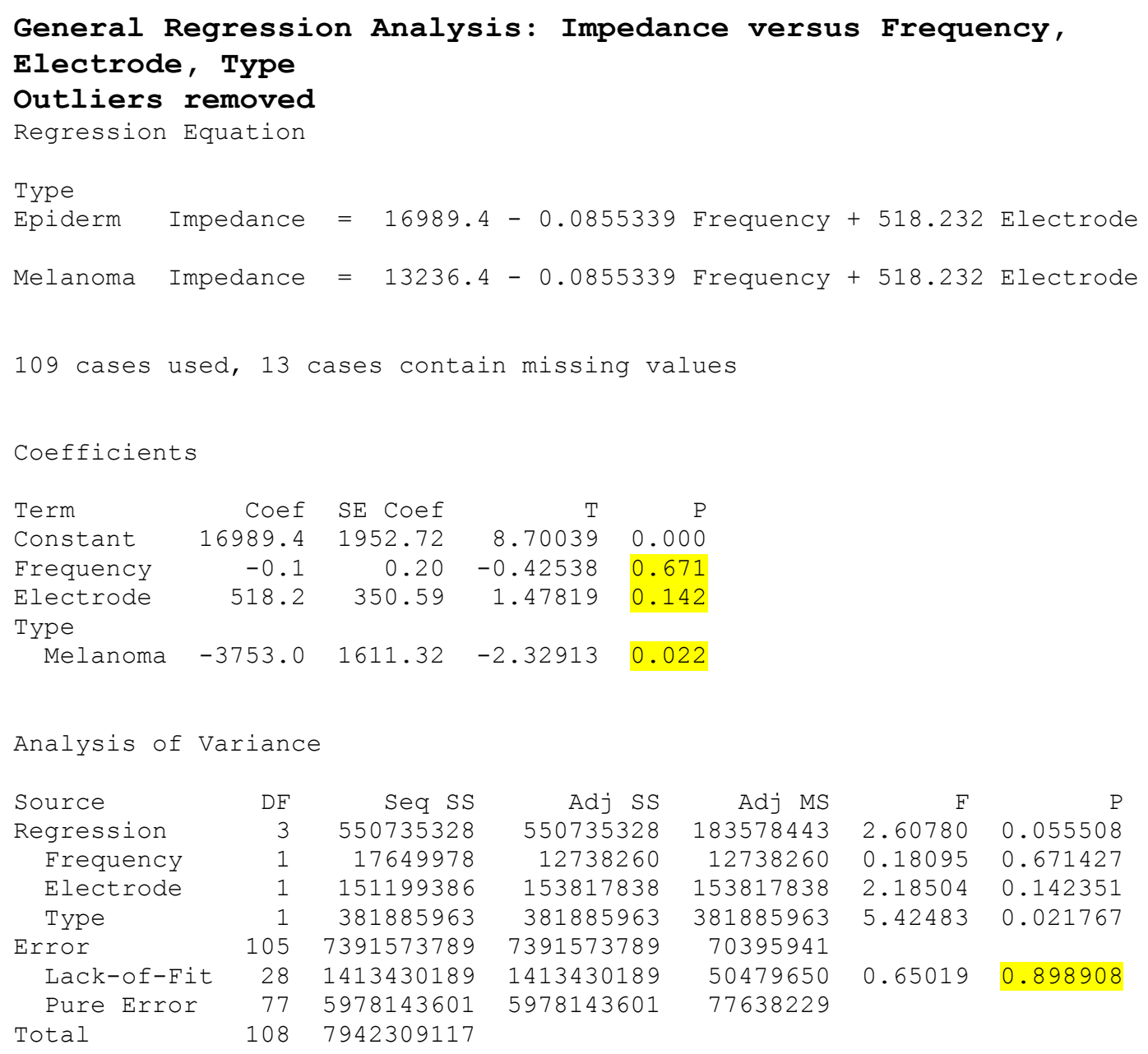

